\title{
SWEPP Gamma-Ray Spectrometer System Software Test Plan and Report
}

\author{
D. A. Femec
}

Published September 1994

\author{
Idaho National Engineering Laboratory \\ EG\&G Idaho, Inc. \\ Idaho Falls, Idaho 83415-7111
}

Prepared for the

U.S. Department of Energy Under DOE Idaho Field Office Contract DE-AC07-761D01570 


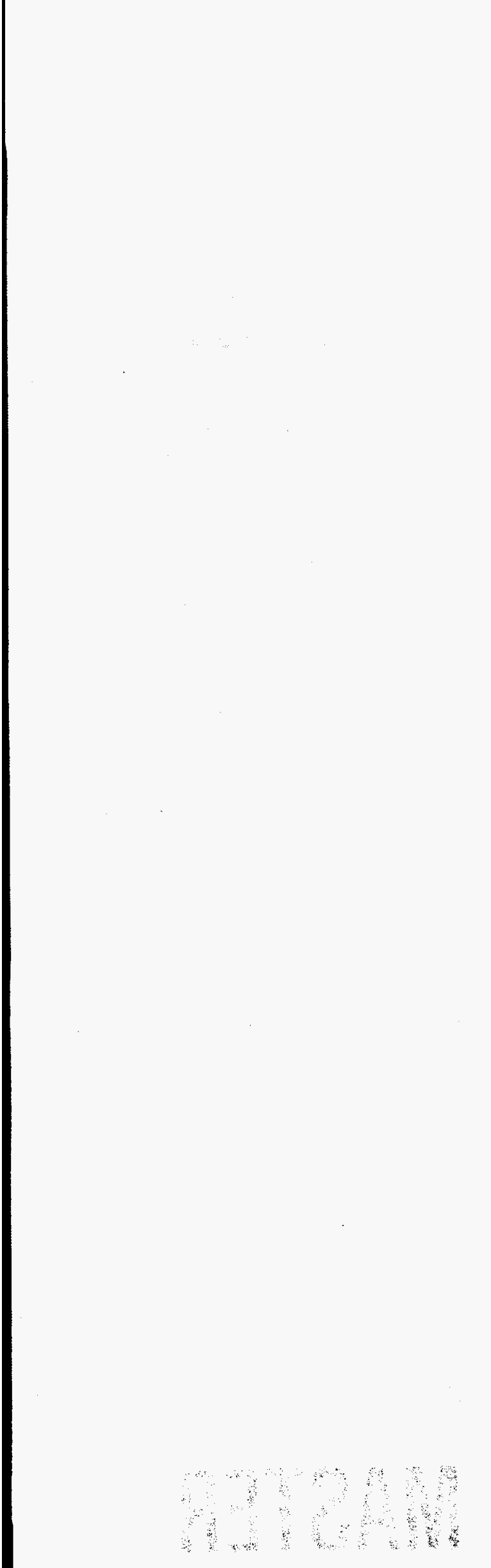

|

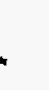
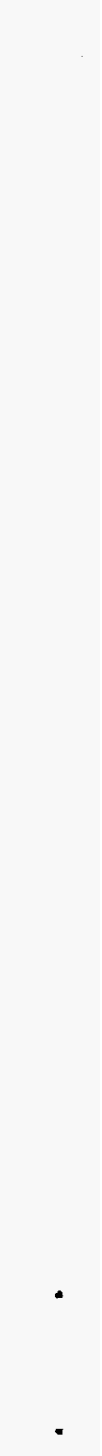

. 


\section{DISCLAIMER}

This report was prepared as an account of work sponsored by an agency of the United States Government. Neither the United States Government nor any agency thereof, nor any of their employees, make any warranty, express or implied, or assumes any legal liability or responsibility for the accuracy, completeness, or usefulness of any information, apparatus, product, or process disclosed, or represents that its use would not infringe privately owned rights. Reference herein to any specific commercial product, process, or service by trade name, trademark, manufacturer, or otherwise does not necéssarily constitute or imply its endorsement, recommendation, or favoring by the United States Government or any agency thereof. The views and opinions of authors expressed herein do not necessarily state or reflect those of the United States Government or any agency thereof. 


\section{DISCLAIMER}

Portions of this document may be illegible in electronic image products. Images are produced from the best available original document. 


\begin{abstract}
The SWEPP Gamma-Ray Spectrometer (SGRS) System has been developed by the Radiation Measurements and Development Unit of the Idaho National Engineering Laboratory to assist in the characterization of the radiological contents of contact-handled waste containers at the Stored Waste Examination Pilot Plant (SWEPP). In addition to determining the concentrations of gamma-ray-emitting radionuclides, the software also calculates attenuation-corrected isotopic mass ratios of specific interest, and provides controls for SGRS hardware as required. This document presents the test plan and report for the data acquisition and analysis software associated with the SGRS system.
\end{abstract}




\section{CONTENTS}

1. INTRODUCTION $\ldots \ldots \ldots \ldots \ldots \ldots \ldots \ldots \ldots \ldots \ldots \ldots \ldots \ldots \ldots \ldots \ldots$

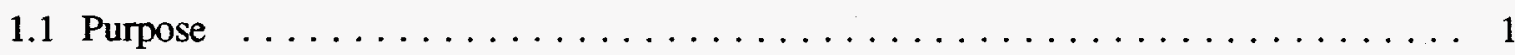

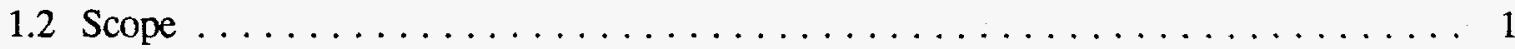

1.3 Definitions, Acronyms, and Abbreviations $\ldots \ldots \ldots \ldots \ldots \ldots \ldots \ldots$

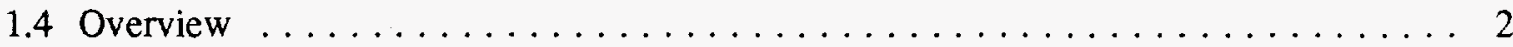

1.5 Registered Trademarks and Copyrights $\ldots \ldots \ldots \ldots \ldots \ldots \ldots \ldots \ldots \ldots$

2. HARDWARE AND SOFTWARE REQUIREMENTS $\ldots \ldots \ldots \ldots \ldots \ldots \ldots \ldots$

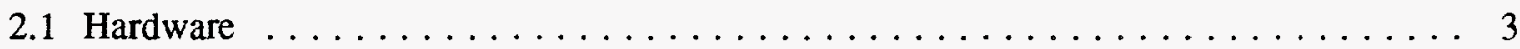

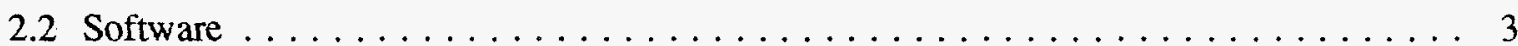

2.2.1 Language and Tools $\ldots \ldots \ldots \ldots \ldots \ldots \ldots \ldots \ldots \ldots \ldots$

2.2.2 Necessary Files for Execution $\ldots \ldots \ldots \ldots \ldots \ldots \ldots \ldots$

3. GC USER INTERFACE TEST PLAN $\ldots \ldots \ldots \ldots \ldots \ldots \ldots \ldots \ldots \ldots \ldots \ldots$

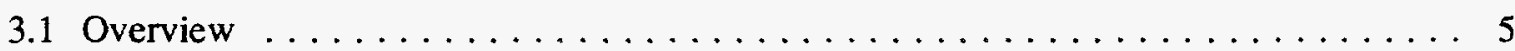

3.2 Initialization of the User's Environment $\ldots \ldots \ldots \ldots \ldots \ldots \ldots \ldots \ldots \ldots \ldots \ldots \ldots$

3.2 .1 DCL.GC_INIT.1 $\ldots \ldots \ldots \ldots \ldots \ldots \ldots \ldots \ldots \ldots \ldots \ldots \ldots$

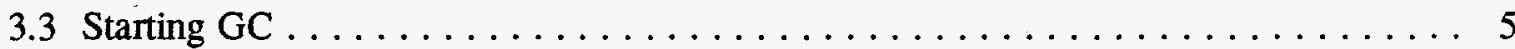

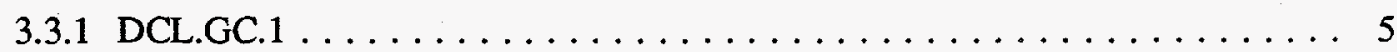

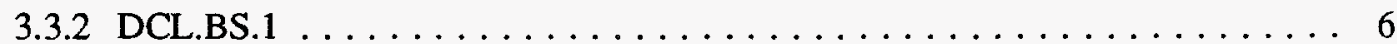

3.4 GC Help, Exit, and Unknown Commands . . . . . . . . . . . . . 7

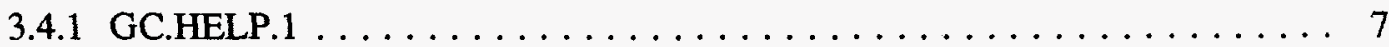

3.4 .2 GC.EXIT.1 ....................... 10

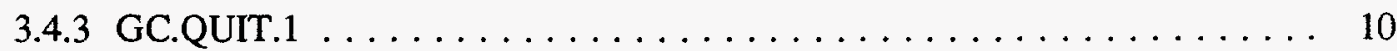


3.4 .4 GC.CONTROL-Z.1 $\ldots \ldots \ldots \ldots \ldots \ldots \ldots \ldots \ldots \ldots \ldots \ldots \ldots$

3.4 .5 GC.UNKNOWN. $1 \ldots \ldots \ldots \ldots \ldots \ldots \ldots \ldots \ldots \ldots \ldots \ldots \ldots \ldots$

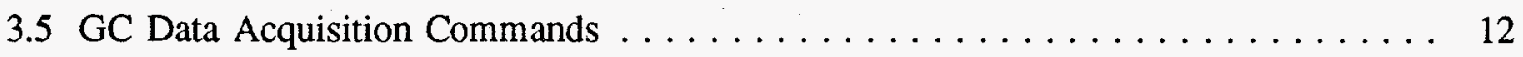

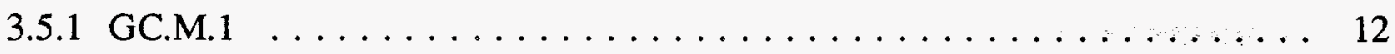

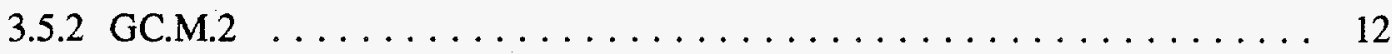

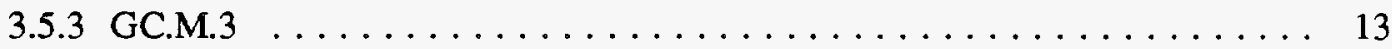

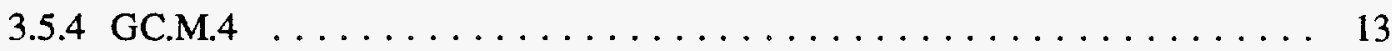

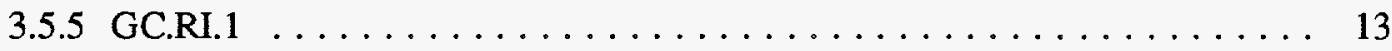

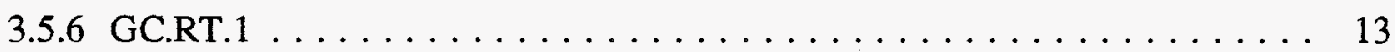

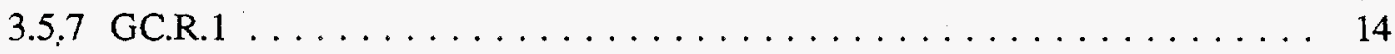

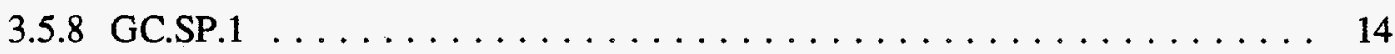

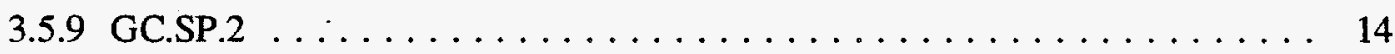

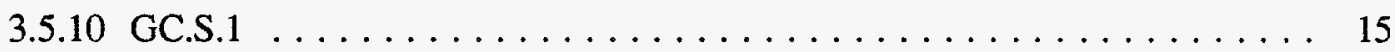

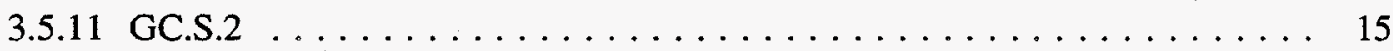

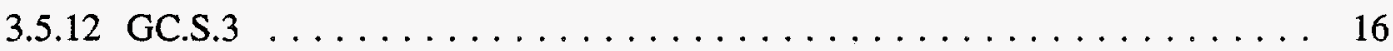

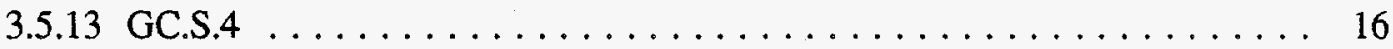

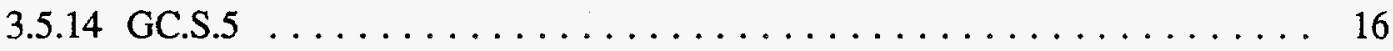

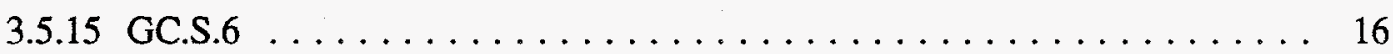

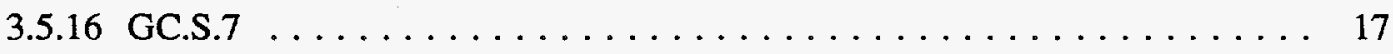

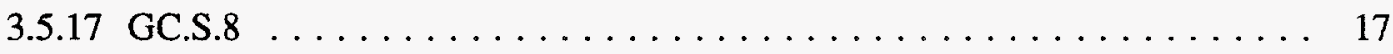

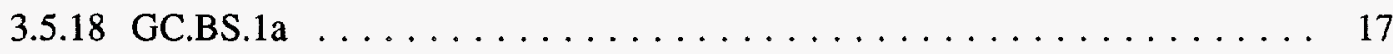

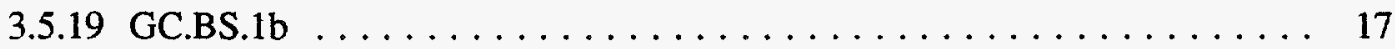

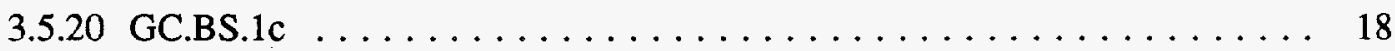

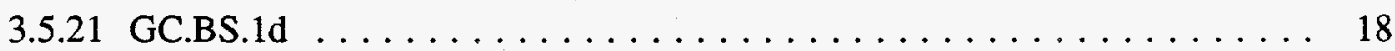

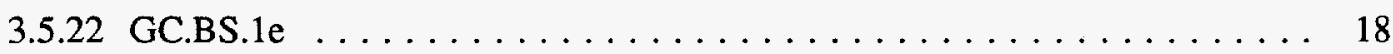




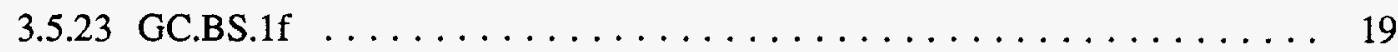

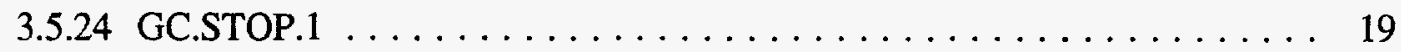

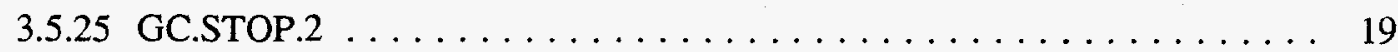

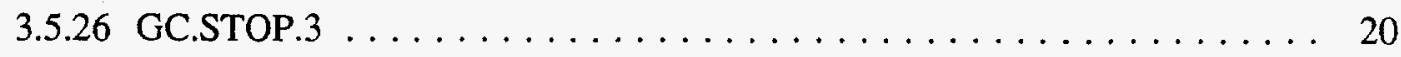

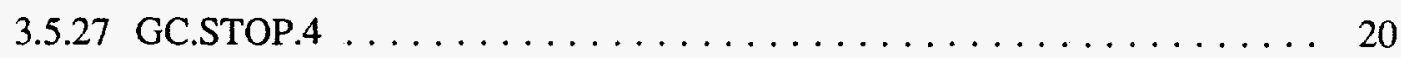

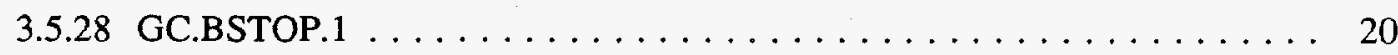

3.6 Spectrum Storage and Analysis Commands $\ldots \ldots \ldots \ldots \ldots \ldots \ldots \ldots \ldots, 21$

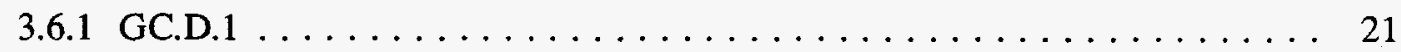

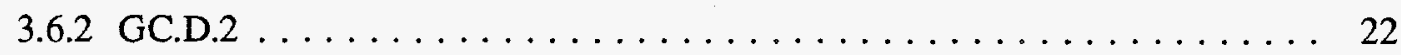

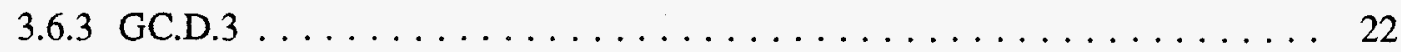

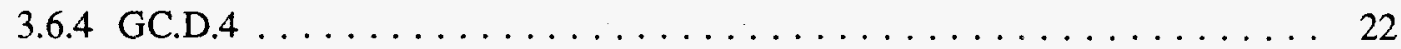

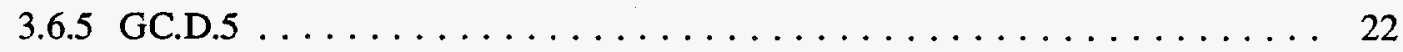

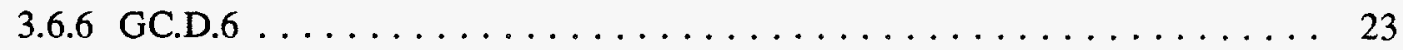

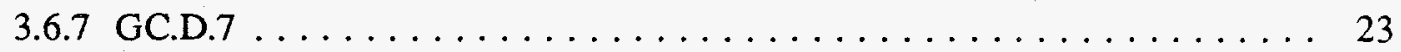

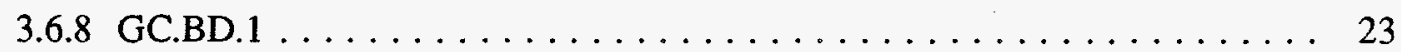

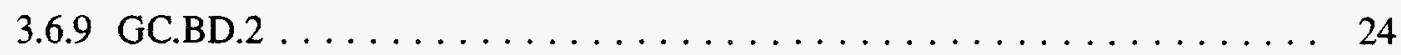

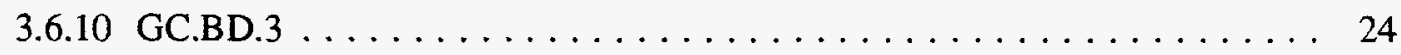

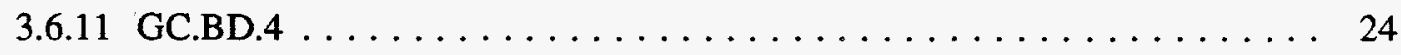

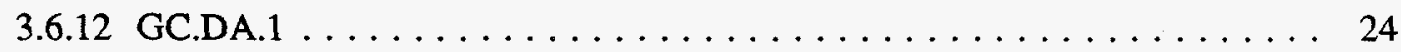

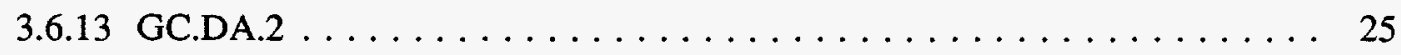

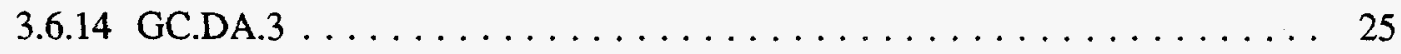

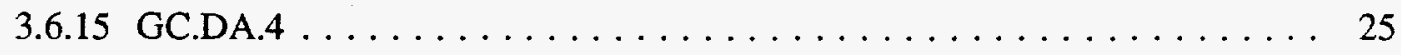

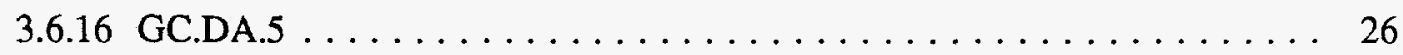

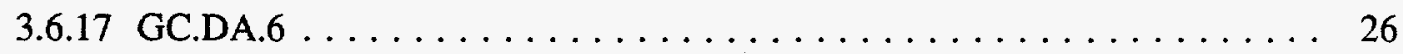

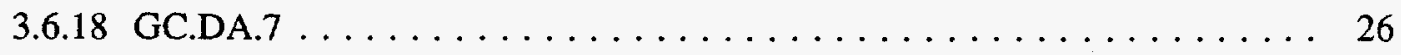




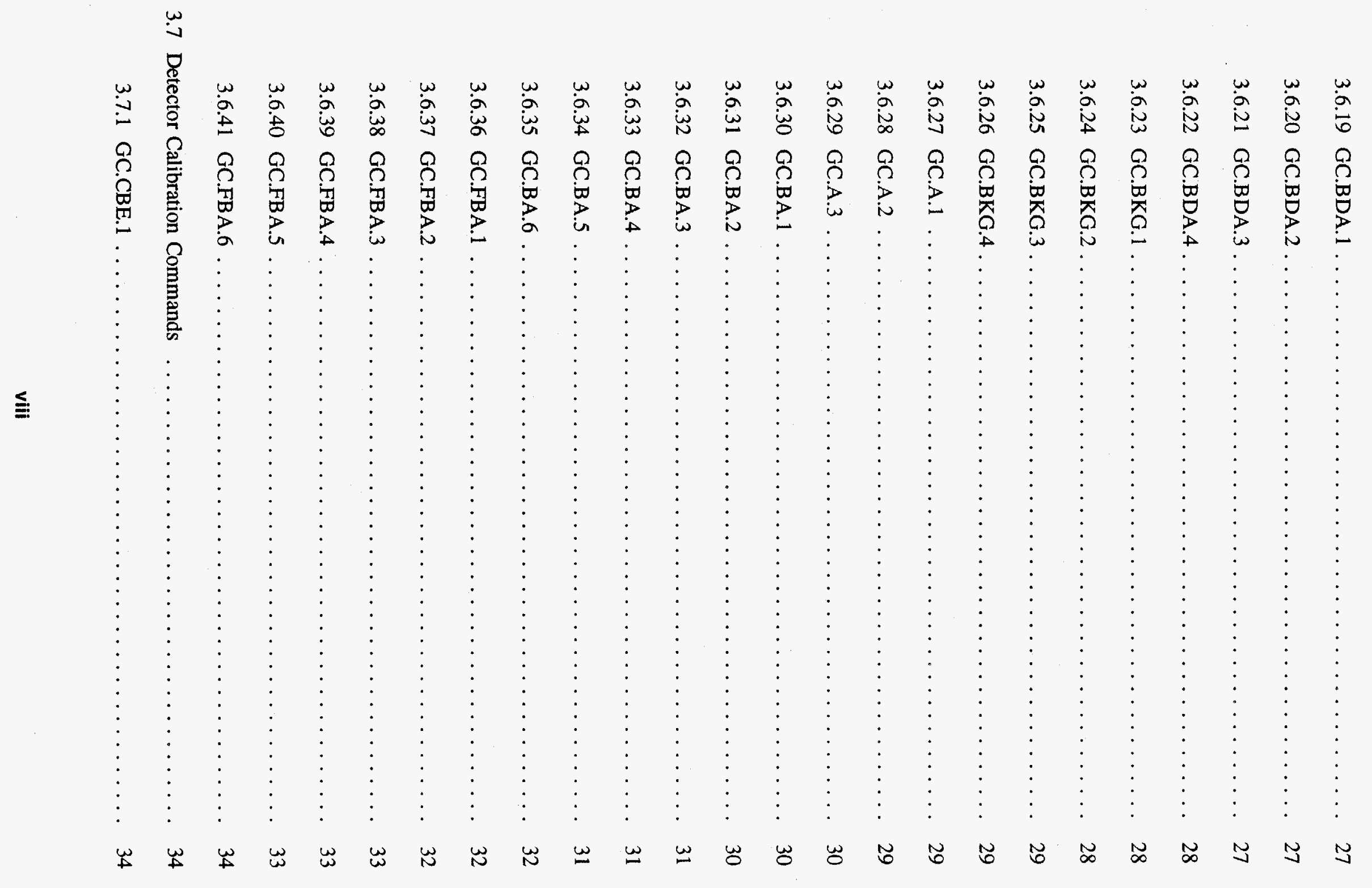




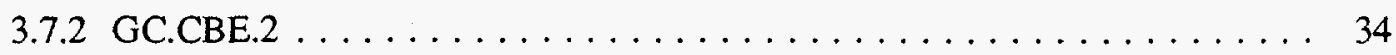

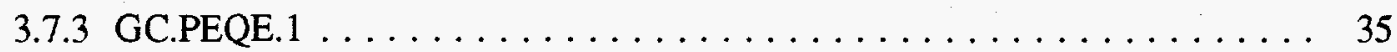

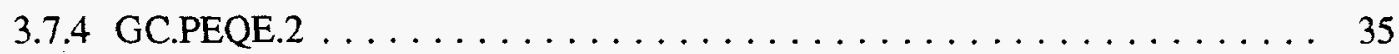

3.7 .5 GC.PEQEH.1 $\ldots \ldots \ldots \ldots \ldots \ldots \ldots \ldots \ldots \ldots \ldots \ldots \ldots \ldots$

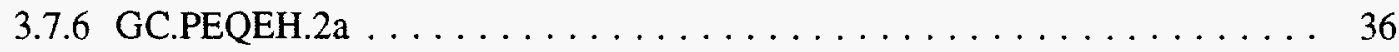

3.7 .7 GC.PEQEH.2b $\ldots \ldots \ldots \ldots \ldots \ldots \ldots \ldots \ldots \ldots \ldots \ldots \ldots$

3.7 .8 GC.PEQEH.2c $\ldots \ldots \ldots \ldots \ldots \ldots \ldots \ldots \ldots \ldots \ldots \ldots \ldots$

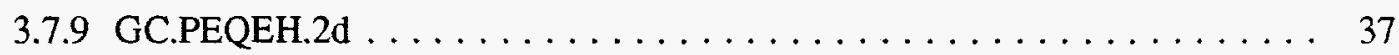

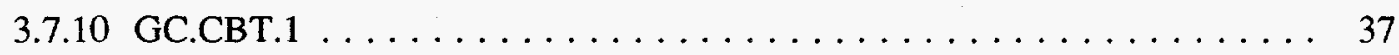

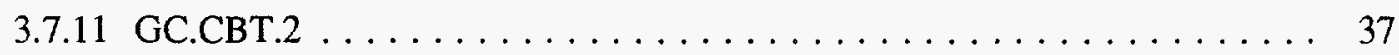

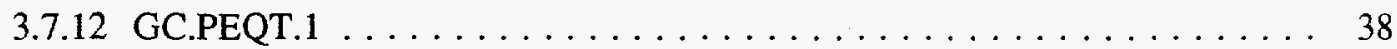

3.7 .13 GC.PEQT. $2 \ldots \ldots \ldots \ldots \ldots \ldots \ldots \ldots \ldots \ldots \ldots \ldots$

3.7 .14 GC.PEQTH.1 $\ldots \ldots \ldots \ldots \ldots \ldots \ldots \ldots \ldots \ldots \ldots \ldots$

3.7 .15 GC.PEQTH.2a $\ldots \ldots \ldots \ldots \ldots \ldots \ldots \ldots \ldots \ldots \ldots \ldots$

3.7 .16 GC.PEQTH.2b . . . . . . . . . . . . . . . . 39

3.7 .17 GC.PEQTH.2c . . . . . . . . . . . . . . . 39

3.7 .18 GC.PEQTH.2d . . . . . . . . . . . . . . . . . 39

3.8 Spectrum Display Commands $\ldots \ldots \ldots \ldots \ldots \ldots \ldots \ldots \ldots \ldots \ldots \ldots$

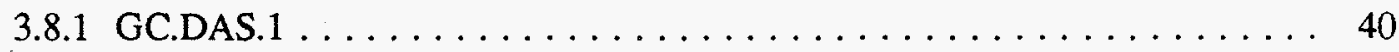

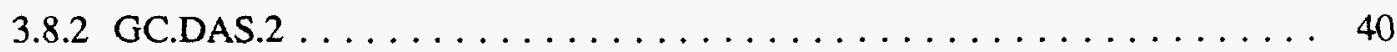

3.9 Batch Job- and Queue-Related Commands $\ldots \ldots \ldots \ldots \ldots \ldots \ldots \ldots$

3.9 .1 GC.TYPELOG. $1 \ldots \ldots \ldots \ldots \ldots \ldots \ldots \ldots \ldots \ldots \ldots \ldots$

3.9 .2 GC.PRINTLOG. $1 \ldots \ldots \ldots \ldots \ldots \ldots \ldots \ldots \ldots \ldots \ldots$

3.9 .3 GC.SHOWQUE. $1 \ldots \ldots \ldots \ldots \ldots \ldots \ldots \ldots \ldots \ldots \ldots \ldots$ 


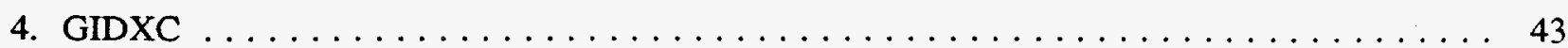

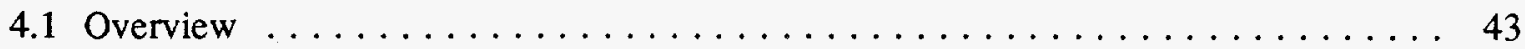

4.2 GIDXC as a Command at the DCL Prompt $\ldots \ldots \ldots \ldots \ldots \ldots \ldots \ldots \ldots \ldots \ldots$

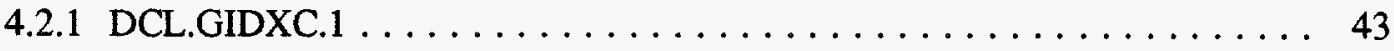

4.2 .2 DCL.GIDXC. $2 \ldots \ldots \ldots \ldots \ldots \ldots \ldots \ldots \ldots \ldots \ldots \ldots$

4.2 .3 DCL.GIDXC. $3 \ldots \ldots \ldots \ldots \ldots \ldots \ldots \ldots \ldots \ldots \ldots$

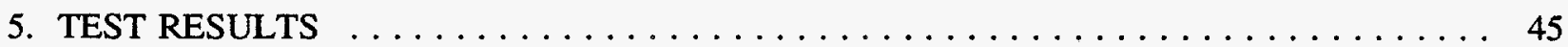

5.1 Test Result Annotations $\ldots \ldots \ldots \ldots \ldots \ldots \ldots \ldots \ldots \ldots \ldots \ldots$

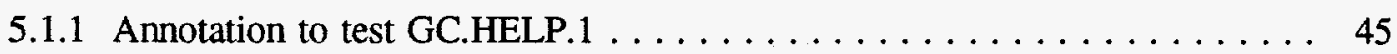

5.1 .2 Annotation to test GC.BS.1f $\ldots \ldots \ldots \ldots \ldots \ldots \ldots \ldots \ldots$

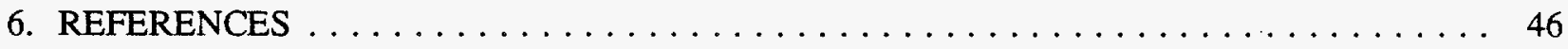

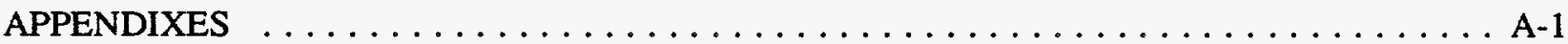

Appendix A. Summaries of Test Cases for GC and GIDXC $\ldots \ldots \ldots \ldots \ldots \ldots \ldots$

A.1 Summary of Test Case Results of September 22, 1994 for GC. . . . . . . . . . A-1

A.2 Summary of Test Case Results of September 22, 1994 for GIDXC . . . . . . . . A A-7

A.3 Blank Summary of Test Cases for GC $\ldots \ldots \ldots \ldots \ldots \ldots \ldots \ldots \ldots$

A.4 Blank Summary of Test Cases for GIDXC $\ldots \ldots \ldots \ldots \ldots \ldots \ldots \ldots$ A-13

Appendix B. Sample Output Files from GC and GIDXC $\ldots \ldots \ldots \ldots \ldots \ldots \ldots \ldots$

B.1 Output from PEQE, Europium-152 Calibration of a Pulsered Detector System . . . . B-1

B.2 A Sample Europium-152 Calibration History Listing From PEQEH $\ldots \ldots \ldots \ldots$. . . 
B.3 Summary Report for a Set of Spectra $\ldots \ldots \ldots \ldots \ldots \ldots \ldots \ldots \ldots$

B.4 PAN\$RATIOS File for the above Set of Spectra $\ldots \ldots \ldots \ldots \ldots \ldots \ldots$

B.5 Full Single Spectrum Output for a Spectrum from the above Set $\ldots \ldots \ldots \ldots$. . . .

B.6 XTP Plot from the above Single Spectrum Analysis $\ldots \ldots \ldots \ldots \ldots \ldots$. . . . 26

\section{FIGURES}

Figure 1. Directory Structures Related to Core VAXGAP Routines and to GC and GIDXC. . . . 4

Figure 2. GC's Main Screen on Startup from the GC Command. . . . . . . . . . 6

Figure 3. GC's Main Screen on Startup from the BS Command. $\ldots \ldots \ldots \ldots \ldots \ldots$

Figure 4. Starting Data Acquisition Using BS; $\ldots \ldots \ldots \ldots \ldots \ldots \ldots \ldots \ldots$

Figure 5. GC Help Screen $\# 1 . \ldots \ldots \ldots \ldots \ldots \ldots \ldots \ldots \ldots \ldots \ldots$

Figure 6. GC Help Screen $\# 2 . \ldots \ldots \ldots \ldots \ldots \ldots \ldots \ldots \ldots \ldots \ldots \ldots \ldots$

Figure 7. GC Help Screen $\# 3 . \ldots \ldots \ldots \ldots \ldots \ldots \ldots \ldots \ldots \ldots \ldots \ldots$

Figure 8. GC Help Screen $\# 4 . \ldots \ldots \ldots \ldots \ldots \ldots \ldots \ldots \ldots \ldots \ldots \ldots$

Figure 9. Confirmatory Message from EXIT; $\ldots \ldots \ldots \ldots \ldots \ldots \ldots \ldots$

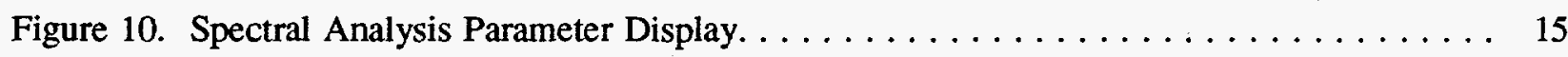

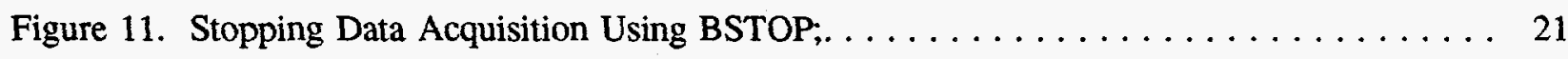

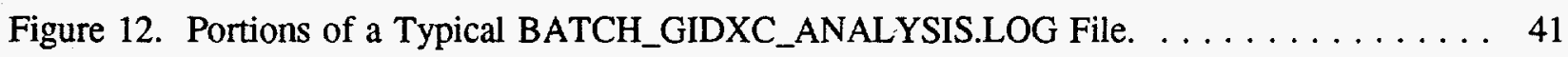

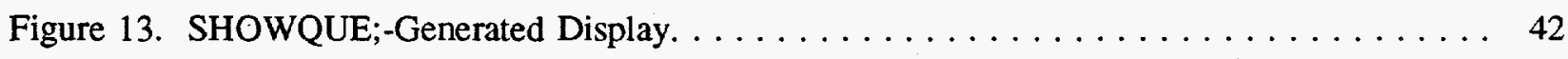




\section{INTRODUCTION}

Nondestructive analysis systems are in use at the Stored Waste Examination Pilot Plant (SWEPP) to characterize the radiological contents of contact-handled waste containers. Drums, bins, and boxes from various waste generators, including Rocky Flats and Argonne National Laboratory West, are currently stored at SWEPP. Before these containers can be shipped to the Waste Isolation Pilot Plant (WIPP), compliance to WIPP's storage, shipping, and disposal requirements must be verified.

This document describes the test plan and report for version 1.00 of the two software components of the SWEPP Gamma-Ray Spectrometer (SGRS) System, excluding the core VAX Gamma-Ray Analysis Program (VAXGAP) version 1 analysis code $[1,2]$. A software design description [3] and user's guide are also available [4]; a familiarity with the latter document is essential for understanding and conducting the tests described herein. The two components are the Gamma-Ray Data Acquisition (GC) program, which provides the user interface to the detector system and turntable, and the Gamma-Ray Isotopic Ratio Analysis (GIDXC) program, which calculates the isotopic ratio from the analysis results [5]. Further development of the code responsible for isotopic ratio calculations, and possibly modifications to this test plan, will occur as additional drum and box content codes [6] are encountered.

GC and GIDXC are being developed by the staff of the Software Development Section of the Radiation Measurements and Development Unit, with technical direction from L. O. Johnson, L. V. East, and E. B. Nieschmidt.

\subsection{Purpose}

This document specifies the test plan for GC and GIDXC and reports the results of the tests on version 1.00 of the software. The intended audience includes developers and validation and verification analysts; the users of GC and GIDXC may also find this document of interest in its description of some of the error-handling capabilities of the programs.

\subsection{Scope}

This document presents a detailed test plan and report for GC and GIDXC. While the errorhandling capabilities are extensively tested through this plan, these tests cannot claim to be exhaustive, treating all possible errors and combinations of errors. No contingency planning is included as part of this report since the SGRS is a standalone system.

\subsection{Definitions, Acronyms, and Abbreviations}

As noted above, a familiarity with Reference 4 is essential for understanding and conducting the tests described herein. Terminology related to the core VAXGAP routines, and related somewhat to gamma-ray spectral analysis in general, follows that used in References 1, 2, and 3. Further, a general understanding of terminology related to the Digital Equipment Corporation's VMS operating system, DECnet communication protocol, DECwindows Motif graphical user interface, FORTRAN compiler, and GKS (Graphical Kernel System) plotting routines is desirable. Otherwise, this document explicitly defines technical terms as they are presented and avoids unnecessary technical jargon for the sake of the general reader. 


\subsection{Overview}

Section 2 reviews the hardware and software requirements for using these programs. Section 3 describes the test plan for GC, while Section 4 describes the test plan for GIDXC. Section 5 presents the results of the tests for GC and GIDXC, conducted on September 22, 1994 by D. A. Schultz and W. Serrano of the SGRS support staff. Section 6 lists the appropriate references for this document. Summaries of the test cases are presented in Appendix A; the first copies detail the actual test results, while the second copies are blank for future use. Appendix B, taken from Reference 4, contains some sample of the hardcopy output generated by GC and GIDXC.

\subsection{Registered Trademarks and Copyrights}

DEC, DECnet, DECwindows, GKS (Graphical Kemel System), VAX, and VMS are registered trademarks of Digital Equipment Corporation (DEC). Motif is a registered trademark of Open Systems Foundation. Slo-Syn is a registered trademark of The Superior Electric Company. 


\section{HARDWARE AND SOFTWARE REQUIREMENTS.}

\subsection{Hardware}

GC and GIDXC are designed to run on a DEC VAX computer (or workstation). At a minimum, a DEC VT330 terminal (or equivalent) is necessary for the user, the GC display routine, DAS [2], requires an X-windowing terminal and a mouse. Hardcopy output and spectral plots are generated on an attached laser printer. Canberra acquisition interface modules (AIMs) are connected to the computer via thin-wire Ethernet and provide the communication link between the computer and the gamma-ray detector systems. Canberra's tumtable, equipped with Superior Electric's Slo-Syn model SS2000D6 packaged drive [7] and model SS20001 programmable motion control [8], is connected to the computer's serial port via an RS232 cable.

\subsection{Software}

\subsubsection{Language and Tools}

GC and GIDXC were developed using DEC FORTRAN and GKS and the DECwindows Motif graphical user interface under the VMS operating system. The VMS operating system, along with runtime versions of FORTRAN and GKS, are required for execution of the programs. The core VAXGAP code, along with Canberra's (formerly Nuclear Data's) AIM control library (composed of FORTRANcallable NMC_ functions), must also be installed.

\subsubsection{Necessary Files for Execution}

The following isotope, insert, limit (or required), and interference libraries $[1,2]$, respectively, are required for analyzing spectra: GE\$ISOTOPE\$LIB:SWEPP.LIB, GE\$LIMIT\$LIB:INSERT.LIB and SWEPPREQ.LIB, and GE\$INTERF\$LIB:SWEPPIF.LIB. User-readable listings of the contents of these libraries are found in Appendix A of Reference 3 or 4. The following user-batch program communication files are needed within the directory pointed to by the logical SYS\$LOGIN for any given user: A1.INPUT, A1.OUTPUT, A2.INPUT, A2.OUTPUT, A3.INPUT, A3.OUTPUT, A4.INPUT, A4.OUTPUT, GIDXC.INPUT, GIDXC.OUTPUT, SLOSYN.DAT, SLOSYN_SPAWN_IN.DAT, and SLOSYN_SPAWN_OT.DAT. These program communication files, which can be created by executing the DCL $^{\mathrm{a}}$ command program INEL\$EXE:GC_USER_INITIALIZATION (see Section 3.2), are generally empty, unless an error occurs during data processing; in that case, the appropriate .OUTPUT file may contain some information useful for the user, developer, or system administrator in tracking down and correcting the cause of the error.

The installation of VAXGAP on the computer creates a specific directory structure on the disk pointed to by the logical GAP\$DISK. The directory structures for this disk and the system disk, including GC- and GIDXC-related additions, and the logicals that point to specific directories within the directory trees, are presented in Figure 1.

a. DCL is an abbreviation for DEC's command language within the VMS operating system. The DCL prompt is the prompt the VMS operating system presents to the user after the user logs in. 
disk root directories subdirectories.... DKA100: (system-specific)

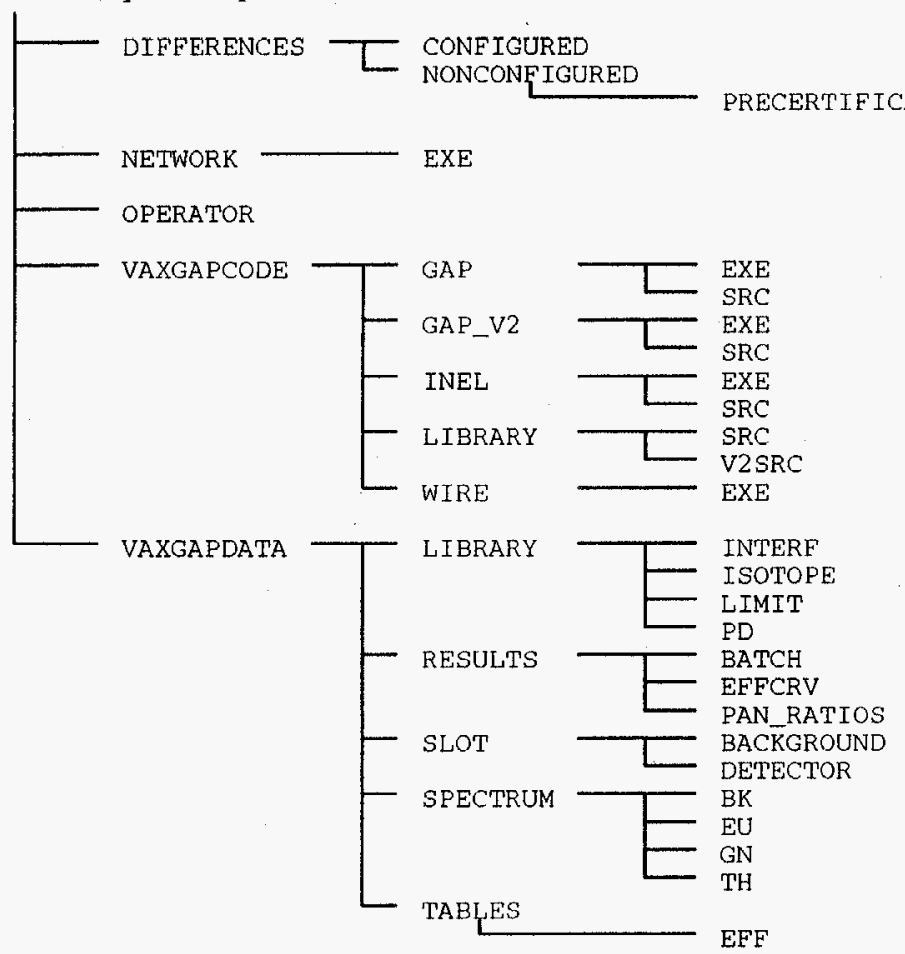

DKA0: (system-specific)

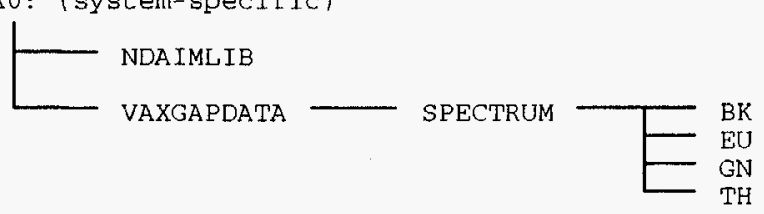

associated logicals

GAP\$DISK， SUSER

\section{DIF\$CON}

DIF\$NON

DIF\$PRE

RML\$NET

$-$

GAP\$EXE

GAP\$SRC

GAPV $\$$ EXE

GAPV2\$SR'C

INEL\$EXE

INELSSRC

LIB\$SRC

LIBV2 $\$$ SRC

WIRESEXE

GE\$ INTERF $\$$ IB

GE\$ ISOTOPE\$LIB

GE\$LIMITSLIB

GE\$PD\$LIB

BATCH\$RESULTS

PAN\$RATIOS

SLOT\$BKG

SLOT\$SPC

BKSSAVE

EUSSAVE

GNSSAVE

THSSAVE

AT\$TABLE
EFFICIENCY \$TABLES

\$SYSTEM, \$DATA

LIB_CAM

BK\$DATA

EUSDATA

GN\$DATA， GE\$DATA

\section{contents}

VAXGAP; data, results, and user directories

difference files from core VAXGAP changes from other post-certification changes from other pre-certification changes

network-related control command files

user files

core VAXGAP executables

source code for the above

core VAXGAP version 2 executables

GC and GIDXC (and non-core VAXGAP) executables source code for the above

VAXGAP function object library and source code same for VAXGAF version 2

historical location of some conversion routines

interference libraries

isotope libraries

limit libraries

parent-daughter correction libraries

radionuclide activity results files by spectrum results from efficiency curve determinations isotopic mass ratio results file by container slot-specific spectrum files, QC/calibration data slot-specific background files

background spectrum files

europium calibration spectrum files

sample (i.e: general) spectrum files

thorium calibration files

attenuation coeficient tables

detector efficiency curves

operating system, compilers, . .

Canberra's AIM control library

background spectrum files archive

europium calibration spectrum files archive sample (1.e.; general) spectrum files archive thorium calibration files archive

Figure 1. Directory Structures Related to Core VAXGAP Routines and to GC and GIDXC. 


\section{GC USER INTERFACE TEST PLAN}

\subsection{Overview}

GC provides the interface between the user and the detector systems and turntable. It also allows the user to perform diagnostic measurements on the detector systems and spectral analyses using GIDXC. The test plan for GC will parallel the presentation of commands in Reference 4; refer to this same reference for more detailed information on each of the commands and on the GC main screen. The nomenclature for the various test cases is <program or command language name $>$.<command (without semicolon) $>$.<sequential test number for the respective command>. For example, for the first test case of entering the command GC_INIT from the DCL prompt, the test case would be DCL.GC_INIT.1; or, for the third test case of entering the $\mathrm{M}$; ( $\mathrm{M}$ for monitor) command within $\mathrm{GC}$, the test case would be GC.M.3. All tests of GC commands are to be performed from within GC.

\subsection{Initialization of the User's Environment}

\subsection{1 .DCL.GC_INIT.1}

3.2.1.1 Purpose. This test addresses the generation of the necessary program communication files.

3.2.1.2 Input Description. Enter the command GC_INIT (including the underscore) at the DCL prompt.

3.2.1.3 Expected Results. The message "User's root directory successfully prepared for executing GC" appears and the user is returned to the DCL prompt. The following thirteen files now exist in the user's root directory: A1.INPUT, A1.OUTPUT, A2.INPUT, A2.OUTPUT, A3.INPUT, A3.OUTPUT, A4.INPUT, A4.OUTPUT, GIDXC.INPUT, GIDXC.OUTPUT, SLOSYN.DAT, SLOSYN_SPAWN_IN.DAT, and SLOSYN_SPAWN_OT.DAT. (To see that these files now exist, enter the command DIR SYS\$LOGIN at the DCL prompt to obtain a listing of all files in the user's root directory.)

3.2.1.4 Pass/Fail Criterion. The test passes if the expected results are obtained.

\subsection{Starting GC}

\subsubsection{DCL.GC.1}

3.3.1.1 Purpose. This test addresses starting the GC user interface using the GC command at the DCL prompt.

3.3.1.2 Input Description. Enter the command GC at the DCL prompt.

3.3.1.3 Expected Results. A screen, the GC main screen, similar to that presented in Figure

b. Throughout this document entering a command implies striking the return key after typing in the command. Also, commands to be entered will appear in bold text. 
2 appears.

\section{SWEPP GAMMA-RAY BARREL COUNTING SYSTEM}

\begin{tabular}{|l|c|c|c|c|c|}
\hline DETECTOR & A1 & A2 & A3 & A4 & \\
\hline STATUS-> & OFF & OFF & OFF & OFF & 5 \\
LIVE--> & & & & & \\
REAL---> \\
INTERVAL \\
ID---->
\end{tabular}

Figure 2. GC's Main Screen on Startup from the GC Command.

3.3.1.4 Pass/Fail Criterion. The test passes if the expected results are obtained.

\subsubsection{DCL.BS.1}

3.3.2.1 Purpose. This test addresses starting the GC user interface using the BS command at the DCL prompt. (Further BS-related tests within GC will be presented in Sections 3.5.18-3.5.23.)

3.3.2.2 Input Description. Enter the command BS 000000 at the DCL prompt. Enter 1.1 in response to the first query, 01 in response to the second query, and TEST CASE in response to the third query.

3.3.2.3 Expected Results. The GC main screen, similar to that presented in Figure 3, appears and three queries requesting more information about the container being examined are presented to the user. The first query, "ENTER THE WEIGHT IN KILOGRAMS," is included in Figure 3; the other two queries are "ENTER THE CONTENT CODE" and "ENTER ANY COMMENTS".

The status for all detector systems changes to "ON", their real and live times change to 0 and then start increasing, their intervals change to 36,000, and the parameter value associated with "MONITOR PU REGION?" changes to "Y". The value associated with "CONTAINER:" changes to "000000". If the value associated with "ON COUNT?" is "Y", the value associated with "ROTATING?" changes to "Y" and the turntable starts rotating. The "ACQUIRE" light on the appropriate AIMs turns on. The messages "DATA COLLECTION STARTED ON ADC A1 A2 A3 A4", "ESTIMATED COUNT LENGTH TO REACH TRIGGER LEVEL NOT CALCULABLE", and "THE PRESENCE OF A LEAD LINER 


\section{SWEPP GAMMA-RAY BARREL COUNTING SYSTEM}

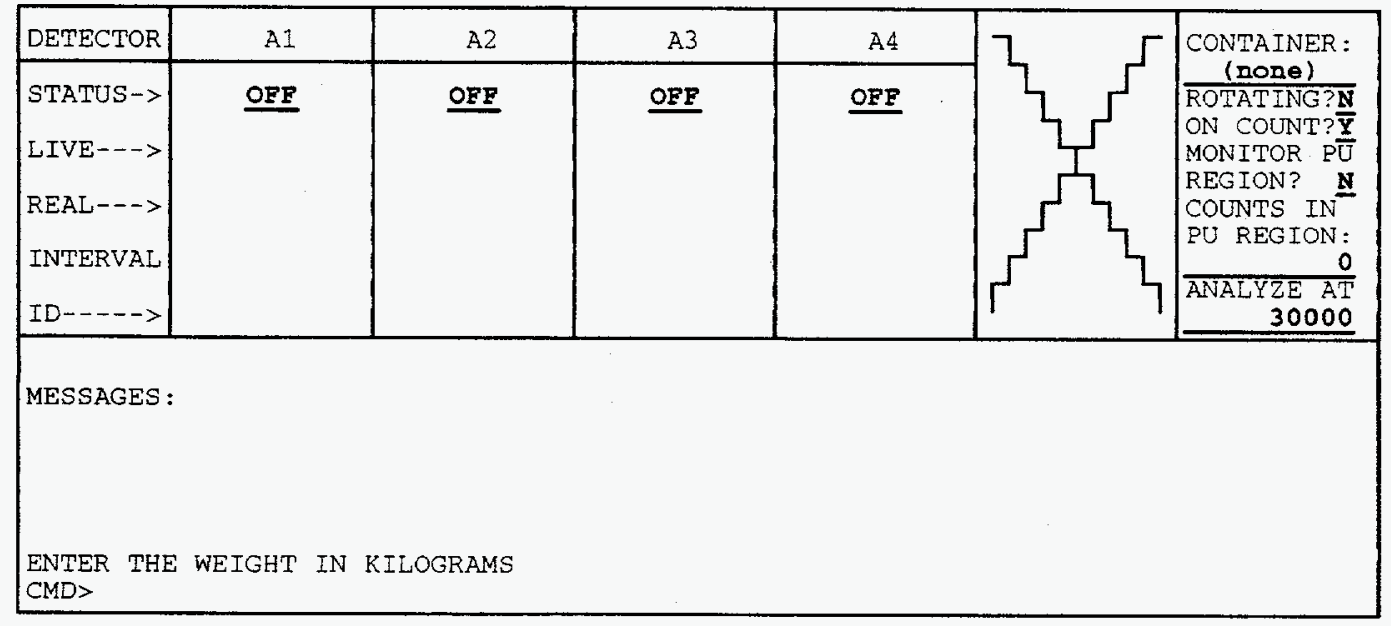

Figure 3. GC's Main Screen on Startup from the BS Command.

CANNOT YET BE RELIABLY DETERMINED" appear below the "MESSAGES:" label (see Figure 4). Shortly after the acquisitions have started, the second message changes to "ESTIMATED COUNT LENGTH TO REACH TRIGGER LEVEL = " followed by some integer number followed by "SEC", where the integer number will change with time (rapidly at first, then more slowly as the acquisition progresses). ${ }^{c}$

3.3.2.4 Pass/Fail Criterion. The test passes if the expected results are obtained.

\subsection{GC Help, Exit, and Unknown Commands}

\subsubsection{GC.HELP.1}

3.4.1.1 Purpose. This test addresses the HELP; command within GC.

3.4.1.2 Input Description. Enter the command HELP; at the GC "CMD>" prompt, then strike the return key each time the message "Press the 'Return' key to continue." appears at the bottom of the screen.

c. It is also possible, though not required for passing this test, that after enough time the third message will change and begin with either "LEAD LINER LIKELY NOT PRESENT" or "LEAD LINER LIKELY PRESENT." This change occurs only after enough counts have been accumulated in a certain region of the gamma-ray spectrum, and this may not happen for a long time depending on what is being observed by the detectors. 


\section{SWEPP GAMMA-RAY BARREL COUNTING SYSTEM}

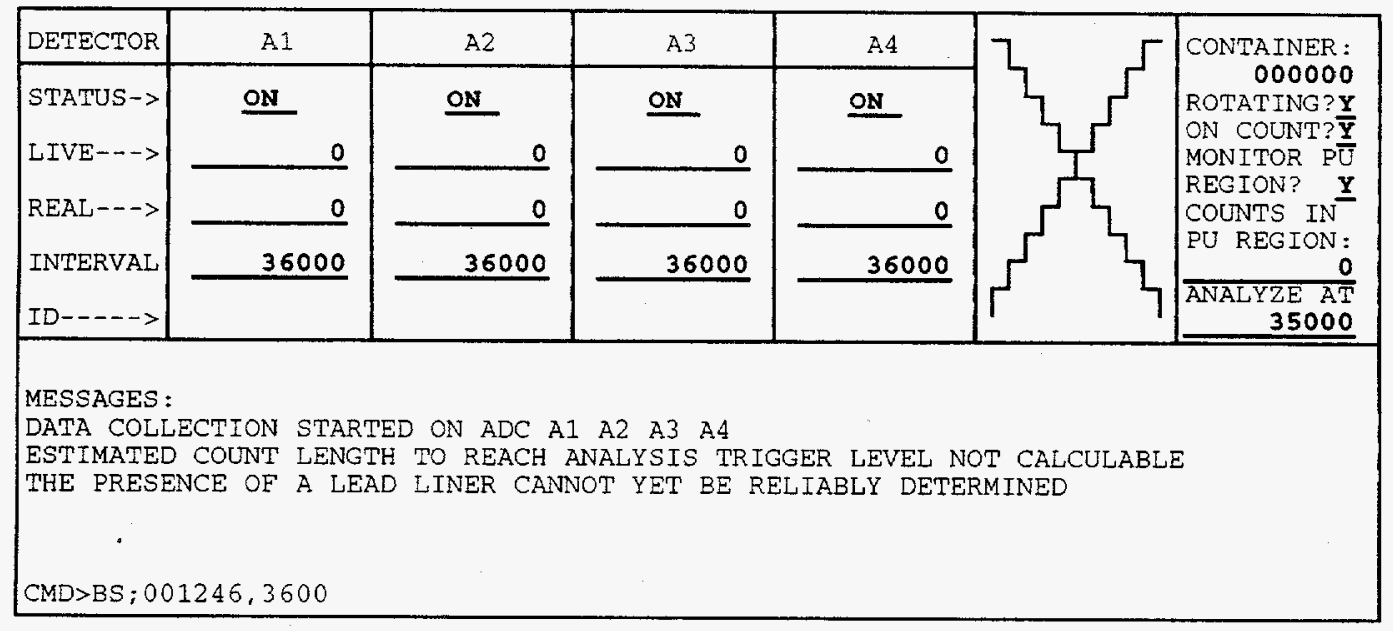

Figure 4. Starting Data Acquisition Using BS;.

COMMANDS AVAILABLE IN "GC" - SCREEN 1 OF 4

DATA ACQUISITION COMMANDS

M; <count limit>... Toggle whether Pu-count monitoring occurs during a count.

RI;..............................

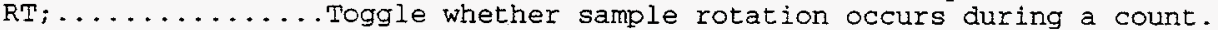

R;....................

$\mathrm{SP} ;<$ detector $>$...... Set the analysis parameters for the specified detector.

$s_{i}<$ detector $\left.(s)\right\rangle,\langle\sec \rangle \ldots$

BS; <container $i \dot{d}>$. $<$ start a

.... Same as $S$, but for al1 detectors.

STOP; <detectors>... Stop data collection on the specified detector(s).

BSTOP;............ Same as STOP, but for all detectors.

Figure 5. GC Help Screen \#1.

3.4.1.3 Expected Results. The GC main screen disappears and the help screens depicted in 
Figures 5 through 8 appear prior to each successive striking of the retum key. After the striking the retum key the fourth time the GC main screen reappears.

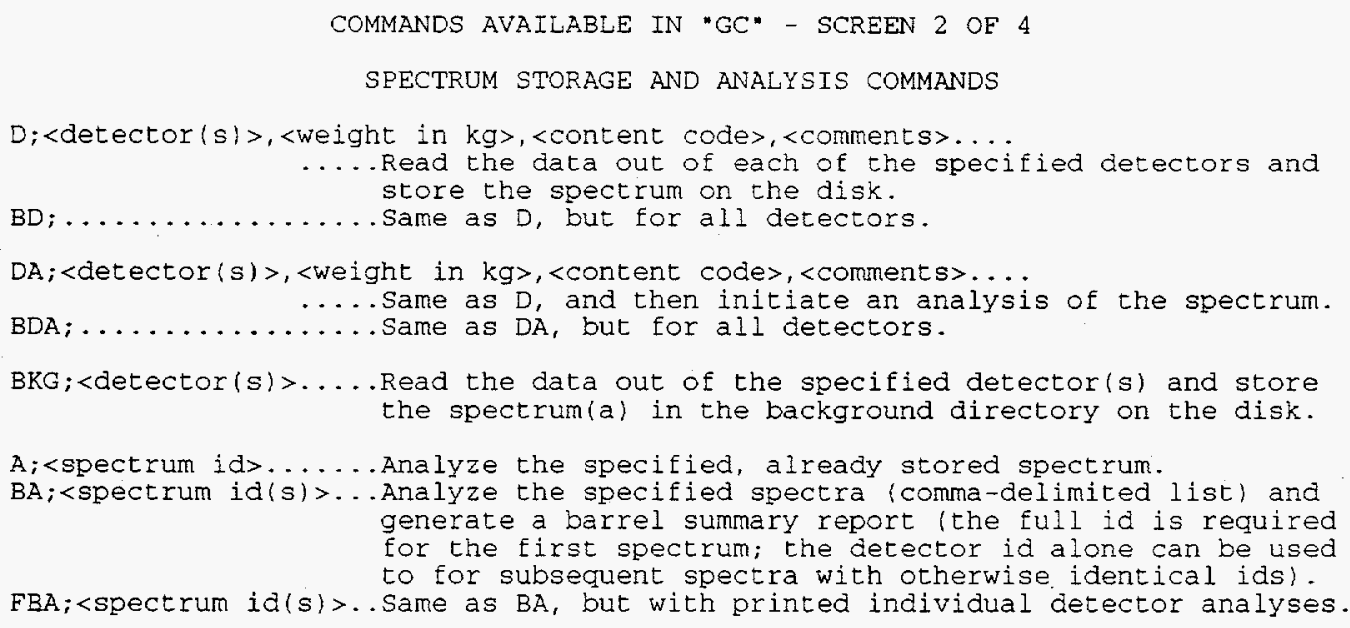

Figure 6. GC Help Screen \#2.

COMMANDS AVAILABLE IN "GC" - SCREEN 3 OF 4

DETECTOR CALIBRATION COMMANDS

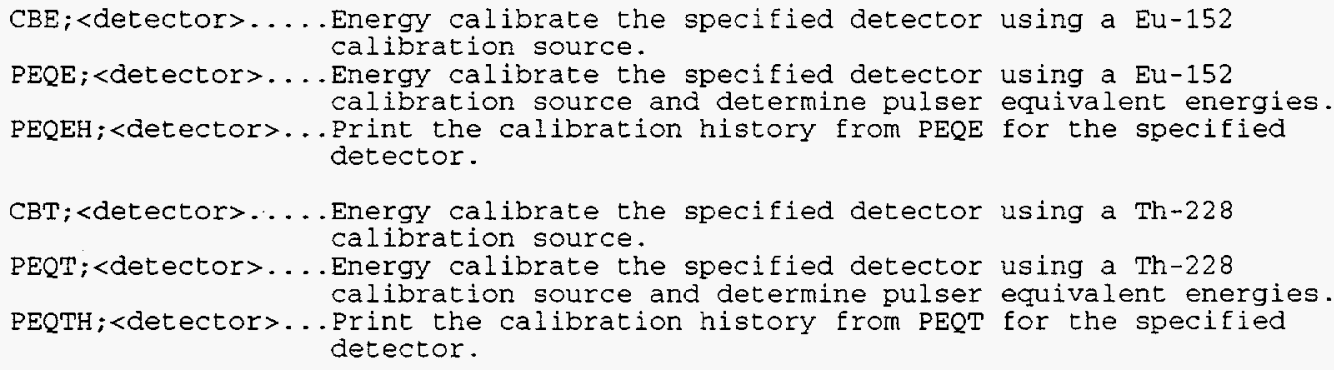

Figure 7. GC Help Screen \#3.

3.4.1.4 Pass/Fail Criterion. The test passes if the expected results are obtained. 


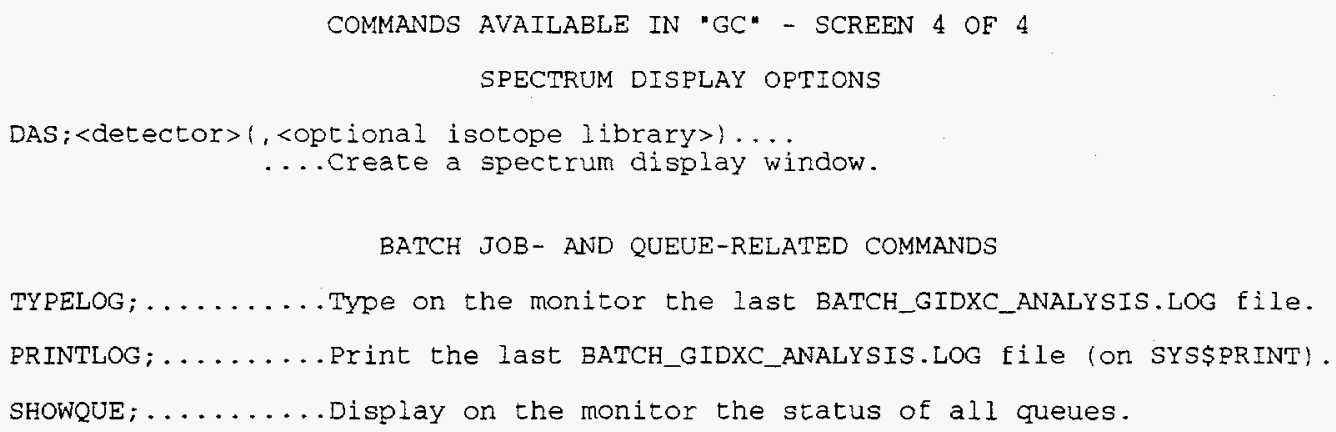

Figure 8. GC Help Screen \#4.

\subsubsection{GC.EXIT.1}

3.4.2.1 Purpose. This test addresses exiting from GC using the EXIT; command.

3.4.2.2 Input Description. Enter the command EXIT; at the GC "CMD>" prompt. Then, if requested to do so, enter EXIT; again.

3.4.2.3 Expected Results. If no acquisitions are in progress, the user should be retumed to the DCL prompt after entering EXIT; the first time. If acquisitions are in progress, the messages "THERE ARE COUNTS IN PROGRESS - EXITING NOW WILL PREVENT AUTOMATIC PROCESSING" and "REPEAT THE COMMAND TO CONFIRM EXITING AT THIS TIME" will appear, as depicted in Figure 9, after entering EXIT; the first time. The user should be retumed to the DCL prompt after entering EXIT; the second time.

3.4.2.4 Pass/Fail Criterion. The test passes if the expected results are obtained.

\subsubsection{GC.QUIT.1}

3.4.3.1 Purpose. This test addresses exiting from GC using the QUIT; command.

3.4.3.2 Input Description. Enter the command QUIT; at the GC "CMD>" prompt. Then, if requested to do so, enter QUIT; again.

3.4.3.3 Expected Results. If no acquisitions are in progress, the user should be retumed to the DCL prompt after entering QUIT; the first time. If acquisitions are in progress, the messages "THERE ARE COUNTS IN PROGRESS - EXITING NOW WILL PREVENT AUTOMATIC PROCESSING" and "REPEAT THE COMMAND TO CONFIRM EXITING AT THIS TIME" will appear after entering QUIT; the first time (the screen will be similar to that in Figure 9 but with "EXIT" replaced with "QUIT" at the "CMD>" prompt). The user should be retumed to the DCL prompt after entering QUIT; the second time. 


\section{SWEPP GAMMA-RAY BARREL COUNTING SYSTEM}

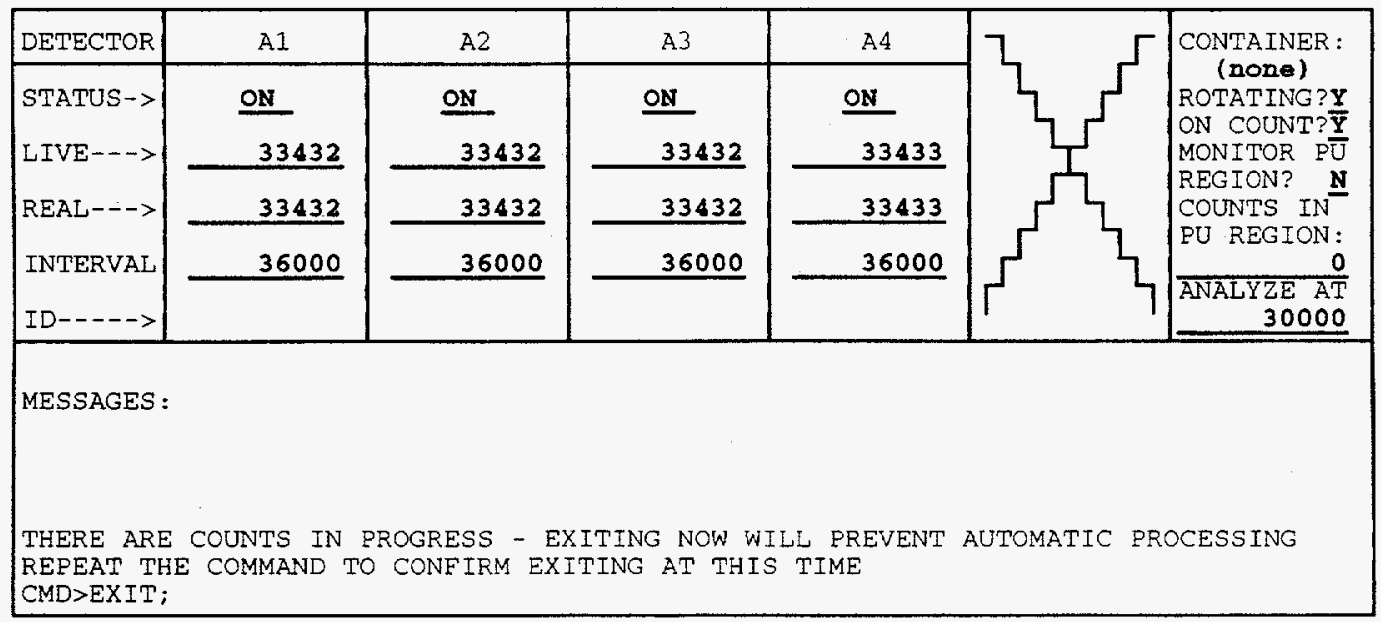

Figure 9. Confirmatory Message from EXIT;

3.4.3.4 Pass/Fail Criterion. The test passes if the expected results are obtained.

\subsubsection{GC.CONTROL-Z.1}

3.4.4.1 Purpose. This test addresses exiting from GC by striking control-z. ${ }^{\mathrm{d}}$

3.4.4.2 Input Description. Strike control-z at the GC "CMD>" prompt. Then, if requested to do so, strike control-z again.

3.4.4.3 Expected Results. If no acquisitions are in progress, the user should be returned to the DCL prompt after striking control-z the first time. If acquisitions are in progress, the messages "THERE ARE COUNTS IN PROGRESS - EXITING NOW WILL PREVENT AUTOMATIC PROCESSING" and "REPEAT THE COMMAND TO CONFIRM EXITING AT THIS TIME" will appear after striking control-z the first time (the screen will be similar to that in Figure 9 but there will be nothing after the "CMD>" prompt). The user should be retumed to the DCL prompt after striking control-z again.

3.4.4.4 Pass/Fail Criterion. The test passes if the expected results are obtained.

\subsubsection{GC.UNKNOWN.1}

d. Striking control-z means to hold down the control key (sometimes labelled Ctrl) while striking the letter $\mathrm{z}$ key. This applies in general to any control-<key $>$ key stroke combination, as well as to alt-<key $>$ key stroke combinations. 
within GC.

3.4.5.1 Purpose. This test addresses GC's response to an unknown command being entered

3.4.5.2 Input Description. Enter the command UNKNOWN; at the GC "CMD>" prompt.

3.4.5.3 Expected Results. The message "BAD OR UNKNOWN COMMAND-'UNKNOWN;'" appears above the "CMD>" prompt.

3.4.5.4 Pass/Fail Criterion. The test passes if the expected results are obtained.

\subsection{GC Data Acquisition Commands}

\subsubsection{GC.M.1}

3.5.1.1 Purpose. This test addresses using the $\mathrm{M}$; command within $\mathrm{GC}$ for toggling ${ }^{\mathrm{e}}$ whether the region of the gamma-ray spectrum where a number of peaks from plutonium isotopes are observed is monitored during a data acquisition started using BS; or S;.

3.5.1.2 Input Description. A data acquisition should not be taking place while performing this test. Enter the command $\mathrm{M}$; at the GC "CMD>" prompt.

3.5.1.3 Expected Results. The parameter value associated with "MONITOR PU REGION?" should remain unchanged. This command has no effect unless data acquisition is occurring.

3.5.1.4 Pass/Fail Criterion. The test passes if the expected results are obtained.

\subsubsection{GC.M.2}

3.5.2.1 Purpose. This test addresses using the M; command within GC for toggling ${ }^{\mathrm{f}}$ whether the region of the gamma-ray spectrum where a number of peaks from plutonium isotopes are observed is monitored during a data acquisition started using BS; or S;.

3.5.2.2 Input Description. A data acquisition needs to be taking place while performing this test. Enter the command M; at the GC "CMD>" prompt. Enter the command again."

3.5.2.3 Expected Results. The parameter value associated with "MONITOR PU REGION?" changes to " $\mathrm{N}$ " if it is displayed as " $\mathrm{Y}$ " prior to the command $\mathrm{M}$; being entered; it changes to " $\mathrm{Y}^{\text {" if it }}$ is displayed as " $\mathrm{N}$ " prior to the command being entered (in this latter case, if the value associated with "ANALYZE $\mathrm{AT}^{\text {"A }}$ is not 30,000 prior to the command being entered, it will be reset to this value).

e. Toggle here, and throughout the document, means to turn something off if it is currently on, or to turn it on if it is currently off.

f. Toggle here, and throughout the document, means to turn something off if it is currently on, or to turn it on if it is currently off.

g. In testing toggles, the user will repeat the command to ensure that the toggle works in both directions. The user should observe the results after each entry of the command, not just after having entered the command twice. 
3.5.2.4 Pass/Fail Criterion. The test passes if the expected results are obtained.

\subsubsection{GC.M.3}

3.5.3.1 Purpose. This test addresses using the M; command within GC for toggling whether the region of the gamma-ray spectrum where a number of peaks from plutonium isotopes are observed is monitored during a data acquisition started using BS; or S; and changing the analysis trigger level (i.e., the count limit).

3.5.3.2 Input Description. A data acquisition needs to be taking place while performing this test. If the parameter value associated with "MONITOR PU REGION?" is displayed as " $Y$ ", enter the command $\mathrm{M}$; at the GC "CMD>" prompt to set it to "N". Enter the command $\mathbf{M} ; 35000$ at the GC "CMD>" prompt.

3.5.3.3 Expected Results. The parameter value associated with "MONITOR PU REGION?" changes from " $N$ " to " $Y$ " and the value associated with "ANALYZE AT" changes from 30,000 to 35,000.

3.5.3.4 Pass/Fail Criterion. The test passes if the expected results are obtained.

\subsubsection{GC.M.4}

3.5.4.1 Purpose. This test addresses using an M; command within GC, as in test GC.M.3, with an invalid analysis trigger level.

3.5.4.2 Input Description. A data acquisition needs to be taking place while performing this test. If the parameter value associated with "MONITOR PU REGION?" is displayed as "Y", enter the command $\mathbf{M}$; at the GC "CMD>" prompt to set it to "N". Enter the command $\mathbf{M} ; \mathbf{A}$ at the GC "CMD>" prompt.

3.5.4.3 Expected Results. The messages "INCOMPLETE COMMAND - COUNT LIMIT INVALID" and "BAD OR UNKNOWN COMMAND--'M;A'" appear above the "CMD>" prompt and no changes are made to the associated parameter values (i.e., to "MONITOR PU REGION?" and "ANALYZE $\left.\mathrm{AT}^{\prime \prime}\right)$.

3.5.4.4 Pass/Fail Criterion. The test passes if the expected results are obtained.

\subsubsection{GC.RI.1.}

3.5.5.1 Purpose. This test addresses using the RI; command within GC to initialize communications with the turntable controller.

3.5.5.2 Input Description. Enter the command RI; at the GC "CMD>" prompt.

3.5.5.3 Expected Results. No messages are displayed on the GC screen, and no parameter values change.

3.5.5.4 Pass/Fall Criterion. The test passes if the expected results are obtained.

\subsubsection{GC.RT.1}


3.5.6.1 Purpose. This test addresses using the RT; command within GC to toggle whether turntable rotation should occur during data acquisition.

3.5.6.2 Input Description. Enter the command RT; at the GC "CMD>" prompt. Enter the command again.

3.5.6.3 Expected Results. The parameter value associated with "ON COUNT?" (found below "ROTATING?") changes to "N" if it is displayed as " $\mathrm{Y}$ " prior to the command RT; being entered; it changes to " $\mathrm{Y}$ " if it is displayed as " $\mathrm{N}$ " prior to the command being entered.

3.5.6.4 Pass/Fail Criterion. The test passes if the expected results are obtained.

\subsubsection{GC.R.1}

3.5.7.1 Purpose. This test addresses using the $\mathrm{R}$; command within GC to toggle whether the turntable is currently rotating.

3.5.7.2 Input Description. Enter the command R; at the GC "CMD>" prompt. Enter the command again.

3.5.7.3 Expected Results. The parameter value associated with "ROTATING?" changes to "N" if it is displayed as " $\mathrm{Y}$ " prior to the command $\mathrm{R}$; being entered, and turntable rotation stops; it changes to " $\mathrm{Y}$ " if it is displayed as " $\mathrm{N}$ " prior to the command being entered, and turntable rotation starts.

3.5.7.4 Pass/Fail Criterion. The test passes if the expected results are obtained.

\subsubsection{GC.SP.1}

3.5.8.1 Purpose. This test addresses using the SP; command within GC to display the current spectral analysis parameters for a single detector system.

3.5.8.2 Input Description. Enter the command SP;A1 at the GC "CMD>" prompt. Make some changes to the fields, then strike control-z to return to GC's main screen.

3.5.8.3 Expected Results. A text screen akin to that presented in Figure 10 appears upon the user entering the command, changes entered in the third column appear in the second column, and GC's main screen reappears after the user strikes control-z.

3.5.8.4 Pass/Fall Criterion. The test passes if the expected results are obtained.

\subsubsection{GC.SP.2}

3.5.9.1 Purpose. This test addresses using the SP; command within GC to display the current spectral analysis parameters for an unknown single detector system.

3.5.9.2 Input Description. Enter the command SP;A5 at the GC "CMD>" prompt.

3.5.9.3 Expected Results. The messages "UNKNOWN DETECTOR NUMBER: '5'" and "BAD OR UNKNOWN COMMAND--'SP;A5" are displayed above the "CMD>" prompt. 


$\begin{array}{lc}\text { "Return key advances to next line. Type "Ctrl z" to exit. } \\ \text { NUCLIDE LIBRARY: } & \text { MASTER } \\ \text { REQUIRED ENERGY LIBRARY: } & \text { SWEPPREQ } \\ \text { INTERFERENCE LIBRARY: } & \text { ZWEIF } \\ \text { BACKGROUND CORRECT (YES or NO)? } & \text { YES } \\ \text { PRINT RESULTS (YES Or NO)? } & \text { YES } \\ \text { SAVE RESULTS (YES or NO)? } & \underline{\text { YES }} \\ \text { SAVE DIRECTORY: } & \text { GESSAVE }\end{array}$

Figure 10. Spectral Analysis Parameter Display.

3.5.9.4 Pass/Fail Criterion. The test passes if the expected results are obtained.

\subsubsection{GC.S.1}

3.5.10.1 Purpose. This test addresses using the S; command within GC to start an acquisition on a single detector system.

3.5.10.2 Input Description. With no acquisitions taking place, enter the command $\mathbf{S ; A 1 , 1 0 0 0}$ at the GC "CMD>" prompt.

3.5.10.3 Expected Results. The status for detector system A1 changes to "ON", its real and live times change to 0 and then start increasing, and its interval changes to 1,000. The "ACQUIRE" light on the appropriate AIM turns on. The message "DATA COLLECTION STARTED ON ADC A1" appears below the "MESSAGES:" label.

3.5.10.4 Pass/Fail Criterion. The test passes if the expected results are obtained.

\subsubsection{GC.S.2}

3.5.11.1 Purpose. This test addresses attempting to improperly use the S; command within GC to start an acquisition on a single detector system on which an acquisition is currently in progress.

3.5.11.2 Input Description. With an acquisition taking place on detector system A1, enter the command S;A1,1000 at the GC "CMD>" prompt.

3.5.11.3 Expected Results. The message "UNABLE TO START DATA COLLECTION ON ADC A1" appears below the "MESSAGES:" label. The current acquisition continues uninterrupted. 
3.5.11.4 Pass/Fail Criterion. The test passes if the expected results are obtained.

\subsubsection{GC.S.3}

3.5.12.1 Purpose. This test addresses using the S; command within GC to start an acquisition on multiple detector systems.

3.5.12.2 Input Description. With no acquisitions taking place, enter the command S;A1$\mathbf{A 3 , 1 5 0 0}$ at the GC "CMD>" prompt.

3.5.12.3 Expected Results. The status for detector systems A1, A2, and A3 changes to "ON", their real and live times change to 0 and then start increasing, and their intervals change to 1,500 . The "ACQUIRE" light on the appropriate AIMs tums on. The message "DATA COLLECTION STARTED ON ADC A1 A2 A3" appears below the "MESSAGES:" label.

3.5.12.4 Pass/Fail Criterion. The test passes if the expected results are obtained.

\subsubsection{GC.S.4}

3.5.13.1 Purpose. This test addresses attempting to improperly use the S; command within $\mathrm{GC}$ to start an acquisition on multiple detector systems on which an acquisition is currently in progress.

3.5.13.2 Input Description. With an acquisition taking place on detector systems $\mathrm{A} 1, \mathrm{~A} 2$, and A3, enter the command S;A1-A3,1000 at the GC "CMD>" prompt.

3.5.13.3 Expected Results. The message "UNABLE TO START DATA COLLECTION ON ADC A1" appears below the "MESSAGES:" label. The current acquisition continues uninterrupted.

3.5.13.4 Pass/Fail Criterion. The test passes if the expected results are obtained.

\subsubsection{GC.S.5}

3.5.14.1 Purpose. This test addresses using an S; command within GC to attempt to start an acquisition on an unknown single detector systems.

3.5.14.2 Input Description. With no acquisitions taking place, enter the command S;A5,1000 at the GC "CMD>" prompt.

3.5.14.3 Expected Results. The messages "UNKNOWN DETECTOR NUMBER: '5'" and "BAD OR UNKNOWN COMMAND--'S;A5,1000" are displayed above the "CMD>" prompt.

3.5.14.4 Pass/Fail Criterion. The test passes if the expected results are obtained.

\subsubsection{GC.S.6}

3.5.15.1 Purpose. This test addresses using an incorrectly formatted S; command within GC to attempt to start an acquisition on multiple detector systems.

3.5.15.2 Input Description. Enter the command $\mathrm{S} ; \mathrm{A1}, \mathrm{A2}, \mathrm{A3}, 1500$ at the GC "CMD>" prompt. 
3.5.15.3 Expected Results. The messages "INCOMPLETE COMMAND - COUNT TIME MISSING OR BAD" and "BAD OR UNKNOWN COMMAND--'S;A1,A2,A3,1500"" appear above the "CMD>" prompt.

3.5.15.4 Pass/Fail Criterion. The test passes if the expected results are obtained.

\subsubsection{GC.S.7}

3.5.16.1 Purpose. This test addresses using an S; command with an invalid count time within $\mathrm{GC}$ to attempt to start an acquisition on a single detector system.

3.5.16.2 Input Description. Enter the command S;A1,ABC at the GC "CMD>" prompt.

3.5.16.3 Expected Results. The messages "INCOMPLETE COMMAND - COUNT TIME MISSING OR BAD" and "BAD OR UNKNOWN COMMAND--'S;A1,ABC" appear above the "CMD>" prompt.

3.5.16.4 Pass/Fail Criterion. The test passes if the expected results are obtained.

\subsubsection{GC.S.8}

3.5.17.1 Purpose. This test addresses using an S; command with an invalid count time within $\mathrm{GC}$ to attempt to start an acquisition on multiple detector systems.

3.5.17.2 Input Description. Enter the command S;A1-A3,ABC at the GC "CMD>" prompt.

3.5.17.3 Expected Results. The messages "INCOMPLETE COMMAND - COUNT TIME MISSING OR BAD" and "BAD OR UNKNOWN COMMAND--'S;A1-A3,ABC" appear above the "CMD>" prompt.

3.5.17.4 Pass/Fall Criterion. The test passes if the expected results are obtained.

\subsubsection{GC.BS.1a}

3.5.18.1 Purpose. This test addresses using the BS; command within GC to start an acquisition on all of the detector systems. There are six parts to this test; the remaining parts follow and should be conducted in order immediately after this test.

3.5.18.2 Input Description. With no acquisitions taking place, enter the command BS;000000 at the GC "CMD>" prompt.

3.5.18.3 Expected Results. The GC main screen, similar to that presented in Figure 3, appears and the query, "ENTER THE WEIGHT IN KILOGRAMS," as included in Figure 3, appears above the "CMD>" prompt.

3.5.18.4 Pass/Fail Criterion. The test passes if the expected results are obtained.

\subsubsection{GC.BS.1b}

3.5.19.1 Purpose. This test addresses entering an incorrect response to the first query generated 
after using the BS; command within GC. This is the second part of a six-part test, all parts of which should be performed in immediate succession.

3.5.19.2 Input Description. After performing test GC.BS.1, in response to the query "ENTER THE WEIGHT IN KILOGRAMS", enter ABC at the GC "CMD>" prompt.

3.5.19.3 Expected Results. The message "INVALID WEIGHT - ENTER A POSITIVE NUMBER" appears above the original query (i.e., above "ENTER THE WEIGHT IN KILOGRAMS").

3.5.19.4 Pass/Fail Criterion. The test passes if the expected results are obtained.

\subsubsection{GC.BS.1C}

3.5.20.1 Purpose. This test addresses entering a correct response to the first query generated after using the BS; command within GC. This is the third part of a six-part test, all parts of which should be performed in immediate succession.

3.5.20.2 Input Description. After performing test GC.BS.2, in response to the query "ENTER THE WEIGHT IN KILOGRAMS", enter 1.1 at the GC "CMD>" prompt.

3.5.20.3 Expected Results. The query "ENTER THE CONTENT CODE" appears above the "CMD>" prompt.

3.5.20.4 Pass/Fail Criterion. The test passes if the expected results are obtained.

\subsubsection{GC.BS.1d}

3.5.21.1 Purpose. This test addresses entering an incorrect response to the second query generated after using the BS; command within GC. This is the fourth part of a six-part test, all parts of which should be performed in immediate succession.

3.5.21.2 Input Description. After performing test GC.BS.3, in response to the query "ENTER THE CONTENT CODE", enter CODE 1 at the GC "CMD>" prompt.

3.5.21.3 Expected Results. The message "INVALID CONTENT CODE" appears above the original query (i.e., above "ENTER THE CONTENT CODE").

3.5.21.4 Pass/Fail Criterion. The test passes if the expected results are obtained.

\subsubsection{GC.BS.1e}

3.5.22.1 Purpose. This test addresses entering a correct response to the first query generated after using the BS; command within GC. This is the fifth part of a six-part test, all parts of which should be performed in immediate succession.

3.5.22.2 Input Description. After performing test GC.BS.4, in response to the query "ENTER THE CONTENT CODE", enter 1 at the GC "CMD>" prompt.

3.5.22.3 Expected Results. The query "ENTER ANY COMMENTS" appears above the "CMD>" prompt. 
3.5.22.4 Pass/Fail Criterion. The test passes if the expected results are obtained.

\subsubsection{GC.BS.1f}

3.5.23.1 Purpose. This test addresses entering a response to the third (and final) query generated after using the BS; command within GC. This is the final part of a six-part test, all parts of which should be performed in immediate succession.

3.5.23.2 Input Description. After performing test GC.BS.5, in response to the query "ENTER ANY COMMENT", enter TEST CASE at the GC "CMD>" prompt.

3.5.23.3 Expected Results. The status for all detector systems changes to "ON", their real and live times change to 0 and then start increasing, their intervals change to 36,000 , and the value associated with "CONTAINER:" changes to "000000". If the value associated with "ON COUNT?" is " $Y$ ", the value associated with "ROTATING?" changes to " $\mathrm{Y}$ " and the turntable starts rotating. The "ACQUIRE" light on the appropriate AIMs tums off. The messages "DATA COLLECTION STARTED ON ADC A1 A2 A3 A4", "ESTIMATED COUNT LENGTH TO REACH TRIGGER LEVEL NOT CALCULABLE", and "THE PRESENCE OF A LEAD LINER CANNOT YET BE RELIABLY DETERMINED" appear below the "MESSAGES:" label (see Figure 4). Shortly after the acquisitions have started, the second message changes to "ESTIMATED COUNT LENGTH TO REACH TRIGGER LEVEL = " followed by some integer number followed by "SEC", where the integer number will change with time (rapidly at first, then more slowly as the acquisition progresses).

3.5.23.4 Pass/Fail Criterion. The test passes if the expected results are obtained.

\subsubsection{GC.STOP.1}

3.5.24.1 Purpose. This test addresses using the STOP; command within GC to stop an acquisition on a single detector system.

3.5.24.2 Input Description. With an acquisition taking place only on detector system A1, enter the command STOP;A1 at the GC "CMD>" prompt.

3.5.24.3 Expected Results. The status for detector system A1 changes to "OFF". The "ACQUIRE" light on the appropriate AIM turns off. The message "DATA COLLECTION STOPPED ON ADC A1" appears below the "MESSAGES:" label.

3.5.24.4 Pass/Fail Criterion. The test passes if the expected results are obtained.

\subsubsection{GC.STOP.2}

3.5.25.1 Purpose. This test addresses using the STOP; command within GC to stop an acquisition on multiple detector systems.

3.5.25.2 Input Description. With acquisitions taking place on only detector systems A1, A2, and A3, enter the command STOP;A1-A3 at the GC "CMD>" prompt.

3.5.25.3 Expected Results. The status for detector systems A1, A2, and A3 changes to "OFF". The "ACQUIRE" light on the appropriate AIMs turns off. The message "DATA COLLECTION STOPPED ON ADC A1 A2 A3" appears below the "MESSAGES:" label. 
3.5.25.4 Pass/Fail Criterion. The test passes if the expected results are obtained.

\subsubsection{GC.STOP.3}

3.5.26.1 Purpose. This test addresses using a STOP; command within GC to attempt to stop an acquisition on an unknown detector system.

3.5.26.2 Input Description. With an acquisition taking place on any of the detector systems, enter the command STOP;A5 at the GC "CMD>" prompt.

3.5.26.3 Expected Results. The messages "UNKNOWN DETECTOR NUMBER: '5'" and "BAD OR UNKNOWN COMMAND--'STOP;A5"" are displayed above the "CMD>" prompt.

3.5.26.4 Pass/Fail Criterion. The test passes if the expected results are obtained.

\subsubsection{GC.STOP.4}

3.5.27.1 Purpose. This test addresses using an incorrectly formatted STOP; command within $\mathrm{GC}$ to attempt to stop an acquisition on multiple detector systems.

3.5.27.2 Input Description. With acquisitions taking place on at least detector systems $\mathrm{A} 1$, $\mathrm{A} 2$, and $\mathrm{A} 3$, enter the command STOP;A1,A2,A3 at the GC "CMD>" prompt.

3.5.27.3 Expected Results. The status for detector system A1 only changes to "OFF". The "ACQUIRE" light on the appropriate AIM turns off. The message "DATA COLLECTION STOPPED ON ADC A1" appears below the "MESSAGES:" label. The acquisitions on detector system A2 and A3 continue uninterrupted.

3.5.27.4 Pass/Fail Criterion. The test passes if the expected results are obtained.

\subsubsection{GC.BSTOP.1}

3.5.28.1 Purpose. This test addresses using the BSTOP; command within GC to stop an acquisition on all of the detector systems.

3.5.28.2 Input Description. With acquisitions having been started on all detector systems using the BS; command, enter the command BSTOP; at the GC "CMD>" prompt.

3.5.28.3 Expected Results. The status for all detector systems changes to "OFF". If the value associated with "ON COUNT?" is " $\mathrm{Y}$ ", the value associated with "ROTATING?" changes to " $N$ " and the turntable stops rotating. The "ACQUIRE" light on the appropriate AIMs turns on. The messages "DATA READ AND SAVED TO FILE FROM ADC A1 A2 A3 A4", "SPAWNING BATCH ANALYSIS FOR THESE SPECTRA - LOOK FOR OUTPUT IN A FEW MINUTES", and "IF NONE IS FOUND, CHECK THE [OPERATOR]BATCH_GIDXC_ANALYSIS.LOG FILE FOR ERRORS" appear below the "MESSAGES:" label (see Figure 11). ${ }^{\mathrm{h}}$

h. It is also possible, though not required for passing this test, that output will be generated at the system laser printer within a few minutes after the BSTOP; command has been issued. The reason output is not required for passing this test is that whether the actual analyses are successful and output is generated 
SWEPP GAMMA-RAY BARREL COUNTING SYSTEM

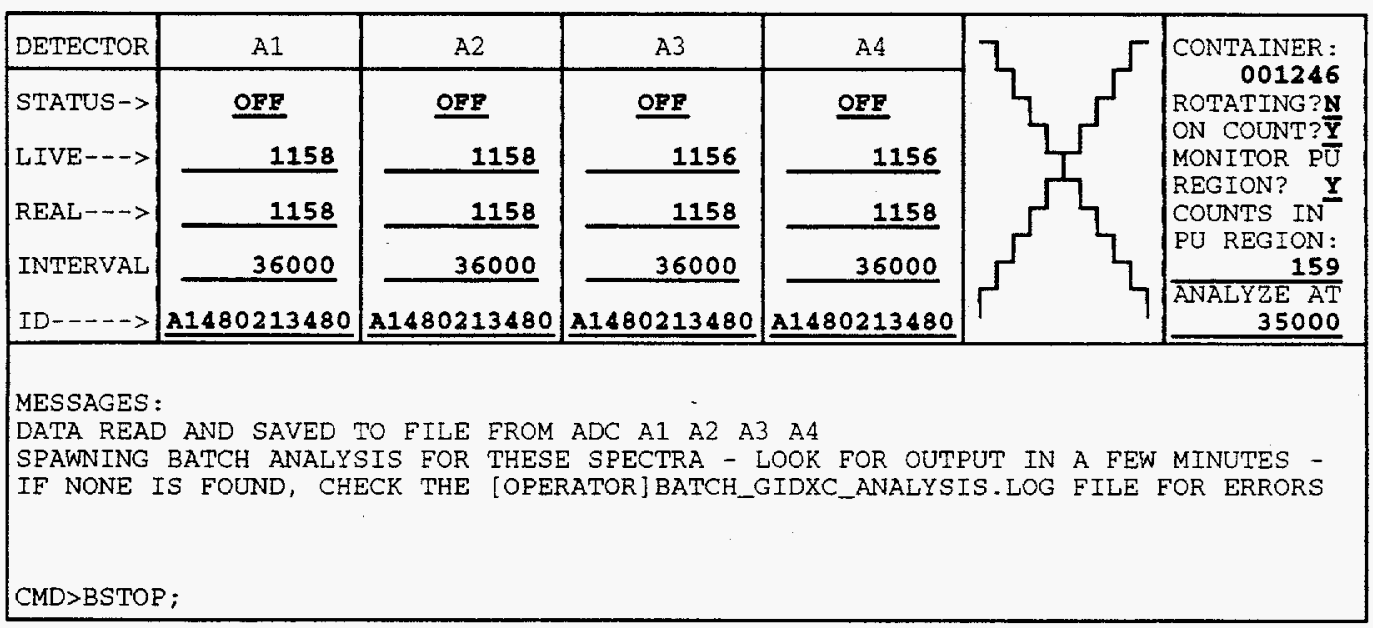

Figure 11. Stopping Data Acquisition Using BSTOP;.

Note: if the acquisitions have not been started using the BS; command, the message that will appear above the "MESSAGES:" label will be similar to that displayed as part of test GC.STOP.2 (Section 3.5.25); the test should then be performed starting with an acquisition started using the BS; command.

3.5.28.4 Pass/Fall Criterion. The test passes if the expected results are obtained.

\subsection{Spectrum Storage and Analysis Commands}

\subsubsection{GC.D.1}

3.6.1.1. Purpose. This test addresses using an incomplete $\mathrm{D}$; command within GC to attempt to save spectral data, currently stored in an AIM, from a single detector system.

3.6.1.2 Input Description. Enter the command D;A1 at the GC "CMD>" prompt.

3.6.1.3 Expected Results. The following messages appear above the "CMD>" prompt: "ERROR!! FORMAT IS 'D;<det,<weigh $>,<$ content code>,<comments>'", "OR 'BD; <weight $>,<$ content code>,<comments>', and "BAD OR UNKNOWN COMMAND--'D;A1'".

3.6.1.4 Pass/Fail Criterion. The test passes if the expected results are obtained.

is generated depends in part on what is being observed by the detectors. 


\subsubsection{GC.D.2}

3.6.2.1 Purpose. This test addresses using a D; command within GC to attempt to save spectral data, currently stored in an AIM, from an unknown detector system. prompt.

3.6.2.2 Input Description. Enter the command D;A5,1.1,01,TEST CASE at the GC "CMD>"

3.6.2.3 Expected Results. The messages "UNKNOWN DETECTOR NUMBER: '5" and "BAD OR UNKNOWN COMMAND--'D;A5,1.1,01,TEST CASE'" appear above the "CMD>" prompt.

3.6.2.4 Pass/Fail Criterion. The test passes if the expected results are obtained.

\subsubsection{GC.D.3}

3.6.3.1 Purpose. This test addresses using a D; command with an invalid weight within GC to attempt to save spectral data, currently stored in an AIM, from a single detector system.

3.6.3.2 Input Description. Enter the command D;A1,ABC,01,TEST CASE at the GC "CMD>" prompt.

3.6.3.3 Expected Results. The following messages appear above the "CMD>" prompt: "ERROR!! FORMAT IS 'D; <det>,<weight>,<content code>,<comments>'", "OR 'BD; <weight>,<content code>,<comments>'", and "BAD OR UNKNOWN COMMAND--'D;A1,ABC,01,TEST CASE'".

3.6.3.4 Pass/Fail Criterion. The test passes if the expected results are obtained.

\subsubsection{GC.D.4}

3.6.4.1 Purpose. This test addresses using a D; command with an invalid content code within GC to attempt to save spectral data, currently stored in an AIM, from a single detector system.

3.6.4.2 Input Description. Enter the command D;A1,1.1,ABC,TEST CASE at the GC "CMD>" prompt.

3.6.4.3 Expected Results. The following messages appear above the "CMD>" prompt: "INVALID CONTENT CODE" and "BAD OR UNKNOWN COMMAND--'D;A1,1.1,ABC,TEST CASE'".

3.6.4.4 Pass/Fall Criterion. The test passes if the expected results are obtained.

\subsubsection{GC.D.5}

3.6.5.1 Purpose. This test addresses using the D; command within GC to save spectral data, currently stored in an AIM, from a single detector system.

3.6.5.2 Input Description. Enter the command D;A1,1.1,01,TEST CASE at the GC "CMD>" prompt.

3.6.5.3 Expected Results. The message "DATA READ AND SAVED TO FILE FROM ADC A1" appears below the "MESSAGES:" label, the "ID" is updated for detector system A1, and any ongoing 
acquisitions continue uninterrupted. A file with the new "ID" preceding the ".DGE" suffix will be created in the save directory specified in the appropriate detector system's analysis parameters.

3.6.5.4 Pass/Fail Criterion. The test passes if the expected results are obtained.

\subsubsection{GC.D.6}

3.6.6.1 Purpose. This test addresses using an incorrectly formatted D; command within GC to save spectral data, currently stored in AIMs, from multiple detector systems.

3.6.6.2 Input Description. Enter the command D;A1,A2,A3,1.1,01,TEST CASE at the GC "CMD>" prompt.

3.6.6.3 Expected Results. The following messages appear above the "CMD>" prompt: "ERROR!! FORMAT IS ' $D$; <de $>$, <weight $>$, <content code>,<comments>'", "OR 'BD; <weigh $>,<$ content code>,<comments>'", and "BAD OR UNKNOWN COMMAND--'D;A1,A2,A3,1.1,01,TEST CASE'".

3.6.6.4 Pass/Fail Criterion. The test passes if the expected results are obtained.

\section{3:6.7 GC.D.7}

3.6.7.1 Purpose. This test addresses using the $\mathrm{D}$; command within GC to save spectral data, currently stored in AIMs, from multiple detector systems.

3.6.7.2 Input Description. Enter the command D;A1-A3,1.1,01,TEST CASE at the GC "CMD>" prompt.

3.6.7.3 Expected Results. The message "DATA READ AND SAVED TO FILE FROM ADC A1 A2 A3" appears below the "MESSAGES:" label, the "ID" is updated for detector systems A1, A2, and $\mathrm{A} 3$, and any ongoing acquisitions continue uninterrupted. Files with the new "ID"s preceding the ".DGE" suffix will be created in the save directory specified in the appropriate detector systems' analysis parameters.

3.6.7.4 Pass/Fall Criterion. The test passes if the expected results are obtained.

\subsubsection{GC.BD.1}

3.6.8.1 Purpose. This test addresses using an incomplete BD; command within GC to attempt to save spectral data, currently stored in AIMs, from all detector systems.

3.6.8.2 Input Description. Enter the command BD;A1 at the GC "CMD>" prompt.

3.6.8.3 Expected Results. The following messages appear above the "CMD>" prompt: "ERROR!! FORMAT IS 'D; <det>,<weight $>$,<content code>,<comments>', "OR 'BD; <weigh $>$, <content code>,<comments>", and "BAD OR UNKNOWN COMMAND--'D;A1-A4,A1'".

i. Note that GC has translated the $\mathrm{BD}$; command into the corresponding $\mathrm{D}$; command. This will be apparent in other test cases as well. GC also translates BDA; commands into the corresponding DA; commands. 
3.6.8.4 Pass/Fail Criterion. The test passes if the expected results are obtained.

\subsubsection{GC.BD.2}

3.6.9.1 Purpose. This test addresses using a BD; command with an invalid weight within GC to attempt to save spectral data, currently stored in AIMs, from all detector systems.

3.6.9.2 Input Description. Enter the command BD;ABC,01,TEST CASE at the GC "CMD>" prompt.

3.6.9.3 Expected Results. The following messages appear above the "CMD>" prompt: "ERROR!! FORMAT IS 'D; <det>,<weight>,<content code>,<comments>', "OR 'BD;<weight>,<content code>,<comments>", and "BAD OR UNKNOWN COMMAND--'D;A1-A4,ABC,01,TEST CASE'".

3.6.9.4 Pass/Fail Criterion. The test passes if the expected results are obtained.

\subsubsection{GC.BD.3}

3.6.10.1 Purpose. This test addresses using a BD; command with an invalid content code within GC to attempt to save spectral data, currently stored in AIMs, from all detector systems.

3.6.10.2 Input Description. Enter the command BD;1.1,ABC,TEST CASE at the GC "CMD>" prompt.

3.6.10.3 Expected Results. The following messages appear above the "CMD>" prompt: "INVALID CONTENT CODE" and "BAD OR UNKNOWN COMMAND--'D;A1-A4,1.1,ABC,TEST CASE".

3.6.10.4 Pass/Fail Criterion. The test passes if the expected results are obtained.

\subsubsection{GC.BD.4}

3.6.11.1 Purpose. This test addresses using the BD; command within GC to save spectral data, currently stored in AIMs, from all detector systems.

3.6.11.2 Input Description. Enter the command BD;1.1,01,TEST CASE at the GC "CMD>" prompt.

3.6.11.3 Expected Results. The message "DATA READ AND SAVED TO FILE FROM ADC A1 A2 A3 A4" appears below the "MESSAGES:" label, the "ID" is updated for all detector systems, and any ongoing acquisitions continue uninterrupted. Files with the new "ID"s preceding the ".DGE" suffix will be created in the save directory specified in the appropriate detector systems' analysis parameters.

3.6.11.4 Pass/Fail Criterion. The test passes if the expected results are obtained.

\subsubsection{GC.DA.1}

3.6.12.1 Purpose. This test addresses using an incomplete DA; command within GC to attempt to save and analyze spectral data, currently stored in an AIM, from a single detector system. 
3.6.12.2 Input Description. Enter the command DA;A1 at the GC "CMD>" prompt.

3.6.12.3 Expected Results. The following messages appear above the "CMD $>$ prompt: "ERROR!! FORMAT IS 'DA; <det>,<weight $>$, <content code>,<comments>'", "OR 'BDA; <weight $>,<$ content code>,<comments>', and "BAD OR UNKNOWN COMMAND--'DA;A1"".

3.6.12.4 Pass/Fail Criterion. The test passes if the expected results are obtained.

\subsubsection{GC.DA.2}

3.6.13.1 Purpose. This test addresses using a DA; command within GC to attempt to save and analyze spectral data, currently stored in an AIM, from an unknown detector system.

3.6.13.2 Input Description. Enter the command DA;A5,1.1,01,TEST CASE at the GC "CMD>" prompt.

3.6.13.3 Expected Results. The messages "UNKNOWN DETECTOR NUMBER: '5'" and "BAD OR UNKNOWN COMMAND--'DA;A5,1.1,01,TEST CASE"" appear above the "CMD>" prompt.

3.6.13.4 Pass/Fail Criterion. The test passes if the expected results are obtained.

\subsubsection{GC.DA.3}

3.6.14.1 Purpose. This test addresses using a DA; command with an invalid weight within GC to attempt to save and analyze spectral data, currently stored in an AIM, from a single detector system.

3.6.14.2 Input Description. Enter the command DA;A1,ABC,01,TEST CASE at the GC "CMD>" prompt.

3.6.14.3 Expected Results. The following messages appear above the "CMD>" prompt: "ERROR!! FORMAT IS 'DA; <det>,<weight $>,<$ content code $>,<$ comments $>$ '", "OR 'BDA; <weight $>$,<content code $>,<$ comments $>$ ', and "BAD OR UNKNOWN COMMAND-'DA;A1,ABC,01,TEST CASE'".

3.6.14.4 Pass/Fall Criterion. The test passes if the expected results are obtained.

\subsubsection{GC.DA.4}

3.6.15.1 Purpose. This test addresses using a DA; command with an invalid content code within GC to attempt to save and analyze spectral data, currently stored in an AIM, from a single detector system.

3.6.15.2 Input Description. Enter the command DA;A1,1.1,ABC,TEST CASE at the GC "CMD>" prompt.

3.6.15.3 Expected Results. The following messages appear above the "CMD>" prompt: "INVALID CONTENT CODE" and "BAD OR UNKNOWN COMMAND--'DA;A1,1.1,ABC,TEST CASE'".

3.6.15.4 Pass/Fail Criterion. The test passes if the expected results are obtained. 


\subsubsection{GC.DA.5}

3.6.16.1 Purpose. This test addresses using the DA; command within GC to save and analyze spectral data, currently stored in an AIM, from a single detector system.

3.6.16.2 Input Description. Enter the command DA;A1,1.1,01,TEST CASE at the GC "CMD>" prompt.

3.6.16.3 Expected Results. The message "DATA READ AND SAVED TO FILE FROM ADC A1" appears only briefly below the "MESSAGES:" label and then is replaced by the messages "SPAWNING BATCH ANALYSIS FOR ADC A1", "PRINTED OUTPUT FROM THESE ANALYSES SHOULD APPEAR IN A FEW MINUTES", and "IF NONE IS FOUND, CHECK THE [OPERATOR]BATCH_GIDXC_ANALYSIS.LOG FILE FOR ERRORS", the "ID" is updated for detector system $A 1$, and any ongoing acquisitions continue uninterrupted. ${ }^{j}$ A file with the new "ID" preceding the ".DGE" suffix will be created in the save directory specified in the appropriate detector system's analysis parameters.

3.6.16.4 Pass/Fail Criterion. The test passes if the expected results are obtained.

\subsubsection{GC.DA.6}

3.6.17.1 Purpose. This test addresses using an improperly formatted DA; command within GC to save and analyze spectral data, currently stored in AIMs, from multiple detector systems.

3.6.17.2 Input Description. Enter the command DA;A1,A2,A3,1.1,01,TEST CASE at the GC "CMD>" prompt.

3.6.17.3 Expected Results. The following messages appear above the "CMD>" prompt: "ERROR!! FORMAT IS 'DA;<det>,<weight $>,<$ content code>,<comments>'", "OR 'BDA; <weight $>,<$ content code $>,<$ comments $>$ ", and "BAD OR UNKNOWN COMMAND-. 'DA;A1,A2,A3,1.1,01,TEST CASE'".

3.6.17.4 Pass/Fail Criterion. The test passes if the expected results are obtained.

\subsubsection{GC.DA.7}

3.6.18.1 Purpose. This test addresses using the DA; command within GC to save and analyze spectral data, currently stored in AIMs, from multiple detector systems.

3.6.18.2 Input Description. Enter the command DA;A1-A3,1.1,01,TEST CASE at the GC "CMD>" prompt.

3.6.18.3 Expected Results. The messages "SPAWNING BATCH ANALYSIS FOR ADC A1 A2" and "DATA READ AND SAVED TO FILE FROM ADC A1 A2" appear only briefly below the

j. It is also possible, though not required for passing this test, that output will be generated at the system laser printer within a few minutes after the DA; command has been issued. The reason output is not required for passing this test is that whether the actual analyses are successful and output is generated depends in part on what is being observed by the detectors. This is also true for the BDA; command. 
"MESSAGES:" label and then are replaced by the messages "SPAWNING BATCH ANALYSIS FOR ADC A1 A2 A3", "PRINTED OUTPUT FROM THESE ANALYSES SHOULD APPEAR IN A FEW MINUTES", and "IF NONE IS FOUND, CHECK THE [OPERATOR]BATCH_GIDXC_ANALYSIS.LOG FILE FOR ERRORS", the "ID" is updated for detector systems A1, A2, and A3, and any ongoing acquisitions continue uninterrupted. Files with the new "ID"s preceding the ".DGE" suffix will be created in the save directory specified in the appropriate detector systems' analysis parameters.

3.6.18.4 Pass/Fail Criterion. The test passes if the expected results are obtained.

\subsubsection{GC.BDA.1}

3.6.19.1 Purpose. This test addresses using an incomplete BDA; command within GC to attempt to save and analyze spectral data, currently stored in AIMs, from all detector systems.

3.6.19.2 Input Description. Enter the command BDA;A1 at the GC "CMD>" prompt.

3.6.19.3 Expected Results. The following messages appear above the "CMD>" prompt: "ERROR!! FORMAT IS 'DA; $<$ det $>$, <weight $>,<$ content code $>,<$ comments $>$ '," "OR 'BDA; <weight $>,<$ content code>,<comments $>$ ", and "BAD OR UNKNOWN COMMAND--'DA;A1A4,A1'".

3.6.19.4 Pass/Fail Criterion. The test passes if the expected results are obtained.

\subsubsection{GC.BDA.2}

3.6.20.1 Purpose. This test addresses using a BDA; command with an invalid weight within GC to attempt to save and analyze spectral data, currently stored in AIMs, from all detector systems.

3.6.20.2 Input Description. Enter the command BDA;ABC,01,TEST CASE at the GC "CMD>" prompt.

3.6.20.3 Expected Results. The following messages appear above the "CMD>" prompt: "ERROR!! FORMAT IS 'DA; <det $>,<$ weight $>,<$ content code $>,<$ comments $>$ '", "OR 'BDA;<weight $>,<$ content code>,<comments>", and "BAD OR UNKNOWN COMMAND--'DA;A1A4,ABC,01,TEST CASE'".

3.6.20.4 Pass/Fail Criterion. The test passes if the expected results are obtained.

\subsubsection{GC.BDA.3}

3.6.21.1 Purpose. This test addresses using a BDA; command with an invalid content code within GC to attempt to save and analyze spectral data, currently stored in AIMs, from all detector systems.

3.6.21.2 Input Description. Enter the command BDA;1.1,ABC,TEST CASE at the GC "CMD>" prompt.

3.6.21.3 Expected Results. The following messages appear above the "CMD>" prompt: "INVALID CONTENT CODE" and "BAD OR UNKNOWN COMMAND--'DA;A1-A4,1.1,ABC,TEST CASE'". 
3.6.21.4 Pass/Fail Criterion. The test passes if the expected results are obtained.

\subsubsection{GC.BDA.4}

3.6.22.1 Purpose. This test addresses using the BDA; command within GC to save and analyze spectral data, currently stored in AIMs, from all detector systems. prompt.

3.6.22.2 Input Description. Enter the command BDA;1.1,01,TEST CASE at the GC "CMD>"

3.6.22.3 Expected Results. The messages "SPAWNING BATCH ANALYSIS FOR ADC A1 A2 A3" and "DATA READ AND SAVED TO FILE FROM ADC A1 A2 A3" appear only briefly below the "MESSAGES:" label and then are replaced by the messages "SPAWNING BATCH ANALYSIS FOR ADC A1 A2 A3 A4", "PRINTED OUTPUT FROM THESE ANALYSES SHOULD APPEAR IN A FEW MINUTES", and "IF NONE IS FOUND, CHECK THE [OPERATOR]BATCH_GIDXC_ANALYSIS.LOG FILE FOR ERRORS", the "ID" is updated for all detector systems, and any ongoing acquisitions continue uninterrupted. Files with the new "ID"s preceding the ".DGE" suffix will be created in the save directory specified in the appropriate detector systems' analysis parameters.

3.6.22.4 Pass/Fail Criterion. The test passes if the expected results are obtained.

\subsubsection{GC.BKG.1}

3.6.23.1 Purpose. This test addresses using the BKG; command within GC to save as a background spectrum an acquisition on a single detector system.

3.6.23.2 Input Description. Enter the command BKG;A1 at the GC "CMD>" prompt.

3.6.23.3 Expected Results. The message "BACKGROUND DATA READ FROM ADC A1 AND SAVED TO FILE" appears below the "MESSAGES:" label and the "ID" is updated for detector system A1. An ongoing acquisition continues uninterrupted. A file with the new "ID" preceding the ".DGE" suffix will be created in the save directory BK\$SAVE. (N.B.: unless this file contains a valid background spectrum, it should be deleted after this test is completed.)

3.6.23.4 Pass/Fail Criterion. The test passes if the expected results are obtained.

\subsubsection{GC.BKG.2}

3.6.24.1 Purpose. This test addresses using the BKG; command within GC to save as background spectra an acquisition on multiple detector systems.

3.6.24.2 Input Description. Enter the command BKG;A1-A3 at the GC "CMD>" prompt.

3.6.24.3 Expected Results. The message "BACKGROUND DATA READ AND SAVED TO FILE FROM ADC A1 A2 A3" appears below the "MESSAGES:" label and the "ID" is updated for detector systems $A 1, A 2$, and A3. Any ongoing acquisitions continue uninterrupted. Files with the new "ID"s preceding the ".DGE" suffix will be created in the save directory BK\$SAVE. (N.B.: unless these files contain valid background spectra, they should be deleted after this test is completed.) 
3.6.24.4 Pass/Fail Criterion. The test passes if the expected results are obtained.

\subsubsection{GC.BKG.3}

3.6.25.1 Purpose. This test addresses using a BKG; command within GC to attempt to save as a background spectrum an acquisition on an unknown detector system.

3.6.25.2 Input Description. Enter the command BKG;A5 at the GC "CMD>" prompt.

3.6.25.3 Expected Results. The messages "UNKNOWN DETECTOR NUMBER: '5'" and "BAD OR UNKNOWN COMMAND--'BKG;A5'" are displayed above the "CMD>" prompt.

3.6.25.4 Pass/Fall Criterlon. The test passes if the expected results are obtained.

\subsubsection{GC.BKG.4}

3.6.26.1 Purpose. This test addresses using an incorrectly formatted BKG; command within $\mathrm{GC}$ to attempt to save as background spectra an acquisition on multiple detector systems.

3.6.26.2 Input Description. Enter the command BKG;A1,A2,A3 at the GC "CMD>" prompt.

3.6.26.3 Expected Results. The message "BACKGROUND DATA READ FROM ADC A1 AND SAVED TO FILE" appears below the "MESSAGES:" label and the "ID" is updated for detector system A1. An ongoing acquisition continues uninterrupted. A file with the new "ID" preceding the ".DGE" suffix will be created in the save directory BKSSAVE. (N.B.: unless this file contains a valid background spectrum, it should be deleted after this test is completed.) None of this occurs for detector systems A2 and A3.

3.6.26.4 Pass/Fail Criterion. The test passes if the expected results are obtained.

\subsubsection{GC.A.1}

3.6.27.1 Purpose. This test addresses using an A; command within GC to attempt to submit an unknown saved spectrum for a full single-spectrum analysis.

3.6.27.2 Input Description. Enter the command A;A1123456789 at the GC "CMD>" prompt.

3.6.27.3 Expected Results. The messages "THE SPECIFIED SPECTRUM 'A1123456789' IS INVALID" and "BAD OR UNKNOWN COMMAND--'A;A1123456789" appear above the "CMD>" prompt.

3.6.27.4 Pass/Fail Criterion. The test passes if the expected results are obtained.

\subsubsection{GC.A.2}

3.6.28.1 Purpose. This test addresses using an A; command within GC to attempt to submit an improperly identified saved spectrum for a full single-spectrum analysis.

3.6.28.2 Input Description. Enter the command A;A146061311 at the GC "CMD>" prompt. 
3.6.28.3 Expected Results. The messages "THE SPECIFIED SPECTRUM NAME 'A146061311' IS NOT 11 CHARACTERS LONG" and "BAD OR UNKNOWN COMMAND-'A;A146061311'" appear above the "CMD>" prompt.

3.6.28.4 Pass/Fall Criterion. The test passes if the expected results are obtained.

\subsubsection{GC.A.3}

3.6.29.1 Purpose. This test addresses using an A; command within GC to submit a single saved spectrum for a full single-spectrum analysis.

3.6.29.2 Input Description. Enter the command A;A1460613110 at the GC "CMD>" prompt.

3.6.29.3 Expected Results. The messages "SPAWNING BATCH ANALYSIS FOR SPECTRUM A1460613110 - LOOK FOR OUTPUT IN A FEW MINU" ("MINU" is truncated to "MINUTES" because of a lack of space on the screen), and "IF NONE IS FOUND, CHECK THE [OPERATOR]BATCH_GIDXC_ANALYSIS.LOG FILE FOR ERRORS" appear below the "MESSAGES:" label. In a few minutes output practically identical ${ }^{k}$ in its analysis results to that presented in Appendixes B.5 and B.6 should appear at the system printer.

3.6.29.4 Pass/Fall Criterion. The test passes if the expected results are obtained.

\subsubsection{GC.BA.1}

3.6.30.1 Purpose. This test addresses using a BA; command within GC to attempt to submit an unknown saved spectrum for analysis with only a summary report being generated. prompt.

3.6.30.2 Input Description. Enter the command BA;A1123456789 at the GC "CMD>"

3.6.30.3 Expected Results. The messages "THE SPECIFIED SPECTRUM 'A1123456789' IS INVALID" and "BAD OR UNKNOWN COMMAND--'BA;A1123456789'" appear above the "CMD>" prompt.

3.6.30.4 Pass/Fail Criterion. The test passes if the expected results are obtained.

\subsubsection{GC.BA.2}

3.6.31.1 Purpose. This test addresses using a BA; command within GC to attempt to submit an unknown set of saved spectrum for analysis with only a summary report being generated.

k. By "practically identical" it is meant that the numerical results should be identical with variations in only the last two digits presented being generally acceptable (such variations are likely due to computerrelated round-off errors); larger variations will require further explanations to be acceptable (for example, different background spectra were used in analyzing the sample spectra, or the efficiency curve has been changed $[1,2])$. This definition also assumes that the spectrum file's contents, as reflected partially in header information at the start of the output, have not been changed. The date the output was generated will likely be different. 
3.6.31.2 Input Description. Enter the command BA;A1123456789,A2123456789,A3123456789,A4123456789 at the GC "CMD>" prompt.

3.6.31.3 Expected Results. The messages "THE SPECIFIED SPECTRUM 'A1123456789' I S I N A L I D" a n d "B A D O R U N K N O W N C O M M A N D "BA;A1123456789,A2123456789,A3123456789,A4123456789" appear above the "CMD>" prompt.

3.6.31.4 Pass/Fail Criterion. The test passes if the expected results are obtained.

\subsubsection{GC.BA.3}

3.6.32.1 Purpose. This test addresses using a BA; command within GC to attempt to submit an improperly identified saved spectrum for analysis with only a summary report being generated.

3.6.32.2 Input Description. Enter the command BA;A146061311 at the GC "CMD>" prompt.

3.6.32.3 Expected Results. The messages "THE SPECIFIED SPECTRUM NAME 'A146061311' IS INVALID" and "BAD OR UNKNOWN COMMAND--"BA;A146061311" appear above the "CMD>" prompt.

3.6.32.4 Pass/Fail Criterion. The test passes if the expected results are obtained.

\subsubsection{GC.BA.4}

3.6.33.1 Purpose. This test addresses using a BA; command within GC to submit a set of saved spectrum for analysis with only a summary report being generated.

3.6.33.2 Input Description. Enter the command BA;A1460613110,A2460613110,A3460613110,A4460613110 at the GC "CMD>" prompt.

3.6.33.3 Expected Results. The messages "SPAWNING BATCH ANALYSIS FOR THESE SPECTRA - LOOK FOR OUTPUT IN A FEW MINUTES", and "IF NONE IS FOUND, CHECK THE [OPERATOR]BATCH_GIDXC_ANALYSIS.LOG FILE FOR ERRORS" appear below the "MESSAGES:" label. In a few minutes output detailing results for spectra A1460613110, A2460613110, A3460613110, and A4460613110 and practically identical in its analysis results to that presented in Appendix B.3 should appear at the system printer.

3.6.33.4 Pass/Fail Criterion. The test passes if the expected results are obtained.

\subsubsection{GC.BA.5}

3.6.34.1 Purpose. This test addresses using an improperly abbreviated BA; command within GC to attempt to submit a set of saved spectrum for analysis with only a summary report being generated.

3.6.34.2 Input Description. Enter the command BA;A1460613110,A2-A4 at the GC "CMD>" prompt.

3.6.34.3 Expected Results. The messages "SPAWNING BATCH ANALYSIS FOR THESE SPECTRA - LOOK FOR OUTPUT IN A FEW MINUTES", and "IF NONE IS FOUND, CHECK THE [OPERATOR]BATCH_GIDXC_ANALYSIS.LOG FILE FOR ERRORS" appear below the "MESSAGES:" 
label. In a few minutes output detailing results only for spectra A1460613110 and A2460613110 should appear at the system printer.

3.6.34.4 Pass/Fall Criterion. The test passes if the expected results are obtained.

\subsubsection{GC.BA.6}

3.6.35.1 Purpose. This test addresses using an abbreviated BA; command within GC to submit a set of saved spectrum for analysis with only a summary report being generated.

3.6.35.2 Input Description. Enter the command BA;A1460613110,A2,A3,A4 at the GC "CMD>" prompt.

3.6.35.3 Expected Results. The messages "SPAWNING BATCH ANALYSIS FOR THESE SPECTRA - LOOK FOR OUTPUT IN A FEW MINUTES", and "IF NONE IS FOUND, CHECK THE [OPERATOR]BATCH_GIDXC_ANALYSIS.LOG FILE FOR ERRORS" appear below the "MESSAGES:" label. In a few minutes output detailing results for spectra A1460613110, A2460613110, A3460613110, and A4460613110 and practically identical in its analysis results to that presented in Appendix B.3 should appear at the system printer.

3.6.35.4 Pass/Fail Criterion. The test passes if the expected results are obtained.

\subsubsection{GC.FBA.1}

3.6.36.1 Purpose. This test addresses using an FBA; command within GC to attempt to submit an unknown saved spectrum for analysis with full single-spectrum output for all the spectra specified and a summary report being generated.

3.6.36.2 Input Description. Enter the command FBA;A1123456789 at the GC "CMD>" prompt.

3.6.36.3 Expected Results. The messages "THE SPECIFIED SPECTRUM 'A1123456789' IS INVALID" and "BAD OR UNKNOWN COMMAND--'FBA;A1123456789'" appear above the "CMD>" prompt.

3.6.36.4 Pass/Fail Criterion. The test passes if the expected results are obtained.

\subsubsection{GC.FBA.2}

3.6.37.1 Purpose. This test addresses using an FBA; command within GC to attempt to submit an unknown set of saved spectrum for analysis with full single-spectrum output for all the spectra specified and a summary report being generated.

3.6.37.2 Input Description. Enter the command FBA;A1123456789,A2123456789,A3123456789,A4123456789 at the GC "CMD>" prompt.

3.6.37.3 Expected Results. The messages "THE SPECIFIED SPECTRUM 'A1123456789' I I N V A L I D" a d "B A D OR U N K OW N C O M M A N D "FBA;A1123456789,A2123456789,A3123456789,A4123456789" appear above the "CMD>" prompt. 
3.6.37.4 Pass/Fail Criterion. The test passes if the expected results are obtained.

\subsubsection{GC.FBA.3}

3.6.38.1 Purpose. This test addresses using an FBA; command within GC to attempt to submit an improperly identified saved spectrum for analysis with full single-spectrum output for all the spectra specified and a summary report being generated.

3.6.38.2 Input Description. Enter the command FBA;A146061311 at the GC "CMD>" prompt.

3.6.38.3 Expected Results. The messages "THE SPECIFIED SPECTRUM NAME 'A146061311' IS INVALID" and "BAD OR UNKNOWN COMMAND--"FBA;A146061311" appear above the "CMD>" prompt.

3.6.38.4 Pass/Fail Criterion. The test passes if the expected results are obtained.

\subsubsection{GC.FBA.4}

3.6.39.1 Purpose. This test addresses using a FBA; command within GC to submit a set of saved spectrum for analysis with full single-spectrum output for all the spectra specified and a summary report being generated.

3.6.39.2 Input Description. Enter the command FBA;A1460613110,A2460613110,A3460613110,A4460613110 at the GC "CMD>" prompt.

3.6.39.3 Expected Results. The messages "SPAWNING BATCH ANALYSIS FOR THESE SPECTRA - LOOK FOR OUTPUT IN A FEW MINUTES", and "IF NONE IS FOUND, CHECK THE [OPERATOR]BATCH_GIDXC_ANALYSIS.LOG FILE FOR ERRORS" appear below the "MESSAGES:" label. In a few minutes output detailing summary results for spectra A1460613110, A2460613110, A3460613110, and A4460613110 and practically identical in its analysis results to that presented in Appendix B.3, along with full single-spectrum analyses for all four spectra (the output for spectrum A1460613110 should be practically identical to that presented in Appendixes B.5 and B.6), should appear at the system printer.

3.6.39.4 Pass/Fail Criterion. The test passes if the expected results are obtained.

\subsubsection{GC.FBA.5}

3.6.40.1 Purpose. This test addresses using an improperly abbreviated FBA; command within GC to attempt to submit a set of saved spectrum for analysis with full single-spectrum output for all the spectra specified and a summary report being generated.

3.6.40.2 Input Description. Enter the command FBA;A1460613110,A2-A4 at the GC "CMD>" prompt.

3.6.40.3 Expected Results. The messages "SPAWNING BATCH ANALYSIS FOR THESE SPECTRA - LOOK FOR OUTPUT IN A FEW MINUTES", and "IF NONE IS FOUND, CHECK THE [OPERATOR]BATCH_GIDXC_ANALYSIS.LOG FILE FOR ERRORS" appear below the "MESSAGES:" label. In a few minutes output detailing results only for spectra A1460613110 and A2460613110 should 
appear at the system printer.

3.6.40.4 Pass/Fail Criterion. The test passes if the expected results are obtained.

\subsubsection{GC.FBA.6}

3.6.41.1 Purpose. This test addresses using an abbreviated FBA; command within GC to submit a set of saved spectrum for analysis with full single-spectrum output for all the spectra specified and a summary report being generated.

3.6.41.2 Input Description. Enter the command FBA;A1460613110,A2,A3,A4 at the GC "CMD>" prompt.

3.6.41.3 Expected Results. The messages "SPAWNING BATCH ANALYSIS FOR THESE SPECTRA - LOOK FOR OUTPUT IN A FEW MINUTES", and "IF NONE IS FOUND, CHECK THE [OPERATOR]BATCH_GIDXC_ANALYSIS.LOG FILE FOR ERRORS" appear below the "MESSAGES:" label. In a few minutes output detailing summary results for spectra A1460613110, A2460613110, A3460613110, and A4460613110 and practically identical in its analysis results to that presented in Appendix B.3, along with full single-spectrum analyses for all four spectra (the output for spectrum A1460613110 should be practically identical to that presented in Appendixes B.5 and B.6), should appear at the system printer.

3.6.41.4 Pass/Fail Criterion. The test passes if the expected results are obtained.

\subsection{Detector Calibration Commands}

\subsubsection{GC.CBE.1}

3.7.1.1 Purpose. This test addresses using a CBE; command within GC to attempt to perform an energy- and width-calibration on a europium-152 calibration spectrum currently stored in the AIM associated with an unknown non-pulsered detector system.

3.7.1.2 Input Description. Enter the command CBE;A5 at the GC "CMD>" prompt.

3.7.1.3 Expected Results. The messages "UNKNOWN DETECTOR NUMBER: '5" and "BAD OR UNKNOWN COMMAND--'CBE;A5" are displayed above the "CMD>" prompt.

3.7.1.4 Pass/Fall Criterion. The test passes if the expected results are obtained.

\subsubsection{GC.CBE.2}

3.7.2.1 Purpose. This test addresses using the CBE; command within GC to perform an energy- and width-calibration on a europium-152 calibration spectrum currently stored in the AIM associated with a non-pulsered detector system.

3.7.2.2 Input Description. Enter the command CBE;A1 at the GC "CMD>" prompt.

3.7.2.3 Expected Results. The GC main screen disappears and the message "PERFORMING 
NONPULSERED EUROPIUM CALIBRATION FOR A1" appears at the top of the screen.'

3.7.2.4 Pass/Fail Criterion. The test passes if the expected results are obtained.

\subsubsection{GC.PEQE.1}

3.7.3.1 Purpose. This test addresses using a PEQE; command within GC to attempt to perform an energy- and width-calibration on a europium-152 calibration spectrum currently stored in the AIM associated with an unknown pulsered detector system.

3.7.3.2 Input Description. Enter the command PEQE;A5 at the GC "CMD>" prompt.

3.7.3.3 Expected Results. The messages "UNKNOWN DETECTOR NUMBER: '5'" and "BAD OR UNKNOWN COMMAND--'PEQE;AS" are displayed above the "CMD>" prompt.

3.7.3.4 Pass/Fail Criterion. The test passes if the expected results are obtained.

\subsubsection{GC.PEQE.2}

3.7.4.1 Purpose. This test addresses using the PEQE; command within GC to perform an energy- and width-calibration on a europium-152 calibration spectrum currently stored in the AIM associated with a pulsered detector system.

3.7.4.2 Input Description. Enter the command PEQE;A1 at the GC "CMD>" prompt.

3.7.4.3 Expected Results. The GC main screen disappears and the message "PERFORMING PULSERED EUROPIUM CALIBRATION FOR A1" appears at the top of the screen. ${ }^{\mathrm{m}}$

3.7.4.4 Pass/Fail Criterion. The test passes if the expected results are obtained.

\subsubsection{GC.PEQEH.1}

3.7.5.1 Purpose. This test addresses using a PEQEH; command within GC to attempt to generate a europium-152 calibration history for an unknown pulsered detector system.

3.7.5.2 Input Description. Enter the command PEQEH;A5 at the GC "CMD>" prompt.

3.7.5.3 Expected Results. The messages "UNKNOWN DETECTOR NUMBER: '5" and

1. It is also possible, though not required for passing this test, that other messages will appear and that output will be generated at the system laser printer within a few minutes after the CBE; command has been issued. The reason output is not required for passing this test is that whether the actual calibration is successful and output is generated depends in part on what is being observed by the detectors. This is true for commands PEQE, CBT, and PEQT as well.

m. If output is generated by this command, it should appear similar in format to the sample presented in Appendix B.1; the numerical values will vary with detector age and condition and depending on settings within the various electronic components associated with the detector. As noted in an earlier footnote, output being generated from a calibration is not a pass/fail criterion. 
"BAD OR UNKNOWN COMMAND--'PEQEH;A5"" are displayed above the "CMD>" prompt.

3.7.5.4 Pass/Fail Criterion. The test passes if the expected results are obtained.

\subsubsection{GC.PEQEH.2a}

3.7.6.1 Purpose. This test addresses using the PEQEH; command within GC to generate a europium-152 calibration history for a pulsered detector system. There are four parts to this test; the remaining parts follow and should be conducted in order immediately after this test. This part tests entering an improperly formatted date.

3.7.6.2 Input Description. Enter the command PEQEH;A1 at the GC "CMD>" prompt. The GC main screen disappears, the message "GENERATING PULSERED EUROPIUM CALIBRATION HISTORY FOR A1" appears at the top of the screen, and a query reading "Enter starting date of report (MMDDYY):" also appears. Enter 010194. A second query reading "Enter ending date of report (MMDDYY):" then appears. Enter 60194.

3.7.6.3 Expected Results. The message "BAD INPUT--PLEASE REENTER" appears below the second query (because a leading zero before the "6" is missing) and the second query reappears.

3.7.6.4 Pass/Fall Criterion. The test passes if the expected results are obtained.

\subsubsection{GC.PEQEH.2b}

3.7.7.1 Purpose. This test continues addressing using the PEQEH; command within GC to generate a europium-152 calibration history for a pulsered detector system. This is the second part of a four-part test, all parts of which should be performed in immediate succession. This part tests entering an invalid date.

3.7.7.2 Input Description. The second query reads "Enter ending date of report (MMDDYY):" then appears. Enter AABBCC.

3.7.7.3 Expected Results. The message "BAD INPUT--PLEASE REENTER" appears below the second query (because $A A B B C C$ is not a valid integer MMDDYY date) and the second query reappears yet again.

3.7.7.4 Pass/Fail Criterion. The test passes if the expected results are obtained.

\subsubsection{GC.PEQEH.2C}

3.7.8.1 Purpose. This test continues addressing using the PEQEH; command within GC to generate a europium-152 calibration history for a pulsered detector system. This is the third part of a fourpart test, all parts of which should be performed in immediate succession. This part tests entering an invalid ending date (one that is earlier than the starting date).

3.7.8.2 Input Description. The second query reads "Enter ending date of report (MMDDYY):" then appears. Enter 010193.

3.7.8.3 Expected Results. The message "BAD INPUT--PLEASE REENTER" appears below the second query (because 010193 is chronologically before 010194) and the second query reappears yet 
again.

3.7.8.4 Pass/Fail Criterion. The test passes if the expected results are obtained.

\subsubsection{GC.PEQEH.2d}

3.7.9.1 Purpose. This test continues addressing using the PEQEH; command within GC to generate a europium-152 calibration history for a pulsered detector system. This is the final part of a fourpart test, all parts of which should be performed in immediate succession.

3.7.9.2 Input Description. The second query reads "Enter ending date of report (MMDDYY):" then appears. Enter 060194.

3.7.9.3 Expected Results. The GC main screen reappears and output practically identical to that presented in Appendix B.2 should be generated at the system printer.

3.7.9.4 Pass/Fail Criterion. The test passes if the expected results are obtained.

\subsubsection{GC.CBT.1}

3.7.10.1 Purpose. This test addresses using a CBT; command within GC to attempt to perform an energy- and width-calibration on a thorium-228 calibration spectrum currently stored in the AIM associated with an unknown non-pulsered detector system.

3.7.10.2 Input Description. Enter the command CBT;A5 at the GC "CMD>" prompt.

3.7.10.3 Expected Results. The messages "UNKNOWN DETECTOR NUMBER: ' 5 '" and "BAD OR UNKNOWN COMMAND--'CBT;A5" are displayed above the "CMD>" prompt.

3.7.10.4 Pass/Fall Criterion. The test passes if the expected results are obtained.

\subsubsection{GC.CBT.2}

3.7.11.1 Purpose. This test addresses using the CBT; command within GC to perform an energy- and width-calibration on a thorium-228 calibration spectrum currently stored in the AIM associated with a non-pulsered detector system.

3.7.11.2 Input Description. Enter the command CBT;A1 at the GC "CMD>" prompt.

3.7.11.3 Expected Results. The GC main screen disappears and the message "PERFORMING NONPULSERED THORIUM CALIBRATION FOR A1" appears at the top of the screen."

3.7.11.4 Pass/Fail Criterion. The test passes if the expected results are obtained.

n. It is also possible, though not required for passing this test, that other messages will appear and that output will be generated at the system laser printer within a few minutes after the CBE; command has been issued. The reason output is not required for passing this test is that whether the actual calibration is successful and output is generated depends in part on what is in front of the detectors. This is true for commands PEQE, CBT, and PEQT as well. 


\subsubsection{GC.PEQT.1}

3.7.12.1 Purpose. This test addresses using a PEQT; command within GC to attempt to perform an energy- and width-calibration on a thorium-228 calibration spectrum currently stored in the AIM associated with an unknown pulsered detector system.

3.7.12.2 Input Description. Enter the command PEQT;A5 at the GC "CMD>" prompt.

3.7.12.3 Expected Results. The messages "UNKNOWN DETECTOR NUMBER: '5" and "BAD OR UNKNOWN COMMAND--'PEQT;A5" are displayed above the "CMD>" prompt.

3.7.12.4 Pass/Fail Criterion. The test passes if the expected results are obtained.

\subsubsection{GC.PEQT.2}

3.7.13.1 Purpose. This test addresses using the PEQT; command within GC to perform an energy- and width-calibration on a thorium-228 calibration spectrum currently stored in the AIM associated with a pulsered detector system.

3.7.13.2 Input Description. Enter the command PEQT;A1 at the GC "CMD>" prompt.

3.7.13.3 Expected Results. The GC main screen disappears and the message "PERFORMING PULSERED THORIUM CALIBRATION FOR A1" appears at the top of the screen."

3.7.13.4 Pass/Fail Criterion. The test passes if the expected results are obtained.

\subsubsection{GC.PEQTH.1}

3.7.14.1 Purpose. This test addresses using a PEQTH; command within GC to attempt to generate a thorium-228 calibration history for an unknown pulsered detector system.

3.7.14.2 Input Description. Enter the command PEQTH;A5 at the GC "CMD>" prompt.

3.7.14.3 Expected Results. The messages "UNKNOWN DETECTOR NUMBER: '5'" and "BAD OR UNKNOWN COMMAND--'PEQTH;A5"" are displayed above the "CMD>" prompt.

3.7.14.4 Pass/Fail Criterion. The test passes if the expected results are obtained.

\subsubsection{GC.PEQTH.2a}

3.7.15.1 Purpose. This test addresses using the PEQTH; command within GC to generate a thorium-228 calibration history for a pulsered detector system. There are four parts to this test; the remaining parts follow and should be conducted in order immediately after this test. This part tests entering an incorrectly formatted date.

o. If output is generated by this command, it should appear similar in format to the sample presented in Appendix B.1; the numerical values will vary with detector age and condition and depending on settings within the various electronic components associated with the detector. As noted in an earlier footnote, output being generated from a calibration is not a pass/fail criterion. 
3.7.15.2 Input Description. Enter the command PEQTH;A1 at the GC "CMD>" prompt. The GC main screen disappears, the message "GENERATING PULSERED THORIUM CALIBRATION HISTORY FOR A1" appears at the top of the screen, and a query reading "Enter starting date of report (MMDDYY):" also appears. Enter 010194. A second query reading "Enter ending date of report (MMDDYY):" then appears. Enter 60194.

3.7.15.3 Expected Results. The message "BAD INPUT--PLEASE REENTER" appears below the second query (because a leading zero before the "6" is missing) and the second query reappears.

3.7.15.4 Pass/Fail Criterion. The test passes if the expected results are obtained.

\subsubsection{GC.PEQTH.2b}

3.7.16.1 Purpose. This test continues addressing using the PEQTH; command within GC to generate a thorium-228 calibration history for a pulsered detector system. This is the second part of a four-part test, all parts of which should be performed in immediate succession. This part tests entering an invalid date.

3.7.16.2 Input Description. The second query reads "Enter ending date of report (MMDDYY):" then appears. Enter AABBCC.

3.7.16.3 Expected Results. The message "BAD INPUT--PLEASE REENTER" appears below the second query (because $A A B B C C$ is not a valid integer MMDDYY date) and the second query reappears yet again.

3.7.16.4 Pass/Fail Criterion. The test passes if the expected results are obtained.

\subsubsection{GC.PEQTH.2C}

3.7.17.1 Purpose. This test continues addressing using the PEQTH; command within GC to generate a thorium-228 calibration history for a pulsered detector system. This is the third part of a fourpart test, all parts of which should be performed in immediate succession. This part tests entering an invalid ending date (one that is earlier than the starting date).

3.7.17.2 Input Description. The second query reads "Enter ending date of report (MMDDYY):" then appears. Enter 010193.

3.7.17.3 Expected Results. The message "BAD INPUT--PLEASE REENTER" appears below the second query (because 010193 is chronologically before 010194) and the second query reappears yet again.

3.7.17.4 Pass/Fail Criterion. The test passes if the expected results are obtained.

\subsubsection{GC.PEQTH.2d}

3.7.18.1 Purpose. This test continues addressing using the PEQTH; command within GC to generate a thorium-228 calibration history for a pulsered detector system. This is the final part of a fourpart test, all parts of which should be performed in immediate succession.

3.7.18.2 Input Description. The second query reads "Enter ending date of report 
(MMDDYY):" then appears. Enter 060194.

3.7.18.3 Expected Results. Execution of GC is aborted with an error message that begins with "\%FOR-F-FILNOTFOU" as of September 22, 1994 because no thorium-228 calibration data has been acquired for detector system $\mathrm{A} 1$.

3.7.18.4 Pass/Fail Criterion. The test passes if the expected results are obtained.

\subsection{Spectrum Display Commands}

\subsubsection{GC.DAS.1}

3.8.1.1 Purpose. This test addresses using a DAS; command within GC to attempt to display the spectral data currently stored in the AIM associated with an unknown detector system.

3.8.1.2 Input Description. Enter the command DAS;A5 at the GC "CMD>" prompt.

- 3.8.1.3 Expected Results. The messages "UNKNOWN DETECTOR NUMBER: '5'" and "BAD OR UNKNOWN COMMAND--'DAS;A5'" are displayed above the "CMD>" prompt.

3.8.1.4 Pass/Fail Criterion. The test passes if the expected results are obtained.

\subsubsection{GC.DAS.2}

3.8.2.1 Purpose. This test addresses using the DAS; command within GC to display the spectral data currently stored in the AIM associated with a detector system. This test should be conducted from an X-windowing terminal equipped with a mouse, not a text-only terminal such as a VT330.

3.8.2.2 Input Description. Enter the command DAS;A1 at the GC "CMD>" prompt. Then click on the "QUIT" button in the upper left-hand comer of the new window that appears [2].

3.8.2.3 Expected Results. After entering the DAS; command, the DAS window appears with the spectral data contained in the AIM associated with detector system A1. Upon clicking on the "QUIT" button the DAS window disappears and control is retumed to the GC main screen.

3.8.2.4 Pass/Fail Criterion. The test passes if the expected results are obtained.

\subsection{Batch Job- and Queue-Related Commands}

\subsubsection{GC.TYPELOG.1}

3.9.1.1 Purpose. This test addresses using the TYPELOG; command within GC to display on the screen the contents of the most-recent BATCH_GIDXC_ANALYSIS.LOG file.

3.9.1.2 Input Description. Enter the command TYPELOG; at the GC "CMD>" prompt. After the contents of the log file scroll by, in response to the message "Press the 'Return' key to continue." appears, strike the retum key.

3.9.1.3 Expected Results. The GC main screen disappears and the contents of the log file 
scroll by on the screen after the TYPELOG; command has been entered. After all of the contents have been displayed, and the return key has been struck, the GC main screen reappears. (Portions of a typical $\log$ file are presented in Figure 12; ellipses mark areas where some of the file has been omitted.)

3.9.1.4 Pass/Fail Criterion. The test passes if the expected results are obtained.

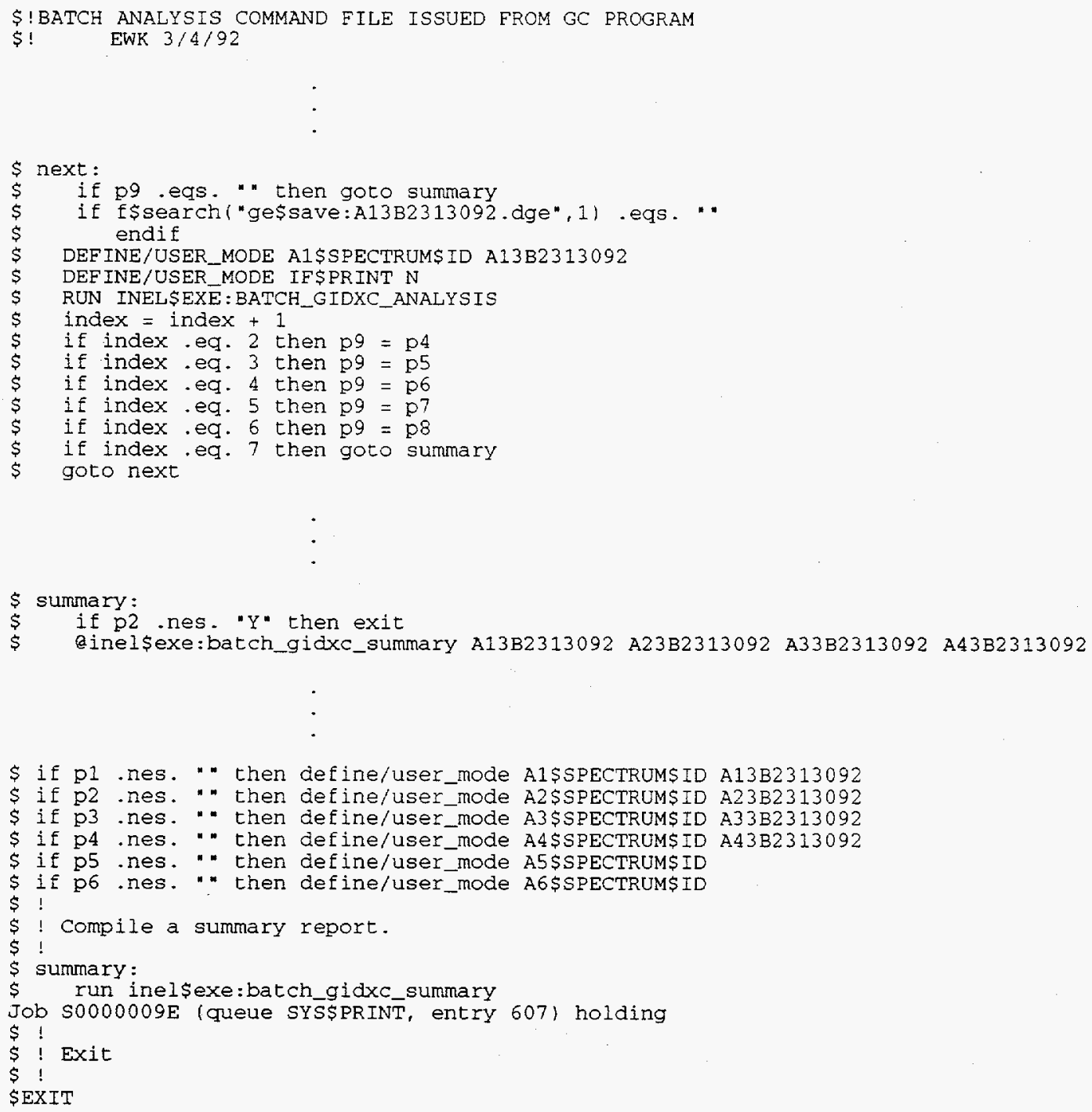

Figure 12. Portions of a Typical BATCH_GIDXC_ANALYSIS.LOG File.

\subsubsection{GC.PRINTLOG.1}


3.9.2.1 Purpose. This test addresses using the PRINTLOG; command within GC to send a copy of the most-recent BATCH_GIDXC_ANALYSIS log file to the system printer.

3.9.2.2 Input Description. Enter the command PRINTLOG; at the GC "CMD>" prompt.

3.9.2.3 Expected Results. The GC main screen blinks and the log file is printed on the system printer.

3.9.2.4 Pass/Fail Criterion. The test passes if the expected results are obtained.

\subsubsection{GC.SHOWQUE.1}

3.9.3.1 Purpose. This test addresses using the SHOWQUE; command within GC to display the status of the computer's batch and print queues.

3.9.3.2 Input Description. Enter the command SHOWQUE; at the GC "CMD>" prompt. After the status display scrolls by, in response to the message "Press the 'Return' key to continue." appears, strike the return key.

3.9.3.3 Expected Results. The GC main screen disappears and the status of the computer's batch and print queues scrolls by on the screen after the SHOWQUE; command has been entered. After the status display is complete, and the retum key has been struck, the GC main screen reappears. (A typical display, generated by SHOWQUE; shortly after an FBA; command was entered, is presented in Figure 13.)

3.9.3.4 Pass/Fail Criterion. The test passes if the expected results are obtained.

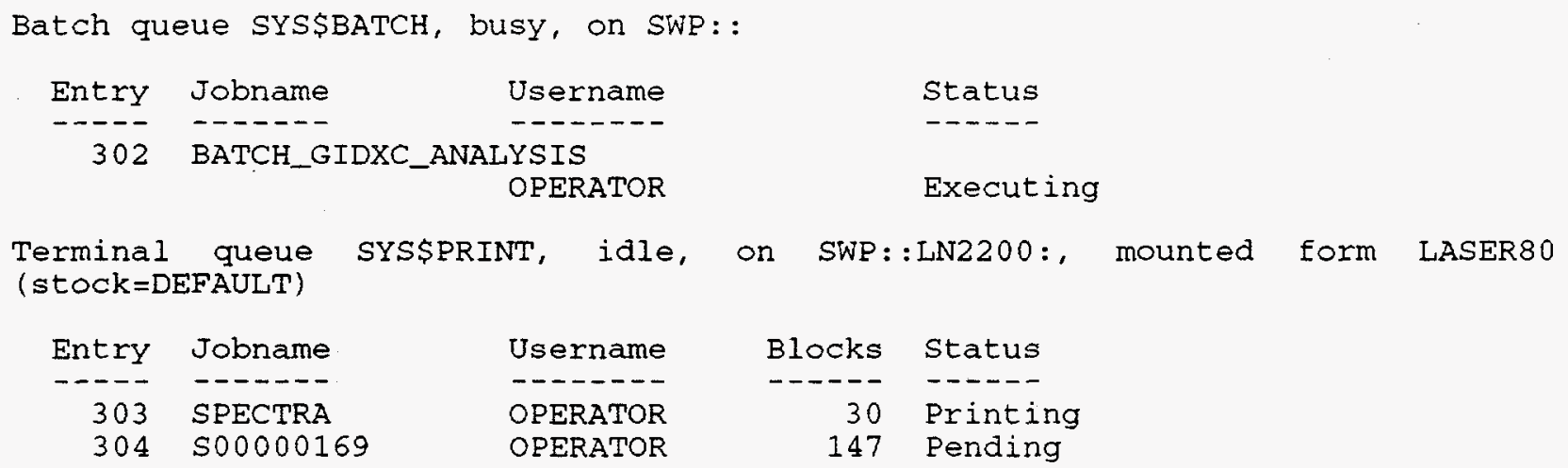

Figure 13. SHOWQUE;-Generated Display. 


\section{GIDXC}

\subsection{Overview}

GIDXC performs the isotopic ratio calculations on a single gamma-ray spectrum or on a set of spectra from a single barrel measurement. In the latter case, a summary report can be generated, along with a PAN\$RATIOS file that contains certain isotopic ratios for use by the SWEPP Assay System (SAS) [9]. GIDXC is part of a number of GC commands, and it can also be used as a command at the DCL prompt; this testing is concemed with the latter implementation. When used as a command at the DCL prompt, GIDXC generates only full single-spectrum analysis output, no matter how many spectra are specified; it is functionally equivalent to the GC A; command. As noted earlier, the nomenclature for the various test cases is $<$ program or command language name $>$.<command (without semicolon) $>$. $<$ sequential test number for the respective command $>$.

\subsection{GIDXC as a Command at the DCL Prompt}

\subsubsection{DCL.GIDXC.1}

4.2.1.1 Purpose. This test addresses using a GIDXC command from the DCL prompt to submit an unknown saved spectrum for a full single-spectrum analysis.

4.2.1.2 Input Description. Enter the command GIDXC A1123456789 at the DCL prompt.

4.2.1.3 Expected Results. The message "SPECTRUM A1123456789 NOT FOUND" appears.

4.2.1.4 Pass/Fail Criterion. The test passes if the expected results are obtained.

\subsubsection{DCL.GIDXC.2}

4.2.2.1 Purpose. This test addresses using the GIDXC command from the DCL prompt to submit a single saved spectrum for a full single-spectrum analysis.

4.2.2.2 Input Description. Enter the command GIDXC A1460613110 at the GC "CMD>" prompt.

4.2.2.3 Expected Results. After up to a few minutes, a message akin to "Job S0000006B (queue SYS\$PRINT, entry 374) started on SYS\$PRINT" appears (the identifier following "Job" and the number following "entry" will likely be different). This signals the start of the analysis output being printed. A while later a message akin to "Job S0000006B (queue SYS\$PRINT, entry 374) completed" appears, signaling that printing is completed.

4.2.2.4 Pass/Fail Criterion. The test passes if the expected results are obtained.

\subsubsection{DCL.GIDXC.3}

4.2.3.1 Purpose. This test addresses using the GIDXC command from the DCL prompt to submit multiple saved spectra for full single-spectrum analysis.

4.2.3.2 Input Description. Enter the command GIDXC A1460613110 A2460613110 
A3460613110 at the GC "CMD>" prompt.

4.2.3.3 Expected Results. After up to a few minutes, a message akin to "Job S0000006B (queue SYS\$PRINT, entry 374) started on SYS\$PRINT" appears (the identifier following "Job" and the number following "entry" will likely be different). This signals the start of the analysis output being printed for the first spectrum specified. (A while later a message akin to "Job S0000006B (queue SYS\$PRINT, entry 374) completed" appears, signaling that printing is completed.)

For the second and third spectra, messages appear that read "GAUSS-ERROR FIT REGION FOR PEAK AT 8064.0 IS TO LARGE. GREATER THAN 300 CHANNELS" and no output is generated.

4.2.3.4 Pass/Fail Criterion. The test passes if the expected results are obtained. 


\section{TEST RESULTS}

The above tests were performed on September 22, 1994 by D. A. Schultz and W. Serrano of the SGRS support staff. Taking into account the annotations that appear as footnotes to Appendix A.1, all tests passed as recorded in Appendixes A.1 and A.2. For completeness, those annotations are included here.

\subsection{Test Result Annotations}

\subsubsection{Annotation to test GC.HELP.1 (Section 3.4.1)}

On the first attempt of this test, blank screens were displayed for help screens 3 and 4 . Once the VMS file protection settings were corrected for the files containing help screens 3 and 4 ("world" protection was changed from RE to RWE), these help screens were properly displayed and the test passed.

\subsubsection{Annotation to test GC.BS.1f (Section 3.5.23)}

On the first attempt of this test, the analysis trigger level was set to zero as the acquisition was started. As a result, because the region of the gamma-ray spectrum where a number of peaks from plutonium isotopes are observed was being monitored, the acquisition terminated almost immediately. The trigger level was set to zero because of the action of test GC.M.4 (see Section 3.5.4) in which an invalid trigger level is purposely entered. After an invalid trigger level is specified, GC does not assume the default value but rather assumes that the user will reenter the $\mathrm{M}$; command properly, providing a valid trigger level. After the command $M$; was entered, all six parts of this test were repeated and yielded the expected results. 


\section{REFERENCES}

1. E. W. Killian and J. K. Hartwell, VAXGAP: A Code for the Routine Analysis of Gamma-Ray Pulse-Height Spectra on a VAX Computer, EGG-2533, May 1988.

2. E. W. Killian and D. A. Femec, Operator's Guide for VAXGAP, a Gamma-Ray Spectrum Analysis Package, EGG-2672, August 1992.

3. D. A. Femec and E. W. Killian, SWEPP Gamma-Ray Spectrometer System Software Design Description, EGG-NRE-11451, August 1994.

4. D. A. Femec, SWEPP Gamma-Ray Spectrometer System Software User's Guide, EGG-NRE11452 , August 1994.

5. W. Serrano, Relative Isotopic Mass Ratio Gamma Measurements, RWMC-EDF-658, June 28, 1994.

6. W. Serrano, Drum Matrix Mass Attenuation Coefficients, RWMC-EDF-722, March 14, 1994.

7. "Installation Instructions for Slo-Syn SS2000D6 Packaged Drive," The Superior Electric Company, 1992.

8. "Installation Instructions for Slo-Syn SS20001 Programmable Motion Control," The Superior Electric Company, Revision B.

9. S. D. Matthews and E. S. Marwil, SWEPP Assay System Software Design Description, EGGRAAM-10424, September 1993 (and documents referenced therein). 


\section{APPENDIXES}

\section{Appendix A. Summaries of Test Cases for GC and GIDXC}

\section{A.1 Summary of Test Case Results of September 22, 1994 for GC.}

\begin{tabular}{|c|c|c|c|c|}
\hline Section & Test Case & Description & Pass/Fail & Page \\
\hline \multicolumn{5}{|c|}{ Initialization of the User's Environment } \\
\hline 3.2 .1 & DCL.GC_INIT.1 & $\begin{array}{l}\text { Generation of necessary program communi- } \\
\text { cation files }\end{array}$ & Pass & 5 \\
\hline \multicolumn{5}{|c|}{ Starting GC } \\
\hline 3.3 .1 & DCL.GC. 1 & $\begin{array}{l}\text { Starting GC using GC at DCL command } \\
\text { prompt }\end{array}$ & Pass & 5 \\
\hline 3.3 .2 & DCL.BS.1 & $\begin{array}{l}\text { Starting GC using BS at DCL command } \\
\text { prompt }\end{array}$ & Pass & 6 \\
\hline \multicolumn{5}{|c|}{ GC Help, Exit, and Unknown Commands } \\
\hline 3.4 .1 & GC.HELP.1 & Displaying help screens & Pass $^{\mathrm{a}}$ & 7 \\
\hline 3.4 .2 & GC.EXIT.1 & Exiting GC using EXIT; & Pass & 10 \\
\hline 3.4 .3 & GC.QUIT.1 & Exiting GC using QUIT; & Pass & 10 \\
\hline 3.4 .4 & GC.CONTROL-Z.1 & Exiting GC using control-z & Pass & 11 \\
\hline 3.4 .5 & GC.UNKNOWN.1 & Unknown command handling & Pass & 11 \\
\hline \multicolumn{5}{|c|}{ GC Data Acquisition Commands } \\
\hline 3.5 .1 & GC.M.1 & $\begin{array}{l}\text { Count limit analysis trigger toggle with no } \\
\text { ongoing acquisition }\end{array}$ & Pass & 12 \\
\hline 3.5 .2 & GC.M.2 & Same as .1 , but with an ongoing acquisition & Pass & 12 \\
\hline 3.5 .3 & GC.M.3 & Resetting analysis trigger level & Pass & 13 \\
\hline 3.5 .4 & GC.M.4 & Same as .1 , but with an invalid value & Pass & 13 \\
\hline 3.5 .5 & GC.RI.1 & Initialize turntable communications & Pass & 13 \\
\hline 3.5 .6 & GC.RT.1 & Rotate-on-acquisition toggle & Pass & 13 \\
\hline 3.5 .7 & GC.R.1 & Manual rotation toggle & Pass & 14 \\
\hline
\end{tabular}

a. On the first attempt of this test, blank screens were displayed for help screens 3 and 4 . Once the VMS file protection settings were corrected for the files containing help screens 3 and 4 ("world" protection was changed from RE to RWE), these help screens were properly displayed and the test passed. 


\begin{tabular}{|c|c|c|c|c|}
\hline 3.5 .8 & GC.SP.1 & Analysis parameters display & Pass & 14 \\
\hline 3.5 .9 & GC.SP.2 & $\begin{array}{l}\text { Same as } .1 \text {, but for an unknown detector } \\
\text { system }\end{array}$ & Pass & 14 \\
\hline 3.5 .10 & GC.S.1 & $\begin{array}{l}\text { Generic start of acquisition on one detector } \\
\text { system }\end{array}$ & Pass & 15 \\
\hline 3.5.11 & GC.S.2 & $\begin{array}{l}\text { Same as } .1 \text {, but with an acquisition already } \\
\text { started }\end{array}$ & Pass & 15 \\
\hline 3.5 .12 & GC.S.3 & $\begin{array}{l}\text { Generic start of acquisition on multiple } \\
\text { detector systems }\end{array}$ & Pass & 16 \\
\hline 3.5 .13 & GC.S.4 & $\begin{array}{l}\text { Same as } .3 \text {, but with acquisitions already } \\
\text { started }\end{array}$ & Pass & 16 \\
\hline 3.5 .14 & GC.S.5 & Same as .1 , but on an unknown detector & Pass & 16 \\
\hline 3.5 .15 & GC.S.6 & Same as .3 , but incorrectly formatted & Pass & 16 \\
\hline 3.5 .16 & GC.S.7 & Same as .1 , but with an invalid count time & Pass & 17 \\
\hline 3.5 .17 & GC.S.8 & Same as .3 , but with an invalid count time & Pass & 17 \\
\hline 3.5 .18 & GC.BS.1a & $\begin{array}{l}\text { Bar code start of acquisition on all detector } \\
\text { systems: command with bar code identifier }\end{array}$ & Pass & 17 \\
\hline 3.5 .19 & GC.BS.1b & Continuation of 1 : invalid weight & Pass & 17 \\
\hline 3.5 .20 & GC.BS.1c & Continuation of .1 : valid weight & Pass & 18 \\
\hline 3.5 .21 & GC.BS.1d & Continuation of $.1:$ invalid content code & Pass & 18 \\
\hline 3.5 .22 & GC.BS.1e & Continuation of .1: valid content code & Pass & 18 \\
\hline 3.5 .23 & GC.BS.1f & Completion of .1 : comments & Pass $^{b}$ & 19 \\
\hline 3.5 .24 & GC.STOP.1 & Stop acquisition on one detector system & Pass & 19 \\
\hline 3.5 .25 & GC.STOP.2 & $\begin{array}{l}\text { Same as } .1 \text {, but with multiple detector } \\
\text { systems }\end{array}$ & Pass & 19 \\
\hline 3.5 .26 & GC.STOP.3 & $\begin{array}{l}\text { Same as } .1 \text {, but with an unknown detector } \\
\text { system }\end{array}$ & Pass & 20 \\
\hline 3.5 .27 & GC.STOP.4 & Same as .2 , but incorrectly formatted & Pass & 20 \\
\hline
\end{tabular}

b. On the first attempt of this test, the analysis trigger level was set to zero as the acquisition was started. As a result, because the region of the gamma-ray spectrum where a number of peaks from plutonium isotopes are observed was being monitored, the acquisition terminated almost immediately. The trigger level was set to zero because of the action of test GC.M.4 (see Section 3.5.4) in which an invalid trigger level is purposely entered. After an invalid trigger level is specified, GC does not assume the default value but rather assumes that the user will reenter the $\mathbf{M}$; command properly, providing a valid trigger level. After the command $\mathrm{M}$; was entered, all six parts of this test were repeated and yielded the expected results. 


\begin{tabular}{|c|c|c|c|c|}
\hline 3.5 .28 & GC.BSTOP.1 & Stop acquisition on all detector systems & Pass & 20 \\
\hline \multicolumn{5}{|c|}{ Spectrum Storage and Analysis Commands } \\
\hline 3.6.1 & GC.D. 1 & $\begin{array}{l}\text { Save spectrum from one detector system, } \\
\text { but command incomplete }\end{array}$ & Pass & 21 \\
\hline 3.6 .2 & GC.D. 2 & $\begin{array}{l}\text { Same as } .1 \text {, but complete with an unknown } \\
\text { detector system }\end{array}$ & Pass & 22 \\
\hline 3.6 .3 & GC.D.3 & Same as .2 , but with only an invalid weight & Pass & 22 \\
\hline 3.6.4 & GC.D.4 & $\begin{array}{l}\text { Same as } .2 \text {, but with only an invalid con- } \\
\text { tent code }\end{array}$ & Pass & 22 \\
\hline 3.6 .5 & GC.D.5 & Same as .2 , but with all values valid & Pass & 22 \\
\hline 3.6 .6 & GC.D.6 & $\begin{array}{l}\text { Save spectra from multiple detector sys- } \\
\text { tems, but incorrectly formatted }\end{array}$ & Pass & 23 \\
\hline 3.6 .7 & GC.D.7 & Same as .6 , but correctly formatted & Pass & 23 \\
\hline 3.6.8 & GC.BD.1 & $\begin{array}{l}\text { Save spectra from all detector systems, but } \\
\text { command incomplete }\end{array}$ & Pass & 23 \\
\hline 3.6 .9 & GC.BD. 2 & $\begin{array}{l}\text { Same as } .1 \text {, but complete with an invalid } \\
\text { weight }\end{array}$ & Pass & 24 \\
\hline 3.6 .10 & GC.BD. 3 & $\begin{array}{l}\text { Same as } .2 \text {, but with only an invalid con- } \\
\text { tent code }\end{array}$ & Pass & 24 \\
\hline 3.6 .11 & GC.BD.4 & Same as .2 , but with all values valid & Pass & 24 \\
\hline 3.6 .12 & GC.DA.1 & $\begin{array}{l}\text { Save and analyze spectrum from one detec- } \\
\text { tor system, but command incomplete }\end{array}$ & Pass & 24 \\
\hline 3.6 .13 & GC.DA. 2 & $\begin{array}{l}\text { Same as } .1 \text {, but complete with an unknown } \\
\text { detector system }\end{array}$ & Pass & 25 \\
\hline 3.6 .14 & GC.DA.3 & Same as .2 , but with only an invalid weight & Pass & 25 \\
\hline 3.6 .15 & GC.DA.4 & $\begin{array}{l}\text { Same as } .2 \text {, but with only an invalid con- } \\
\text { tent code }\end{array}$ & Pass & 25 \\
\hline 3.6.16 & GC.DA.5 & Same as .2 , but with all values valid & Pass & 26 \\
\hline 3.6.17 & GC.DA. 6 & $\begin{array}{l}\text { Save spectra from multiple detector sys- } \\
\text { tems, but incorrectly formatted }\end{array}$ & Pass & 26 \\
\hline 3.6 .18 & GC.DA.7 & Same as .6, but correctly formatted & Pass & 26 \\
\hline 3.6 .19 & GC.BDA.1 & $\begin{array}{l}\text { Save and analyze spectra from all detector } \\
\text { systems, but command incomplete }\end{array}$ & Pass & 27 \\
\hline 3.6 .20 & GC.BDA.2 & $\begin{array}{l}\text { Same as } .1 \text {, but complete with an invalid } \\
\text { weight }\end{array}$ & Pass & 27 \\
\hline
\end{tabular}




\begin{tabular}{|c|c|c|c|c|}
\hline 3.6 .21 & GC.BDA.3 & $\begin{array}{l}\text { Same as } .2 \text {, but with only an invalid con- } \\
\text { tent code }\end{array}$ & Pass & 27 \\
\hline 3.6 .22 & GC.BDA.4 & Same as .2 , but with all values valid & Pass & 28 \\
\hline 3.6 .23 & GC.BKG.1 & $\begin{array}{l}\text { Save a background spectrum from one } \\
\text { detector system }\end{array}$ & Pass & 28 \\
\hline 3.6 .24 & GC.BKG.2 & $\begin{array}{l}\text { Save background spectra from multiple } \\
\text { detector systems }\end{array}$ & Pass & 28 \\
\hline 3.6 .25 & GC.BKG.3 & $\begin{array}{l}\text { Same as } .1 \text {, but with an unknown detector } \\
\text { system }\end{array}$ & Pass & 29 \\
\hline 3.6 .26 & GC.BKG.4 & Same as .2 , but incorrectly formatted & Pass & 29 \\
\hline 3.6 .27 & GC.A.1 & $\begin{array}{l}\text { Full single-spectrum analysis of a saved } \\
\text { spectrum, but with an unknown spectrum }\end{array}$ & Pass & 29 \\
\hline $\begin{array}{c}3.6 .28 \\
\cdot\end{array}$ & GC.A.2 & $\begin{array}{l}\text { Same as } .1 \text {, but with spectrum improperly } \\
\text { identified }\end{array}$ & Pass & 29 \\
\hline 3.6 .29 & GC.A.3 & $\begin{array}{l}\text { Same as } .1 \text {, but with spectrum properly } \\
\text { identified }\end{array}$ & Pass & 30 \\
\hline 3.6.30 & GC.BA.1 & $\begin{array}{l}\text { Summary report-only analysis of a saved } \\
\text { spectrum, but with an unknown spectrum }\end{array}$ & Pass & 30 \\
\hline 3.6 .31 & GC.BA.2 & $\begin{array}{l}\text { Same as } .1 \text {, but with a set of unknown } \\
\text { spectra }\end{array}$ & Pass & 30 \\
\hline 3.6 .32 & GC.BA.3 & $\begin{array}{l}\text { Same as .1, but with spectrum improperly } \\
\text { identified }\end{array}$ & Pass & 31 \\
\hline 3.6 .33 & GC.BA.4 & Same as .2 , but with known spectra & Pass & 31 \\
\hline 3.6 .34 & GC.BA.5 & $\begin{array}{l}\text { Same as } .4 \text {, but with improper abbrevia- } \\
\text { tions }\end{array}$ & Pass & 31 \\
\hline 3.6 .35 & GC.BA. 6 & Same as .4 , but with proper abbreviations & Pass & 32 \\
\hline 3.6.36 & GC.FBA.1 & $\begin{array}{l}\text { Full single-spectrum and summary report } \\
\text { analysis of a saved spectrum, but with an } \\
\text { unknown spectrum }\end{array}$ & Pass & 32 \\
\hline 3.6.37 & GC.FBA.2 & $\begin{array}{l}\text { Same as } .1 \text {, but with a set of unknown } \\
\text { spectra }\end{array}$ & Pass & 32 \\
\hline 3.6.38 & GC.FBA.3 & $\begin{array}{l}\text { Same as } .1 \text {, but with spectrum improperly } \\
\text { identified }\end{array}$ & Pass & 33 \\
\hline 3.6.39 & GC.FBA.4 & Same as .2 , but with known spectra & Pass & 33 \\
\hline 3.6 .40 & GC.FBA. 5 & $\begin{array}{l}\text { Same as } .4 \text {, but with improper abbrevia- } \\
\text { tions }\end{array}$ & Pass & 33 \\
\hline 3.6 .41 & GC.FBA. 6 & Same as .4 , but with proper abbreviations & Pass & 34 \\
\hline
\end{tabular}




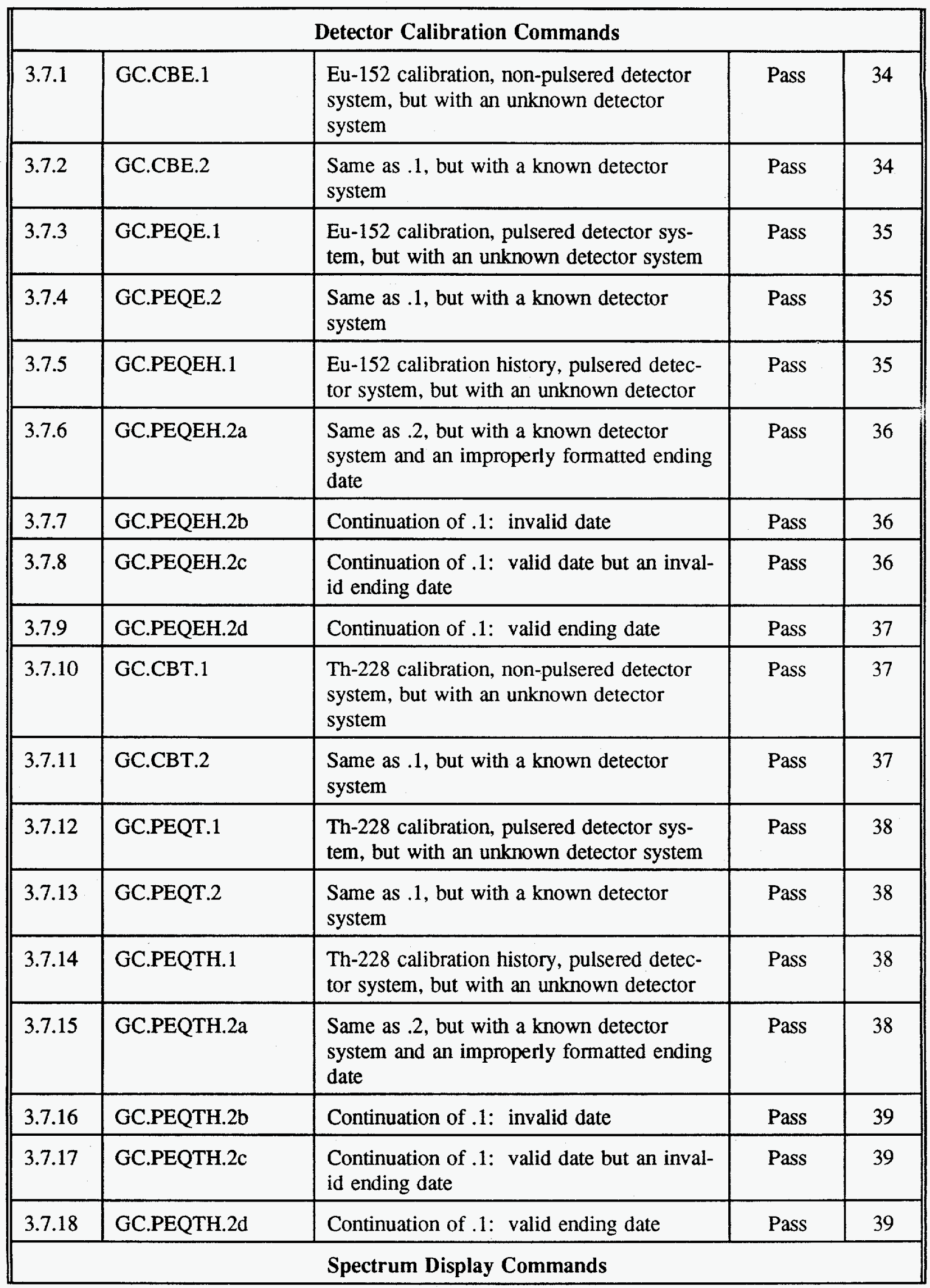




\begin{tabular}{|c|c|c|c|c|}
\hline 3.8 .1 & GC.DAS.1 & $\begin{array}{l}\text { Generate DAS display of detector system } \\
\text { data, but with an unknown detector system }\end{array}$ & Pass & 40 \\
\hline 3.8 .2 & GC.DAS.2 & $\begin{array}{l}\text { Same as .1, but with a known detector } \\
\text { system }\end{array}$ & Pass & 40 \\
\hline \multicolumn{5}{|c|}{ Batch Job- and Queue-Related Commands } \\
\hline 3.9 .1 & GC.TYPELOG.1 & $\begin{array}{l}\text { List of screen contents of GIDXC batch } \\
\text { analysis } \log \text { file }\end{array}$ & Pass & 40 \\
\hline 3.9 .2 & GC.PRINTLOG.1 & $\begin{array}{l}\text { Print contents of GIDXC batch analysis log } \\
\text { file }\end{array}$ & Pass & 41 \\
\hline 3.9 .3 & GC.SHOWQUE.1 & Show status of all batch and print queues & Pass & 42 \\
\hline
\end{tabular}




\section{A.2 Summary of Test Case Results of September 22, 1994 for GIDXC}

\begin{tabular}{||l|l|l|c|c||}
\hline Section & Test Case & Description & Pass/Fail & Page \\
\hline \hline \multicolumn{5}{|c|}{ GIDXC as a Command at the DCL Prompt } \\
\hline 4.2 .1 & DCL.GIDXC.1 & $\begin{array}{l}\text { Full single-spectrum analysis, but with an } \\
\text { unknown spectrum }\end{array}$ & Pass & 43 \\
\hline 4.2 .3 & DCL.GIDXC.3 & Same as .1, but with a known spectrum & Pass & 43 \\
\hline
\end{tabular}




\section{A.3 Blank Summary of Test Cases for GC}

\begin{tabular}{|c|c|c|c|c|}
\hline Section & Test Case & Description & Pass/Fail & Page \\
\hline \multicolumn{5}{|c|}{ Initialization of the User's Environment } \\
\hline 3.2 .1 & DCL.GC_INIT.1 & $\begin{array}{l}\text { Generation of necessary program communi- } \\
\text { cation files }\end{array}$ & & 5 \\
\hline \multicolumn{5}{|c|}{ Starting GC } \\
\hline 3.3.1 & DCL.GC. 1 & $\begin{array}{l}\text { Starting GC using GC at DCL command } \\
\text { prompt }\end{array}$ & & 5 \\
\hline 3.3.2 & DCL.BS.1 & $\begin{array}{l}\text { Starting GC using BS at DCL command } \\
\text { prompt }\end{array}$ & & 6 \\
\hline \multicolumn{5}{|c|}{ GC Help, Exit, and Unknown Commands } \\
\hline 3.4.1 & GC.HELP.1 & Displaying help screens & & 7 \\
\hline 3.4.2 & GC.EXIT.1 & Exiting GC using EXIT; & & 10 \\
\hline 3.4.3 & GC.QUIT.1 & Exiting GC using QUIT; & & 10 \\
\hline 3.4 .4 & GC.CONTROL-Z.1 & Exiting GC using control-z & & 11 \\
\hline 3.4.5 & GC.UNKNOWN.1 & Unknown command handling & & 11 \\
\hline \multicolumn{5}{|c|}{ GC Data Acquisition Commands } \\
\hline 3.5 .1 & GC.M.1 & $\begin{array}{l}\text { Count limit analysis trigger toggle with no } \\
\text { ongoing acquisition }\end{array}$ & & 12 \\
\hline 3.5.2 & GC.M.2 & Same as .1 , but with an ongoing acquisition & & 12 \\
\hline 3.5 .3 & GC.M.3 & Resetting analysis trigger level & & 13 \\
\hline 3.5.4 & GC.M.4 & Same as .1 , but with an invalid value & & 13 \\
\hline 3.5 .5 & GC.RI.1 & Initialize turntable communications & & 13 \\
\hline 3.5 .6 & GC.RT.1 & Rotate-on-acquisition toggle & & 13 \\
\hline 3.5 .7 & GC.R.1 & Manual rotation toggle & & 14 \\
\hline 3.5 .8 & GC.SP.1 & Analysis parameters display & & 14 \\
\hline 3.5 .9 & GC.SP.2 & $\begin{array}{l}\text { Same as .1, but for an unknown detector } \\
\text { system }\end{array}$ & & 14 \\
\hline 3.5 .10 & GC.S.1 & $\begin{array}{l}\text { Generic start of acquisition on one detector } \\
\text { system }\end{array}$ & & 15 \\
\hline 3.5 .11 & GC.S.2 & $\begin{array}{l}\text { Same as .1, but with an acquisition already } \\
\text { started }\end{array}$ & & 15 \\
\hline
\end{tabular}




\begin{tabular}{|c|c|c|c|}
\hline 3.5 .12 & GC.S.3 & $\begin{array}{l}\text { Generic start of acquisition on multiple } \\
\text { detector systems }\end{array}$ & 16 \\
\hline 3.5 .13 & GC.S.4 & $\begin{array}{l}\text { Same as } .3 \text {, but with acquisitions already } \\
\text { started }\end{array}$ & 16 \\
\hline 3.5 .14 & GC.S.5 & Same as .1 , but on an unknown detector & 16 \\
\hline 3.5 .15 & GC.S.6 & Same as .3 , but incorrectly formatted & 16 \\
\hline 3.5 .16 & GC.S.7 & Same as .1 , but with an invalid count time & 17 \\
\hline 3.5 .17 & GC.S.8 & Same as .3 , but with an invalid count time & 17 \\
\hline 3.5 .18 & GC.BS.1a & $\begin{array}{l}\text { Bar code start of acquisition on all detector } \\
\text { systems: command with bar code identifier }\end{array}$ & 17 \\
\hline 3.5 .19 & GC.BS.1b & Continuation of .1 : invalid weight & 17 \\
\hline 3.5 .20 & GC.BS.1c & Continuation of .1 : valid weight & 18 \\
\hline 3.5 .21 & GC.BS.1d & Continuation of .1 : invalid content code & 18 \\
\hline 3.5 .22 & GC.BS.1e & Continuation of .1 : valid content code & 18 \\
\hline 3.5 .23 & GC.BS.1f & Completion of .1: comments & 19 \\
\hline 3.5 .24 & GC.STOP.1 & Stop acquisition on one detector system & 19 \\
\hline 3.5.25 & GC.STOP.2 & $\begin{array}{l}\text { Same as .1, but with multiple detector } \\
\text { systems }\end{array}$ & 19 \\
\hline 3.5 .26 & GC.STOP.3 & $\begin{array}{l}\text { Same as } .1 \text {, but with an unknown detector } \\
\text { system }\end{array}$ & 20 \\
\hline 3.5.27 & GC.STOP.4 & Same as .2 , but incorrectly formatted & 20 \\
\hline 3.5 .28 & GC.BSTOP.1 & Stop acquisition on all detector systems & 20 \\
\hline \multicolumn{4}{|c|}{ Spectrum Storage and Analysis Commands } \\
\hline 3.6 .1 & GC.D.1 & $\begin{array}{l}\text { Save spectrum from one detector system, } \\
\text { but command incomplete }\end{array}$ & 21 \\
\hline 3.6 .2 & GC.D.2 & $\begin{array}{l}\text { Same as } .1 \text {, but complete with an unknown } \\
\text { detector system }\end{array}$ & 22 \\
\hline 3.6 .3 & GC.D.3 & Same as .2 , but with only an invalid weight & 22 \\
\hline 3.6 .4 & GC.D.4 & $\begin{array}{l}\text { Same as } .2 \text {, but with only an invalid con- } \\
\text { tent code }\end{array}$ & 22 \\
\hline 3.6 .5 & GC.D.5 & Same as .2 , but with all values valid & 22 \\
\hline 3.6 .6 & GC.D.6 & $\begin{array}{l}\text { Save spectra from multiple detector sys- } \\
\text { tems, but incorrectly formatted }\end{array}$ & 23 \\
\hline 3.6 .7 & GC.D.7 & Same as .6, but correctly formatted & 23 \\
\hline
\end{tabular}




\begin{tabular}{|c|c|c|c|}
\hline 3.6 .8 & GC.BD.1 & $\begin{array}{l}\text { Save spectra from all detector systems, but } \\
\text { command incomplete }\end{array}$ & 23 \\
\hline 3.6 .9 & GC.BD. 2 & $\begin{array}{l}\text { Same as .1, but complete with an invalid } \\
\text { weight }\end{array}$ & 24 \\
\hline 3.6 .10 & GC.BD.3 & $\begin{array}{l}\text { Same as } .2 \text {, but with only an invalid con- } \\
\text { tent code }\end{array}$ & 24 \\
\hline 3.6 .11 & GC.BD.4 & Same as .2 , but with all values valid & 24 \\
\hline 3.6.12 & GC.DA.1 & $\begin{array}{l}\text { Save and analyze spectrum from one detec- } \\
\text { tor system, but command incomplete }\end{array}$ & 24 \\
\hline 3.6.13 & GC.DA.2 & $\begin{array}{l}\text { Same as } .1 \text {, but complete with an unknown } \\
\text { detector system }\end{array}$ & 25 \\
\hline 3.6.14 & GC.DA. 3 & Same as .2 , but with only an invalid weight & 25 \\
\hline 3.6 .15 & GC.DA.4 & $\begin{array}{l}\text { Same as } .2 \text {, but with only an invalid con- } \\
\text { tent code }\end{array}$ & 25 \\
\hline 3.6 .16 & GC.DA.5 & Same as .2 , but with all values valid & 26 \\
\hline 3.6 .17 & GC.DA.6 & $\begin{array}{l}\text { Save spectra from multiple detector sys- } \\
\text { tems, but incorrectly formatted }\end{array}$ & 26 \\
\hline 3.6 .18 & GC.DA.7 & Same as .6, but correctly formatted & 26 \\
\hline 3.6 .19 & GC.BDA.1 & $\begin{array}{l}\text { Save and analyze spectra from all detector } \\
\text { systems, but command incomplete }\end{array}$ & 27 \\
\hline 3.6 .20 & GC.BDA. 2 & $\begin{array}{l}\text { Same as } .1 \text {, but complete with an invalid } \\
\text { weight }\end{array}$ & 27 \\
\hline 3.6 .21 & GC.BDA. 3 & $\begin{array}{l}\text { Same as } .2 \text {, but with only an invalid con- } \\
\text { tent code }\end{array}$ & 27 \\
\hline 3.6 .22 & GC.BDA.4 & Same as .2 , but with all values valid & 28 \\
\hline 3.6 .23 & GC.BKG.1 & $\begin{array}{l}\text { Save a background spectrum from one } \\
\text { detector system }\end{array}$ & 28 \\
\hline 3.6 .24 & GC.BKG.2 & $\begin{array}{l}\text { Save background spectra from multiple } \\
\text { detector systems }\end{array}$ & 28 \\
\hline 3.6 .25 & GC.BKG. 3 & $\begin{array}{l}\text { Same as } .1 \text {, but with an unknown detector } \\
\text { system }\end{array}$ & 29 \\
\hline 3.6 .26 & GC.BKG.4 & Same as .2, but incorrectly formatted & 29 \\
\hline 3.6.27 & GC.A.1 & $\begin{array}{l}\text { Full single-spectrum analysis of a saved } \\
\text { spectrum, but with an unknown spectrum }\end{array}$ & 29 \\
\hline 3.6 .28 & GC.A. 2 & $\begin{array}{l}\text { Same as .1, but with spectrum improperly } \\
\text { identified }\end{array}$ & 29 \\
\hline
\end{tabular}




\begin{tabular}{|c|c|c|c|}
\hline 3.6 .29 & GC.A.3 & $\begin{array}{l}\text { Same as } .1 \text {, but with spectrum properly } \\
\text { identified }\end{array}$ & 30 \\
\hline 3.6.30 & GC.BA.1 & $\begin{array}{l}\text { Summary report-only analysis of a saved } \\
\text { spectrum, but with an unknown spectrum }\end{array}$ & 30 \\
\hline 3.6.31 & GC.BA.2 & $\begin{array}{l}\text { Same as } .1 \text {, but with a set of unknown } \\
\text { spectra }\end{array}$ & 30 \\
\hline 3.6.32 & GC.BA.3 & $\begin{array}{l}\text { Same as .1, but with spectrum improperly } \\
\text { identified }\end{array}$ & 31 \\
\hline 3.6 .33 & GC.BA.4 & Same as .2 , but with known spectra & 31 \\
\hline 3.6 .34 & GC.BA.5 & $\begin{array}{l}\text { Same as } .4 \text {, but with improper abbrevia- } \\
\text { tions }\end{array}$ & 31 \\
\hline 3.6.35 & GC.BA. 6 & Same as .4 , but with proper abbreviations & 32 \\
\hline 3.6 .36 & GC.FBA.1 & $\begin{array}{l}\text { Full single-spectrum and summary report } \\
\text { analysis of a saved spectrum, but with an } \\
\text { unknown spectrum }\end{array}$ & 32 \\
\hline 3.6 .37 & GC.FBA.2 & $\begin{array}{l}\text { Same as } .1 \text {, but with a set of unknown } \\
\text { spectra }\end{array}$ & 32 \\
\hline 3.6.38 & GC.FBA.3 & $\begin{array}{l}\text { Same as .1, but with spectrum improperly } \\
\text { identified }\end{array}$ & 33 \\
\hline 3.6.39 & GC.FBA.4 & Same as .2 , but with known spectra & 33 \\
\hline 3.6 .40 & GC.FBA.5 & $\begin{array}{l}\text { Same as } .4 \text {, but with improper abbrevia- } \\
\text { tions }\end{array}$ & 33 \\
\hline 3.6 .41 & GC.FBA. 6 & Same as .4 , but with proper abbreviations & 34 \\
\hline \multicolumn{4}{|c|}{ Detector Calibration Commands } \\
\hline 3.7 .1 & GC.CBE.1 & $\begin{array}{l}\text { Eu-152 calibration, non-pulsered detector } \\
\text { system, but with an unknown detector } \\
\text { system }\end{array}$ & 34 \\
\hline 3.7 .2 & GC.CBE. 2 & $\begin{array}{l}\text { Same as } .1 \text {, but with a known detector } \\
\text { system }\end{array}$ & 34 \\
\hline 3.7 .3 & GC.PEQE.1 & $\begin{array}{l}\text { Eu- } 152 \text { calibration, pulsered detector sys- } \\
\text { tem, but with an unknown detector system }\end{array}$ & 35 \\
\hline 3.7 .4 & GC.PEQE. 2 & $\begin{array}{l}\text { Same as } .1 \text {, but with a known detector } \\
\text { system }\end{array}$ & 35 \\
\hline 3.7 .5 & GC.PEQEH.1 & $\begin{array}{l}\text { Eu-152 calibration history, pulsered detec- } \\
\text { tor system, but with an unknown detector }\end{array}$ & 35 \\
\hline 3.7 .6 & GC.PEQEH.2a & $\begin{array}{l}\text { Same as } .2 \text {, but with a known detector } \\
\text { system and an improperly formatted ending } \\
\text { date }\end{array}$ & 36 \\
\hline
\end{tabular}




\begin{tabular}{|c|c|c|c|}
\hline 3.7 .7 & GC.PEQEH.2b & Continuation of .1: invalid date & 36 \\
\hline 3.7 .8 & GC.PEQEH.2c & $\begin{array}{l}\text { Continuation of .1: valid date but an inval- } \\
\text { id ending date }\end{array}$ & 36 \\
\hline 3.7 .9 & GC.PEQEH.2d & Continuation of .1 : valid ending date & 37 \\
\hline 3.7 .10 & GC.CBT.1 & $\begin{array}{l}\text { Th- } 228 \text { calibration, non-pulsered detector } \\
\text { system, but with an unknown detector } \\
\text { system }\end{array}$ & 37 \\
\hline 3.7 .11 & GC.CBT.2 & $\begin{array}{l}\text { Same as } .1 \text {, but with a known detector } \\
\text { system }\end{array}$ & 37 \\
\hline 3.7 .12 & GC.PEQT.1 & $\begin{array}{l}\text { Th- } 228 \text { calibration, pulsered detector sys- } \\
\text { tem, but with an unknown detector system }\end{array}$ & 38 \\
\hline 3.7 .13 & GC.PEQT.2 & $\begin{array}{l}\text { Same as } .1 \text {, but with a known detector } \\
\text { system }\end{array}$ & 38 \\
\hline 3.7 .14 & GC.PEQTH.1 & $\begin{array}{l}\text { Th- } 228 \text { calibration history, pulsered detec- } \\
\text { tor system, but with an unknown detector }\end{array}$ & 38 \\
\hline 3.7 .15 & GC.PEQTH.2a & $\begin{array}{l}\text { Same as } .2 \text {, but with a known detector } \\
\text { system and an improperly formatted ending } \\
\text { date }\end{array}$ & 38 \\
\hline 3.7 .16 & GC.PEQTH.2b & Continuation of .1 : invalid date & 39 \\
\hline 3.7 .17 & GC.PEQTH.2c & $\begin{array}{l}\text { Continuation of .1: valid date but an inval- } \\
\text { id ending date }\end{array}$ & 39 \\
\hline 3.7 .18 & GC.PEQTH.2d & Continuation of .1 : valid ending date & 39 \\
\hline \multicolumn{4}{|c|}{ Spectrum Display Commands } \\
\hline 3.8 .1 & GC.DAS.1 & $\begin{array}{l}\text { Generate DAS display of detector system } \\
\text { data, but with an unknown detector system }\end{array}$ & 40 \\
\hline 3.8 .2 & GC.DAS. 2 & $\begin{array}{l}\text { Same as } .1 \text {, but with a known detector } \\
\text { system }\end{array}$ & 40 \\
\hline \multicolumn{4}{|c|}{ Batch Job- and Queue-Related Commands } \\
\hline 3.9 .1 & GC.TYPELOG.1 & $\begin{array}{l}\text { List of screen contents of GIDXC batch } \\
\text { analysis } \log \text { file }\end{array}$ & 40 \\
\hline 3.9 .2 & GC.PRINTLOG.1 & $\begin{array}{l}\text { Print contents of GIDXC batch analysis log } \\
\text { file }\end{array}$ & 41 \\
\hline 3.9 .3 & GC.SHOWQUE.1 & Show status of all batch and print queues & 42 \\
\hline
\end{tabular}




\section{A.4 Blank Summary of Test Cases for GIDXC}

\begin{tabular}{||l|l|l|c|c||}
\hline \hline Section & Test Case & Description & Pass/Fail & Page \\
\hline \hline \multicolumn{3}{|c|}{ GIDXC as a Command at the DCL Prompt } \\
\hline 4.2 .1 & DCL.GIDXC.1 & $\begin{array}{l}\text { Full single-spectrum analysis, but with an } \\
\text { unknown spectrum }\end{array}$ & & 43 \\
\hline 4.2 .2 & DCL.GIDXC.2 & Same as .1, but with a known spectrum & & 43 \\
\hline 4.2 .3 & DCL.GIDXC.3 & Same as .1, but with multiple spectra & & 43 \\
\hline
\end{tabular}




\section{Appendix B. Sample Output Files from GC and GIDXC}

The following sample listings are mentioned in the body of this document. All form feeds within the listings have been preserved as hard page breaks in the interest of faithfully representing the output the user should expect to receive.

\section{B.1 Output from PEQE, Europium-152 Calibration of a Pulsered Detector System}

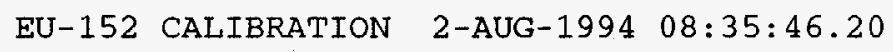

ANALYSIS OF CALIBRATION LINES USING NEW PULSER EQUIVALENTS

\begin{tabular}{|c|c|c|c|c|c|c|c|c|}
\hline CENTROID & WIDTH & ENERGY & AREA & FLAGS & MICROCURRIES & \&ERROR & NET MICROCURRIES & \&ERROR \\
\hline $\begin{array}{r}667.02 \\
1804.56 \\
4026.78 \\
5730.49 \\
7243.42\end{array}$ & $\begin{array}{r}3.3 \\
4.9 \\
7.4 \\
9.2 \\
10.6\end{array}$ & $\begin{array}{r}121.79 \\
344.26 \\
778.88 \\
1112.10 \\
1408.01\end{array}$ & $\begin{array}{r}15587 . \\
16313 . \\
3754 . \\
2895 . \\
3647 .\end{array}$ & $\begin{array}{l}0 \\
0 \\
0 \\
0 \\
0\end{array}$ & $\begin{array}{l}2.053 \mathrm{E}+01 \\
2.294 \mathrm{E}+01 \\
2.429 \mathrm{E}+01 \\
2.496 \mathrm{E}+01 \\
2.564 \mathrm{E}+01\end{array}$ & $\begin{array}{l}0.9 \\
1.0 \\
1.8 \\
2.1 \\
2.0\end{array}$ & & \\
\hline
\end{tabular}


CALIBRATION NUCLIDE DATA

\begin{tabular}{|c|c|c|c|c|c|c|c|c|c|c|c|}
\hline \multicolumn{2}{|c|}{ NUCLIDE } & DATE & TIME & ENERGY & WIDTH & UCURIES & \& ERROR & FLAG & NET UCURIES & \multicolumn{2}{|c|}{ \& ERROR } \\
\hline EU & 152 & $\begin{array}{l}070594 \\
070794 \\
071194 \\
071894 \\
080194 \\
080294\end{array}$ & $\begin{array}{l}0919 \\
1116 \\
0850 \\
1611 \\
1700 \\
0835\end{array}$ & $\begin{array}{l}121.79 \\
121.79 \\
121.79 \\
121.79 \\
121.79 \\
121.79\end{array}$ & $\begin{array}{l}3.4 \\
3.4 \\
3.4 \\
3.4 \\
3.4 \\
3.3\end{array}$ & $\begin{array}{l}2.0658 \mathrm{E}+01 \\
2.0410 \mathrm{E}+01 \\
2.0619 \mathrm{E}+01 \\
2.3313 \mathrm{E}+01 \\
2.0745 \mathrm{E}+01 \\
2.0533 \mathrm{E}+01\end{array}$ & $\begin{array}{l}1.5 \\
1.0 \\
1.4 \\
0.8 \\
0.9 \\
0.9\end{array}$ & $\begin{array}{l}0 \\
0 \\
0 \\
0 \\
0 \\
0\end{array}$ & & & \\
\hline & & $\begin{array}{l}070594 \\
070794 \\
071194 \\
071894 \\
080194 \\
080294\end{array}$ & $\begin{array}{l}0919 \\
1116 \\
0850 \\
1611 \\
1700 \\
0835\end{array}$ & $\begin{array}{l}344.25 \\
344.25 \\
344.25 \\
344.25 \\
344.25 \\
344.25\end{array}$ & $\begin{array}{l}4.9 \\
4.8 \\
4.9 \\
4.9 \\
5.0 \\
4.9\end{array}$ & $\begin{array}{l}2.3153 \mathrm{E}+01 \\
2.3038 \mathrm{E}+01 \\
2.2954 \mathrm{E}+01 \\
2.5262 \mathrm{E}+01 \\
2.3153 \mathrm{E}+01 \\
2.2944 \mathrm{E}+01\end{array}$ & $\begin{array}{l}0.9 \\
0.6 \\
0.6 \\
1.0 \\
1.2 \\
1.0\end{array}$ & $\begin{array}{l}0 \\
0 \\
0 \\
0 \\
0 \\
0\end{array}$ & & & \\
\hline & & $\begin{array}{l}070594 \\
070794 \\
071194 \\
071894 \\
080194 \\
080294\end{array}$ & $\begin{array}{l}0919 \\
1116 \\
0850 \\
1611 \\
1700 \\
0835\end{array}$ & $\begin{array}{l}778.90 \\
778.90 \\
778.89 \\
778.89 \\
778.89 \\
778.88\end{array}$ & $\begin{array}{l}7.3 \\
7.3 \\
7.6 \\
7.2 \\
7.6 \\
7.4\end{array}$ & $\begin{array}{l}2.4169 \mathrm{E}+01 \\
2.4408 \mathrm{E}+01 \\
2.4161 \mathrm{E}+01 \\
2.5961 \mathrm{E}+01 \\
2.4921 \mathrm{E}+01 \\
2.4291 \mathrm{E}+01\end{array}$ & $\begin{array}{l}1.7 \\
1.6 \\
1.4 \\
1.3 \\
2.0 \\
1.8\end{array}$ & $\begin{array}{l}0 \\
0 \\
0 \\
0 \\
0 \\
0\end{array}$ & & & \\
\hline & & $\begin{array}{l}070594 \\
070794 \\
071194 \\
071894 \\
080194 \\
080294\end{array}$ & $\begin{array}{l}0919 \\
1116 \\
0850 \\
1611 \\
1700 \\
0835\end{array}$ & $\begin{array}{l}1112.07 \\
1112.08 \\
1112.09 \\
1112.08 \\
1112.07 \\
1112.10\end{array}$ & $\begin{array}{l}9.4 \\
9.3 \\
9.3 \\
9.2 \\
9.3 \\
9.2\end{array}$ & $\begin{array}{l}2.5513 E+01 \\
2.5319 E+01 \\
2.5024 E+01 \\
2.5469 E+01 \\
2.6033 E+01 \\
2.4958 E+01\end{array}$ & $\begin{array}{l}2.6 \\
1.7 \\
1.6 \\
1.7 \\
2.0 \\
2.1\end{array}$ & $\begin{array}{l}0 \\
0 \\
0 \\
0 \\
0 \\
0\end{array}$ & & & \\
\hline & & $\begin{array}{l}070594 \\
070794 \\
071194 \\
071894 \\
080194 \\
080294\end{array}$ & $\begin{array}{l}0919 \\
1116 \\
0850 \\
1611 \\
1700 \\
0835\end{array}$ & $\begin{array}{l}1408.02 \\
1408.02 \\
1408.01 \\
1408.03 \\
1408.03 \\
1408.01\end{array}$ & $\begin{array}{l}10.5 \\
10.8 \\
10.5 \\
10.5 \\
10.6 \\
10.6\end{array}$ & $\begin{array}{l}2.5417 \mathrm{E}+01 \\
2.6161 \mathrm{E}+01 \\
2.5445 \mathrm{E}+01 \\
2.6874 \mathrm{E}+01 \\
2.5824 \mathrm{E}+01 \\
2.5636 \mathrm{E}+01\end{array}$ & $\begin{array}{l}1.9 \\
1.5 \\
1.8 \\
1.3 \\
1.8 \\
2.0\end{array}$ & $\begin{array}{l}0 \\
0 \\
0 \\
0 \\
0 \\
0\end{array}$ & & & \\
\hline & & $\begin{array}{l}070594 \\
070794 \\
071194 \\
071894 \\
080194 \\
080294\end{array}$ & $\begin{array}{l}0919 \\
1116 \\
0850 \\
1611 \\
1700 \\
0835\end{array}$ & & & & & & $\begin{array}{l}2.3259 E+01 \\
2.3038 E+01 \\
2.2954 E+01 \\
2.5421 E+01 \\
2.3153 E+01 \\
2.3112 E+01\end{array}$ & & $\begin{array}{l}0.8 \\
0.6 \\
0.6 \\
0.8 \\
1.2 \\
0.9\end{array}$ \\
\hline
\end{tabular}


SPECTROMETER CALIBRATION DATA

\begin{tabular}{llllcl} 
DATE & TIME & ZERO & GAIN & LOW PULSER EQ. & HIGH PULSER EQ. \\
\hline 070594 & 0919 & -37.33 & 0.195 & 147.59 & 1414.84 \\
070794 & 1116 & -39.64 & 0.196 & 147.60 & 1414.89 \\
071194 & 0850 & -41.91 & 0.196 & 147.58 & 1414.84 \\
071894 & 1611 & -47.17 & 0.196 & 147.77 & 1415.07 \\
080194 & 1700 & -47.09 & 0.196 & 147.70 & 1414.95 \\
080294 & 0835 & -44.36 & 0.196 & 147.58 & 1414.74
\end{tabular}

\section{B.2 A Sample Europium-152 Calibration History Listing From PEQEH}

QUALITY CONTROL DATA SHEET

$$
\begin{aligned}
& \text { DETECTOR: AI } \\
& \text { FOR } \text { PERIOD } \\
& 010194 \text { TO } 060194
\end{aligned}
$$

\begin{tabular}{cccrrll} 
NUCLIDE & DATE & ENERGY & WIDTH & AREA & UCURIE & 8ERR \\
EU 152 & 042794 & 121.79 & 3.39 & 73643 & $1.66 \mathrm{E}+01$ & 1.00 \\
& 050594 & & 3.39 & 94582 & $1.76 \mathrm{E}+01$ & 0.60 \\
& 050594 & & 3.39 & 11061 & $1.74 \mathrm{E}+01$ & 1.26 \\
& 052594 & & 3.36 & 5445 & $5.71 \mathrm{E}+00$ & 2.09 \\
& 052594 & & 3.43 & 19793 & $5.69 \mathrm{E}+00$ & 1.46 \\
& 060194 & & 3.30 & 9335 & $2.30 \mathrm{E}+01$ & 1.17 \\
\hline AVERAGES: & & & 3.38 & 35643 & $1.43 \mathrm{E}+01$ & \\
STD DEV: & & & 0.04 & 38412 & $7.06 \mathrm{E}+00$ & \\
EU 152 & 042794 & 344.25 & 4.96 & 48242 & $1.16 \mathrm{E}+01$ & 0.67 \\
& 050594 & & 4.98 & 61749 & $1.22 \mathrm{E}+01$ & 0.75 \\
& 050594 & & 4.91 & 7304 & $1.22 \mathrm{E}+01$ & 1.87 \\
& 052594 & & 5.00 & 5796 & $6.49 \mathrm{E}+00$ & 1.36 \\
& 052594 & & 4.90 & 20896 & $6.42 \mathrm{E}+00$ & 0.72 \\
& 060194 & & 4.90 & 9711 & $2.56 \mathrm{E}+01 \#$ & 1.52 \\
\hline AVERAGES: & & & 4.94 & 25617 & $1.24 \mathrm{E}+01$ & \\
STD DEV: & & & 0.04 & 23753 & $7.00 \mathrm{E}+00$ & \\
EU 152 & 042794 & 778.89 & 7.34 & 9986 & $1.11 \mathrm{E}+01$ & 1.36 \\
& 050594 & & 7.54 & 13112 & $1.20 \mathrm{E}+01$ & 1.38
\end{tabular}




\begin{tabular}{|c|c|c|c|c|c|c|}
\hline & $\begin{array}{l}050594 \\
052594 \\
052594 \\
060194\end{array}$ & & $\begin{array}{l}7.47 \\
7.14^{*} \\
7.43 \\
7.32\end{array}$ & $\begin{array}{l}1555 \\
1264 \\
4716 \\
2102\end{array}$ & $\begin{array}{l}1.20 \mathrm{E}+01 \\
6.52 \mathrm{E}+00 \\
6.67 \mathrm{E}+00 \\
2.55 \mathrm{E}+01\end{array}$ & $\begin{array}{l}2.79 \\
3.07 \\
2.35 \\
2.59\end{array}$ \\
\hline $\begin{array}{l}\text { AVERAGES: } \\
\text { STD DEV: }\end{array}$ & & & $\begin{array}{l}7.37 \\
0.14\end{array}$ & $\begin{array}{l}5456 \\
4974\end{array}$ & $\begin{array}{l}1.23 \mathrm{E}+01 \\
6.95 \mathrm{E}+00\end{array}$ & \\
\hline EU 152 & $\begin{array}{l}042794 \\
050594 \\
050594 \\
052594 \\
052594 \\
050194\end{array}$ & 1112.11 & $\begin{array}{l}9.01 \\
9.07 \\
9.68 \\
9.19 \\
9.47 \\
9.11\end{array}$ & $\begin{array}{r}7622 \\
9777 \\
1138 \\
993 \\
3732 \\
1656\end{array}$ & $\begin{array}{l}1.12 \mathrm{E}+01 \\
1.19 \mathrm{E}+01 \\
1.17 \mathrm{E}+01 \\
6.82 \mathrm{E}+00 \\
7.03 \mathrm{E}+00 \\
2.68 \mathrm{E}+01\end{array}$ & $\begin{array}{l}1.56 \\
1.72 \\
3.30 \\
3.44 \\
1.80 \\
3.15\end{array}$ \\
\hline $\begin{array}{l}\text { AVERAGES: } \\
\text { STD DEV: }\end{array}$ & & & $\begin{array}{l}9.26 \\
0.26\end{array}$ & $\begin{array}{l}4153 \\
3719\end{array}$ & $\begin{array}{l}1.26 \mathrm{E}+01 \\
7.33 \mathrm{E}+00\end{array}$ & \\
\hline EU 152 & $\begin{array}{l}042794 \\
050594 \\
050594 \\
052594 \\
052594 \\
060194\end{array}$ & 1408.01 & $\begin{array}{l}10.70 \\
10.94 \\
10.21 \\
10.47 \\
10.75 \\
10.49\end{array}$ & $\begin{array}{r}9484 \\
12056 \\
1391 \\
1214 \\
4503 \\
2076\end{array}$ & $\begin{array}{l}1.14 \mathrm{E}+01 \\
1.20 \mathrm{E}+01 \\
1.17 \mathrm{E}+01 \\
6.80 \mathrm{E}+00 \\
6.92 \mathrm{E}+00 \\
2.74 \mathrm{E}+01\end{array}$ & $\begin{array}{l}1.11 \\
1.12 \\
2.86 \\
3.04 \\
1.61 \\
2.31\end{array}$ \\
\hline $\begin{array}{l}\text { AVERAGES: } \\
\text { STD DEV: }\end{array}$ & & & $\begin{array}{r}10.59 \\
0.26\end{array}$ & $\begin{array}{l}5121 \\
4604\end{array}$ & $\begin{array}{l}1.27 \mathrm{E}+01 \\
7.57 \mathrm{E}+00\end{array}$ & \\
\hline
\end{tabular}


QUALITY CONTROL DATA SHEET

DETECTOR: A.1

FOR PERIOD

010194 TO 060194

\begin{tabular}{llll} 
NUCLIDE & DATE & NET_UCURIE & \&ERROR \\
\hline EU 152 & 042794 & $1.156 \mathrm{E}+01$ & 0.56 \\
& 050594 & $1.214 \mathrm{E}+01$ & 0.57 \\
& 050594 & $1.207 \mathrm{E}+01$ & 1.33 \\
& 052594 & $6.535 \mathrm{E}+00$ & 1.14 \\
& 052594 & $6.429 \mathrm{E}+00$ & 0.69 \\
& 060194 & $2.589 \mathrm{E}+01$ * & 1.14 \\
\hline
\end{tabular}

AVERAGE:

1. $24 \mathrm{E}+01$
7. $11 \mathrm{E}+00$ 
QUALITY CONTROL DATA SHEET

DETECTOR: $A 1$

FOR PERIOD

010194 TO 060194

\begin{tabular}{lcccccc} 
DATE & ENERGY ZERO & ENERGY_B & WIDTH_A & LOW PEQ & HIGH PEQ & COMMENTS \\
042794 & -17.362 & 0.194 & $2.877^{2}$ & 147.40 & 1414.46 & \\
050594 & -17.049 & 0.194 & 2.862 & 145.54 & 1412.78 & \\
050594 & -17.576 & 0.194 & 2.945 & 145.56 & 1412.82 & \\
052594 & -19.606 & 0.195 & 2.901 & 147.63 & 1414.78 & \\
052594 & -19.887 & 0.195 & 2.832 & 147.64 & 1414.82 & \\
060194 & $-40.947 \#$ & 0.196 & 2.791 & 147.60 & 1414.82 & \\
\hline AVERAGES & -22.071 & 0.195 & 2.868 & 146.90 & 1414.08 & \\
STD DEV & 9.325 & 0.001 & 0.054 & 1.04 & 1.00 &
\end{tabular}

NOTE:

1$.$) * Indicates a lower control limit (warning) value that is out of statistical agreement with$ QA results:

$$
\begin{aligned}
& >3 \text { std. dev. for "Energy zero". "Width_A" and "Energy._B" values. } \\
& >5 \text { std. dev. for "Net Ucuries" and "Pulser" values. }
\end{aligned}
$$

2.) \# Indicates and uppper control limit (action) value that is out of statistical agreement with QA results:

$$
>4 \text { std. dev. For "Energy zero", "Width_A" and "Energy_B" values. }
$$

3.) The $>6$ std. dev. for "Net Ucuries" and "Pulser" values.

4. Due ca results = (average value - current value/sta. dev.).

it was necessary to set the control limit criteria above the usual two and three standard deviation criteria.

\section{B.3 Summary Report for a Set of Spectra}

$* \star * * * * * * * * *$ SWEPF BARREL MONITOR GAMMA-RAY SPECTROMETERY SUMMARY REPORT V. O1.00 - FINAL REPORT - GENERATED $3-$ AUG $-94 * \star * * \star * * * * * *$

SAMPLE NAME: Barrel $023277:$ : \#4

SAMPLE ID(S): A1460613110 A2460613110 A3460613110 A4460613110

SAMPLE COLLECTION (DATE/TIME): 60694/1311.

SAMPLE COUNTED (DATE/TIME): $60694 / 1311$

SAMPLE QUANTITY: $6.30000 \mathrm{E}+04$ QUANTITY UNITS: $G$
OPERATOR:

APPROVED BY:

COMMENTS: 
GRAND WEIGHTED AVERAGE ISOTOPIC MASS RATIOS (8) FOR ALL DETECTORS

$\begin{array}{llll}\text { PU-241 to PU-239: } & 1.78+1- & 0.06) \mathrm{E}-01 \\ \mathrm{AM}-241 \text { to } \mathrm{PU}-239: & 3.19+/- & 0.09) \mathrm{E}-01\end{array}$

PU-238 to PU-239: ( $1.2+1-\quad 0.4) E-02$

ISOTOPIC MASS RATIOS ( $z$ ) OBSERVED BY DETECTOR \# 1 (AND POSSIBLY OTHERS) (THE STANDARD SET CAN BE CALCULATED)

PU-241 to PU-239: ( $1.78+1-0.06)$ E-01 (OBSERVED BY DETECTOR(S) $1,2,3,4$ AM-241 to PU-239: ( $3.19+1-\quad 0.09)$ E-01 (OBSERVED BY DETECTOR(S) $1,2,3,4$ $\begin{array}{ll}\text { PU-240 to PU-239: RATIO NOT DETERMINABLE (OBSERVED BY DETECTOR(S) } 1 \\ \text { BECAUSE } & \text { THE FIRST LINE USED HAS A NON-TRUE-POSITIVE ACTIVITY } \\ \text { PU-238 tO } & \end{array}$

PU-238 to PU-239: RATIO NOT DETERMINABLE (OBSERVED BY DETECTOR(S) 1

-235 tO PU-239: RATIO NOT DETERMINABLE (OBSERVED BY DETECTOR(S) 1

BECAUSE THE FIRST LINE USED HAS A NON-TRUE-POSITIVE ACTIVITY

AM-241 to U -235: RATIO NOT DETERMINABLE (OBSERVED BY DETECTOR (S) 1
BECAUSE

ISOTOPIC MASS RATIOS ( $($ ) OBSERVED BY DETECTOR \# 2 (AND POSSIBLY OTHERS) (THE STANDARD SET CAN BE CALCULATED)

PU-240 to PU-239: RATIO NOT DETERMINABLE (OBSERVED BY DETECTOR(S) 2 BECAUSE THE FIRST LINE USED HAS A NON-TRUE-POSITIVE ACTIVITY

ISOTOPIC MASS RATIOS ( 8 ) OBSERVED BY DETECTOR \# 2 (AND POSSIBLY OTHERS)

IONLY A RESTRICTED SET CAN BE CALCULATED - EXCESSIVE URANIUM IS LIKELY PRESENT

PU-238 to PU-239: ( $1.2+/-\quad 0.4$ ) E-02 (OBSERVED BY DETECTOR(S) 2

ISOTOPIC MASS RATIOS ( 8 ) OBSERVED BY DETECTOR \# 2 (AND POSSIBLY OTHERS) (THE STANDARD SET CAN BE CALCULATED)

U -235 to PU-239: RATIO NOT DETERMINABLE IOBSERVED BY DETECTOR(S) 2 BECAUSE THE FIRST LINE USED HAS A NON-TRUE-POSITIVE ACTIVITY

AM-241 to U -235: RATIO NOT DETERMINABLE IOBSERVED BY DETECTOR(S) 2
BECAUSE
THE SECOND LINE USED HAS A NON-TRUE-POSITIVE ACTIVITY

ISOTOPIC MASS RATIOS ( 8 ) OBSERVED BY DETECTOR \# 3 (AND POSSIBLY OTHERS) (THE STANDARD SET CAN BE CALCULATED)

PU-240 to PU-239: RATIO NOT DETERMINABLE (OBSERVED BY DETECTOR(S) 3 )

$\begin{array}{lll}\text { BECAUSE } & \text { THE FIRST LINE USED HAS A NON-TRUE-POSITIVE ACTIVITY } \\ \text { PU-238 tO PU-239: } & \text { RATIO NOT DETERMINABLE (OBSERVED BY DETECTOR(S) } 3\end{array}$

BECAUSE THE FIRST LINE USED HAS A NON-TRUE-POSITIVE ACTIVITY

U -235 to PU-239: RATIO NOT DETERMINABLE (OBSERVED BY DETECTOR(S) 3 BECAUSE THE FIRST LINE USED HAS A NON-TRUE-POSITIVE ACTIVITY

AM-241 to U -235: RATIO NOT DETERMINABLE COBSERVED BY DETECTOR(S) BECAUSE THE SECOND LINE USED HAS A NON-TRUE-POSITIVE ACTIVITY 
ISOTOPIC MASS RATIOS ( 8 ) OBSERVED BY DETECTOR \# 4 (AND POSSIBLY OTHERS) (THE STANDARD SET CAN BE CALCULATED)

PU-240 to PU-239: RATIO NOT DETERMINABLE (OBSERVED BY DETECTOR(S) 4 , BECAUSE THE FIRST LINE USED HAS A NON-TRUE-POSITIVE ACTIVITY PU-238 to PU-239: RATIO NOT DETERMINABLE (OBSERVED BY DETECTOR(S) BECAUSE THE FIRST LINE USED HAS A NON-TRUE-POSITIVE ACTIVITY

U -235 tO PU-239: RATIO NOT DETERMINABLE (OBSERVED BY DETECTOR (S) BECAUSE 235 . THE FIRST LINE USED HAS A NON-TRUE-POSITIVE ACTIVITY

AM-241 to U -235: RATIO NOT DETERMINABLE (OBSERVED BY DETECTOR (S)
BECAUSE

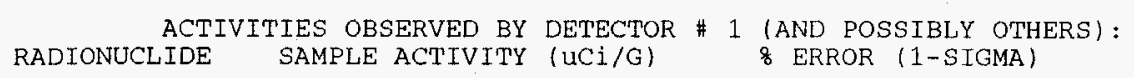

$\begin{array}{llr}92 \mathrm{U} & 235 & 1.522 \mathrm{E}-05 \\ 92 \mathrm{U} & 233 & 1.379 \mathrm{E}-01 \\ 94 \mathrm{PU} & 241 & 2.406 \mathrm{E}+02 \\ 94 \mathrm{PU} & 240 & -5.217 \mathrm{E}+00 \\ 94 \mathrm{PU} & 239 & 7.858 \mathrm{E}+01 \\ 95 \mathrm{AM} & 241 & 9.815 \mathrm{E}+00\end{array}$

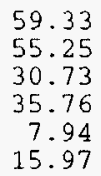

TRU RADIONUCLIDES AND OTHERS $>5 \%$ OF PU-239 OBSERVED BY DETECTOR (S)

ACTIVITIES OBSERVED BY DETECTOR \# 2 (AND POSSIBLY OTHERS):
RADIONUCLIDE

$\begin{array}{lllll}94 \mathrm{PU} & 241 & 4.776 \mathrm{E}+02 & 4.49 & 2,3,4 \\ 94 \mathrm{PU} & 239 & 1.698 \mathrm{E}+02 & 0.54 & 2,3 \\ 95 \mathrm{AM} & 241 & 2.272 \mathrm{E}+01 & 5.50 & 2,4\end{array}$

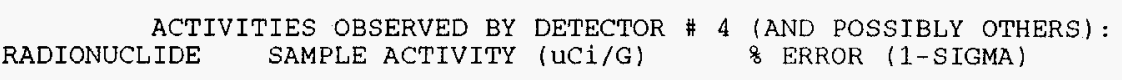
$94 \mathrm{PU} \quad 239$<smiles>[Y][Y][V]</smiles>

TRU RADIONUCLIDES AND OTHERS > 5\% OF PU-239 BSERVED BY DETECTOR(S)

4

TRU RADIONUCLIDES AND OTHERS > 58 OF PU-239 OBSERVED BY DETECTOR(S

\section{B.4 PAN\$RATIOS File for the above Set of Spectra}

; Mass Fractions and Ratios for Container 023277

; Generated 3-AUG-94 by BATCH_GIDXC_SUMMARY V. 01.00

PU_MASS_FRACTIONS
$2389.4744 \mathrm{E}-03$
$2.7541 \mathrm{E}-03$
$239-7.9412 \mathrm{E}-01$
$4.5056 \mathrm{E}-03$
$5.8210 \mathrm{E}-02$
$241 \quad 1.4117 \mathrm{E}-01$
$.0000 \mathrm{E}+00$
$2.4000 \mathrm{E}-04 \quad 0.0000 \mathrm{E}+00$

END

PU_MASS_RATIOS
238
1. 1931E-02
$3.4674 \mathrm{E}-03$ 


$\begin{array}{lrl}240 & 0.0000 \mathrm{E}+00 & 0.0000 \mathrm{E}+00 \\ 241 & 1.7777 \mathrm{E}-01 & 6.2467 \mathrm{E}-03 \\ 242 & 0.0000 \mathrm{E}+00 & 0.0000 \mathrm{E}+00 \\ \text { END } & \\ \text { AM_PU_MASS_RATIOS } & \\ \text { END } 241 & 3.1857 \mathrm{E}-01 & 9.3321 \mathrm{E}-03 \\ \text { U_PU_MASS_RATIOS } & \\ \text { END } 235 & 0.0000 \mathrm{E}+00 & 0.0000 \mathrm{E}+00 \\ \text { AM_U_MASS_RATIOS } & \\ \text { END } & 0.0000 \mathrm{E}+00 & 0.0000 \mathrm{E}+00\end{array}$

\section{B.5 Full Single Spectrum Output for a Spectrum from the above Set}

$\star \star * \star * * * * * * * *$ SWEPP. BARREL MONITOR GAMMA-RAY SPECTROMETERY SUMMARY REPORT V $01.00-$ MASS RATIOS - GENERATED $3-$ AUG $-94 * * * * * * * * * * *$

SAMPLE NAME: Barrel 023277 : \#4

SAMPLE ID: $\quad$ A1460613110 $\quad 00000$

SAMPLE COLLECTION (DATE/TIME): 60694/1311

SAMPLE COUNTED (DATE/TIME): 60694/1311

SAMPLE QUANTITY : $6.30000 E+04$ QUANTITY UNITS:

ATTENUATION TABLE USED: 02

COMPUTED AREA FOR LINE AT: 778.9 IS NOT TRUE-POSITIVE

$X$-EFFECTIVE FOR EU-152 WILL BE SET TO ZERO

COMPUTED AREA FOR LINE AT: 163.4 IS NOT TRUE-POSITIVE

$X$ - AND T-EFFECTIVE FOR U-235 WILL BE SET TO ZERO

FOR NUCLIDE PU-239:

$\mathrm{X}$-EFFECTIVE $=1 \quad 8 .+1-\quad 3,1 \mathrm{E}+00 \mathrm{CM}$

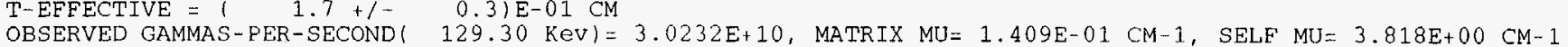


OBSERVED GAMMAS-PER-SECOND $(203.55 \mathrm{KeV})=5.4430 \mathrm{E}+10$, MATRIX MU $=1.199 \mathrm{E}-01 \mathrm{CM}-1, \quad$ SELF MU $=1.257 \mathrm{E}+00 \mathrm{CM}-1$ OBSERVED GAMMAS-PER-SECOND $(345.01 \mathrm{KeV})=7.6962 \mathrm{E}+10$, MATRIX MU $=9.902 \mathrm{E}-02 \mathrm{CM}-1$, SELF MU $=3.912 \mathrm{E}-01 \mathrm{CM}-1$ OBSERVED GAMMAS-PER-SECOND $(413.7 .1 \mathrm{KeV})=7.9925 \mathrm{E}+10$, MATRIX MU $=9.228 \mathrm{E}-02 \mathrm{CM}-1, \quad S E L F$ MU $=2.731 \mathrm{E}-01 \mathrm{CM}-1$

AVERAGE STANDARD DEVIATION OF OBSERVED GAMMAS-PER-SECOND FROM THE PREDICTED VALUE $=1.70 \mathrm{E}+09$

FOR NUCLIDE EU-152

X-EFFECTIVE $=0$ CM (I.E., NO CORRECTION

BECAUSE OF THE NON-TRUE-POSITIVE LINE AREA NOTED ABOVE

FOR NUCLIDE U-235:

$X$-EFFECTIVE $=0$ CM (I.E., NO CORRECTION)

BECAUSE OF THE NON-TRUE-POSITIVE LINE AREA NOTED ABOVE

ISOTOPIC MASS RATIOS $(8)$

(THE STANDARD SET CAN BE CALCULATED)

PU-241 (148.54 keV) to PU-239(144.20 keV): ( $1.93+/-0.17)$ E-01

AM-241 (146.55 keV) to PU-239 (144.20 keV): ( $2.9+/-\quad 1.0)$ E-01

AM-241 (125.29 keV) to PU-239(129.30 keV): $\begin{array}{r}- \text { USED IN THE FOLLOWING WEIGHTED AVERAGE } \\ 3.23+/-\quad 0.19) \text { E-01 }\end{array}$

PU-240 (160.31 keV) to PU-239 (161.48 keV): (RATIO NOT DETERMINABLE)

THE FIRST LINE USED HAS A NON-TRUE-POSITIVE ACTIVITY

PU-238 (152.72 keV) to PU-239 (144.20 keV):

RATIO NOT DETERMINABLE)

- THE FIRST LINE USED HAS A NON-TRUE-POSITIVE ACTIVITY

U $-235(185.72 \mathrm{keV})$ to PU-239 $(203.55 \mathrm{keV})$ :

U $-235(185.72 \mathrm{keV})$ to PU-239 (129.30 keV):

U $-235(163.36 \mathrm{keV})$ to $\mathrm{PU}-239(161.48 \mathrm{keV})$ : - THE FIRST LINE USED HAS A NON-TRUE-POSITIVE ACTIVITY

- THE FIRST LINE USED HAS A NON-TRUE-POSITIVE ACTIVITY (RATIO NOT DETERMINABLE)

- THE FIRST LINE USED HAS A NON-TRUE-POSITIVE ACTIVITY

AM-241 (169.56 keV) to U $-235(163.36 \mathrm{keV})$

(RATIO NOT DETERMINABLE)

- THE SECOND LINE USED HAS A NON-TRUE-POSITIVE ACTIVITY 
ISOTOPIC MASS RATIOS ( $(8)$

(THE STANDARD SET CAN BE CALCULATED)

PU-238 (152.72 keV) to PU-241 (148.54 keV):

$$
\text { 5. }+1-\quad 3.1 \mathrm{E}+00
$$

$x, t$ corrected numerator gps $=0.3966 \mathrm{E}+10$ THE FIRST LINE USED $\exp \left(\mathrm{mu}^{*} \mathrm{x}\right)=0.2988 \mathrm{E}+01$, $\exp (\mathrm{smu} * \mathrm{t})=0.1515 \mathrm{E}+01$, INTCOR subtraction $=0.0000 \mathrm{E}+00$ uncor

$x, t$ correction $=0.0000 \mathrm{E}+00$ uncorrected denominator $\mathrm{gps}=0.1060 \mathrm{E}+12$, error $=0.4997 \mathrm{E}+10$

PU-241 (148.54 keV) to PU-239 (144.20 keV): ( $1.93+/-0.17)$ E-01 int $=0.1565 \mathrm{E}+01$, INTOR subtraction $=0.0000 \mathrm{E}+00$ uncorrected numerator $g \mathrm{ps}=0.106 \mathrm{E}+12$, error $=0.4997 \mathrm{E}+10$

$x, t$ corrected denominator gps $=0.1552 \mathrm{E}+12$, error $=0.1552 \mathrm{E}+11$ action $=0.0000 \mathrm{E}+00$ uncorrected denominator $(\mathrm{s}=0.3124 \mathrm{E}+11$, error $=0.2195 \mathrm{E}+10$

AM-241 (146.55 keV) to PU-239 (144.20 keV): ( $2.9+1-\quad 1.0)$ E-01

$x, t$ corrected numerator gps $=0.6481 \mathrm{E}+11$, error $=0.2267 \mathrm{E}+11$ $\exp \left(m u^{*} x\right)=0.3039 \mathrm{E}+01, \exp (\mathrm{smu} * t)=0.1591 \mathrm{E}+01, \quad$ INTCOR subtraction $=0.8273 \mathrm{E}+10$ uncorrected numerator gps $=0.1340 \mathrm{E}+11$, error $=0.1656 \mathrm{E}+10$

$x, t$ corrected denominator $\mathrm{gps}=0.1552 \mathrm{E}+12$, error $=0.1552 \mathrm{E}+11$. uncorrected denominator gos $=0.3124 \mathrm{E}+11$, INTCOR subera

PU-240 (160.31 keV) to PU-239 (161.48 keV): (RATIO NOT DETERMINABLE)

作

exp $\left(m u^{*} x\right)=0.2936 \mathrm{E}+01, \exp (\mathrm{smu} * \mathrm{t})=0.1436 \mathrm{E}+01$, INTCO $\exp (m u(x)=0.2936 \mathrm{E}+01$, $\exp (\operatorname{smu} * \mathrm{~L})=0.1436 \mathrm{E}+01$, INTCOR subtraction $=0.1518 \mathrm{E}+11$ $t$ corrected denominator gps $=0.1728 \mathrm{E}+12$, error $=0.2183 \mathrm{E}+11$

$\exp \left(m^{*} x\right)=0.2928 \mathrm{E}+01, \exp \left(\operatorname{smu}^{*} t\right)=0.1426 \mathrm{E}+01$, INTCOR subtraction $=0.0000 \mathrm{E}+00$ uncorrected denominator gps $=0.4139 \mathrm{E}+11$, error $=0.4047 \mathrm{E}+10$

ISOTOPIC MASS RATIOS (o)

ONLY A RESTRICTED SET CAN BE CALCULATED - EXCESSIVE URANIUM IS LIKELY PRESENT)

PU-240 (160.31 keV) to PU-239 (161.48 keV): (RATIO NOT DETERMINABLE)

$x, t$ corrected numerator gps $=0.4556 \mathrm{E}+11$, error $=0.1341 \mathrm{E}+11$

$\exp \left(m u^{*} x\right)=0.2936 \mathrm{E}+01, \exp \left(\mathrm{smu}^{*} t\right)=0.1436 \mathrm{E}+01, \operatorname{INTCOR}$ subtraction $=0.1518 \mathrm{E}+11$ uncorrected numerator gps $=0.1080 \mathrm{E}+11$, error $=0.1209 \mathrm{E}+10$

$x, t$ corrected denominator $g p s=0.1728 \mathrm{E}+12$, error $=0.2183 \mathrm{E}+11$

$\exp \left(m^{*} x\right)=0.2928 E+01, \exp \left(\mathrm{smu}^{*} t\right)=0.1426 \mathrm{E}+01$, INTCOR subtraction $=0.0000 \mathrm{E}+00$

uncorrected denominator gps $=0.4139 \mathrm{E}+11$, error $=0.4047 \mathrm{E}+10$

PU-241 (148.54 keV) to PU-239.(161.48 keV): ( $1.7+1-0.2)$ E-01 
$x, t$ corrected numerator gps $=0.5013 \mathrm{E}+12$, error $=0.4379 \mathrm{E}+11$ $\exp \left(m u^{*} x\right)=0.3021 \mathrm{E}+01, \exp \left(\mathrm{smu}^{*} \mathrm{t}\right)=0.1565 \mathrm{E}+01, \operatorname{INTCOR}$ subtraction $=0.0000 \mathrm{E}+00$ uncorrected numerator gps $=0.1060 \mathrm{E}+12$, error $=0.4997 \mathrm{E}+10$

$x, t$ corrected denominator gps $=0.1728 \mathrm{E}+12$, error $=0.2183 \mathrm{E}+11$

$\exp \left(\mathrm{mu}^{*} \mathrm{X}\right)=0.2928 \mathrm{E}+01, \exp \left(\mathrm{smu}^{*} \mathrm{t}\right)=0.1426 \mathrm{E}+01$, INTCOR subtraction=0.0000E +00 uncorrected denominator $\mathrm{gps}=0.4139 \mathrm{E}+11$, error $=0.4047 \mathrm{E}+10$

AM-241 (125.29 keV) to PU-239 (129.30 keV): ( $3.23+/-0.19)$ E-01

$\mathrm{x}, \mathrm{t}$ corrected numerator gps $=0.3600 \mathrm{E}+11$, error $=0.2702 \mathrm{E}+10$ $\exp \left(m u^{*} x\right)=0.3255 \mathrm{E}+01, \exp \left(\mathrm{smu}^{*} t\right)=0.1877 \mathrm{E}+01$, INTCOR subtraction=0.5185E+09 uncorrected numerator gps $=0.5892 \mathrm{E}+10$, error $=0.2249 \mathrm{E}+09$

$\mathrm{x}, \mathrm{t}$ corrected denominator $\mathrm{gps}=0.1826 \mathrm{E}+12$, error $=0.1197 \mathrm{E}+11$

$\exp \left(\mathrm{mu}^{*} \mathrm{X}\right)=0.3209 \mathrm{E}+01, \exp \left(\mathrm{smu}^{*} \mathrm{t}\right)=0.1882 \mathrm{E}+01$, INTCOR subt raction $=0.0000 \mathrm{E}+00$ uncorrected denominator gps $=0.3023 \mathrm{E}+11$, error $=0.6112 \mathrm{E}+09$

U $-235(163.36 \mathrm{keV})$ to PU-239 (161.48 keV): (RATIO NOT DETERMINABLE)

- THE FIRST LINE USED HAS AN ACTIVITY BELOW DETECTION LIMITS

$x, t$ corrected numerator gps $=-.2626 \mathrm{E}+06$, error $=0.3730 \mathrm{E}+06$ $\exp \left(m u^{*} x\right)=0.2915 E+01, \exp \left(s^{*} t\right)=0.1409 E+01, \quad$ INTCOR subtraction $=0.0000 E+00$ uncorrected numerator gps $=-.6391 \mathrm{E}+05$, error $=-.9065 \mathrm{E}+05$

$x, t$ corrected denominator gps $=0.1728 \mathrm{E}+12$, error $=0.2183 \mathrm{E}+11$

$\exp \left(\mathrm{mu}^{*} \mathrm{X}\right)=0.2928 \mathrm{E}+01, \exp \left(\mathrm{smu}^{*} t\right)=0.1426 \mathrm{E}+01$, INTCOR subtraction $=0.0000 \mathrm{E}+00$

uncorrected denominator gps $=0.4139 \mathrm{E}+11$, error $=0.4047 \mathrm{E}+10$

ISOTOPIC MASS RATIOS $(8)$

(ONLY A RESTRICTED SET CAN BE CALCULATED - EXCESSIVE AMERICIUM IS LIKELY PRESENT)

PU-240 (160.31 keV) tO PU-239 (129.30 keV): (RATIO NOT DETERMINABLE)

$\mathrm{x}, \mathrm{t}$ corrected numerator gps $=0.4556 \mathrm{E}+11$, error $=0.1341 \mathrm{E}+11$ HIRS AN ACITITY BELOW DETECTION LIMITS $\exp \left(\mathrm{mu}^{*} x\right)=0.2936 \mathrm{E}+01, \exp (\mathrm{smu} * \mathrm{t})=0.1436 \mathrm{E}+01$, INTCOR subtraction $=0.1518 \mathrm{E}+11$ uncorrected numerator gps $=0.1080 \mathrm{E}+11$, error $=0.1209 \mathrm{E}+10$ $x, t$ corrected denominator gp $=0.1826 \mathrm{E}+12$, error $=0.1197 \mathrm{E}+11$
$\exp \left(\mathrm{mu}^{*} \mathrm{X}\right)=0.3209 \mathrm{E}+01$, exp $\left(\mathrm{smu}^{*} \mathrm{t}\right)=0.1882 \mathrm{E}+01$, INTCOR subtraction $=0.0000 \mathrm{E}+00$ $\exp \left(\mathrm{mu}^{*} X\right)=0.3209 \mathrm{E}+01$, $\exp (\mathrm{smu} * \mathrm{t})=0.1882 \mathrm{E}+01$, INTCOR subtraction $=0.0000 \mathrm{E}+00$
uncorrected denominator $\mathrm{gps}=0.3023 \mathrm{E}+11$, error $=0.6112 \mathrm{E}+09$

PU-241 (148.54 keV) to PU-239(129.30 keV): ( $1.64+1-0.11)$ E-01

$x, t$ corrected numerator gps $=0.5013 \mathrm{E}+12$, error $=0.4379 \mathrm{E}+11$ $\exp \left(\mathrm{mu}^{*} \mathrm{X}\right)=0.3021 \mathrm{E}+01, \exp (\mathrm{smu} t)=0.1565 \mathrm{E}+01$, INTCOR subtraction $=0.0000 \mathrm{E}+00$ uncorrected numerator gps $=0.1060 \mathrm{E}+12$, error $=0.4997 \mathrm{E}+10$ $x, t$ corrected denominator gps $=0.1826 \mathrm{E}+12$, error $=0.1197 \mathrm{E}+11$
$\exp \left(\mathrm{mu}^{*} \mathrm{x}\right)=0.3209 \mathrm{E}+01$, exp $\left(\mathrm{smu}^{*} \mathrm{t}\right)=0.1882 \mathrm{E}+01$, INTCOR subtraction $=0.0000 \mathrm{E}+00$

AM-241 (125.29 keV) to PU-239(129.30 keV): ( $3.23+/-0.19)$ E-01

$x, t$ corrected numerator gps $=0.3600 \mathrm{E}+11$, error $=0.2702 \mathrm{E}+10$ $\exp \left(m^{*} \times\right)=0.3255 \mathrm{E}+01$, exp (smu*t) $=0.1877 \mathrm{E}+01$ INTCOR subtraction $=0.5185 \mathrm{E}+09$ $\exp \left(m^{*} X\right)=0.3255 \mathrm{E}+01, \exp \left(\mathrm{smu}^{*} t\right)=0.1877 \mathrm{E}+01$, INTCOR subt

uncorrected numerator gps $=0.5892 \mathrm{E}+10$, error $=0.2249 \mathrm{E}+09$
$\mathrm{x}, \mathrm{t}$ corrected denominator gps $=0.1826 \mathrm{E}+12$, error $=0.1197 \mathrm{E}+11$

exp $\left(\mathrm{mu}^{*} \mathrm{x}\right)=0.3209 \mathrm{E}+01$ exp $(\mathrm{smu} * \mathrm{t})=0.1882 \mathrm{E}+01$, INTCOR subtraction $=0.0000 \mathrm{E}+00$ $\exp \left(\mathrm{mu}^{*} \mathrm{x}\right)=0.3209 \mathrm{E}+01, \exp \left(\mathrm{smu} \mathrm{u}^{*} \mathrm{t}\right)=0.1882 \mathrm{E}+01, \mathrm{INTCOR}$ suberac

U $-235(185.72 \mathrm{keV})$ to PU-239(129.30 keV): ( 4.+1- 5.)E-01

ATET LTE USED WAS FTT BY LTNEAR METHODS - THE RATTO MAY BE IN ERROR $x, t$ corrected numerator gos $=0.2461 E+05$, error $=0.2973 \mathrm{E}+05$ 
$\exp \left(\mathrm{mu}^{*} \mathrm{x}\right)=0.2785 \mathrm{E}+01, \exp \left(\mathrm{smu}^{*} \mathrm{t}\right)=0.1307 \mathrm{E}+01$, INTCOR subtraction $=0.0000 \mathrm{E}+00$ uncorrected numerator gps $=0.6760 \mathrm{E}+04$, error $=0.8147 \mathrm{E}+04$

$x\left(m^{*}\right)=0.3209 \mathrm{E}+01$. uncorrected denominator gos $=0.3023 \mathrm{E}+11$, error $=0.6112 \mathrm{E}+09$

U -235 (185.72 keV) to PU-239 (203.55 keV): ( $4 .+1-5$.$) E-01$

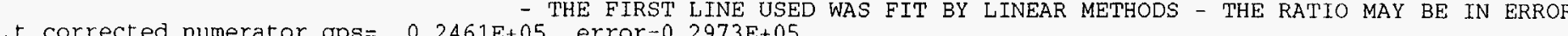
exp $\left(\mathrm{mu}^{*} \mathrm{x}\right)=0.2785 \mathrm{E}+01$,

explarrection $=0.0000 \mathrm{E}+00$

$x, t$ corrected denominator gps $=0.1808 \mathrm{~F}+12$, error $=0.1699 \mathrm{E}+11$

$\exp \left(\mathrm{mu}^{*} \mathrm{x}\right)=0.2698 \mathrm{E}+01, \exp \left(\mathrm{smu} \mathrm{t}^{*}\right)=0.1232 \mathrm{E}+01$, INTCOR subtraction=0.0000E+00

uncorrected denominator $90 s=0.5443 \mathrm{E}+11$, error $=0.1140 \mathrm{E}+10$

\section{ISOTOPIC MASS RATIOS (8)}

(THIS IS A TEST SET)

PU-238 (152.72 keV) to PU-239 $(144.20 \mathrm{keV}):(199+1-6.1 \mathrm{E}-03$

$x, t$ corrected numerator gps $=0,3966 \mathrm{E}+10$, error $=0.2647 \mathrm{E}+10$ $\exp \left(m u^{*} x\right)=0.2988 \mathrm{E}+01, \exp \left(s m u^{*} t\right)=0.1515 \mathrm{E}+01$, INTCOR subtraction $=0.0000 \mathrm{E}+00$

uncorrected numerator $\mathrm{gps}=0.8762 \mathrm{E}+09$, error $=0.5810 \mathrm{E}+09$

$x, t$ corrected denominator gps $=0.1552 \mathrm{E}+12$, error $=0.1552 \mathrm{E}+11$

$\exp \left(m u^{*} x\right)=0.3060 \mathrm{E}+01, \exp \left(\mathrm{smu}^{\star} t\right)=0.1623 \mathrm{E}+01, \quad$ INTCOR subtraction=0.0000 +00

uncorrected denominator gps $=0.3124 \mathrm{E}+11$, error $=0.2195 \mathrm{E}+10$

PU-238 (152.72 kev) to PU-239 (129.30 kev): ( 8 + $/ 1$ 5.) E-03

$x, t$ corrected numerator gps $=0.3966 \mathrm{E}+10$, error $=0.2647 \mathrm{E}+10$

WAS FIT BY LINEAR METHODS - THE RATIO MAY BE IN ERROR $\exp \left(m^{*} x\right)=0.2988 \mathrm{E}+01, \exp \left(\mathrm{smu}^{*} t\right)=0.1515 \mathrm{E}+01, \quad$ INTCOR subtraction $=0.0000 \mathrm{E}+00$

uncorrected numerator gps $=0.8762 \mathrm{E}+09$, error $=0.5810 \mathrm{E}+09$

$\exp \left(\mathrm{mu}^{*} \mathrm{x}\right)=0.3209 \mathrm{E}+01, \exp \left(\mathrm{smu}^{*} \mathrm{t}\right)=0.1882 \mathrm{E}+01$, INTCOR subtraction $=0.0000 \mathrm{E}+00$

uncorrected denominator gps $=0.3023 \mathrm{E}+11$, error $=0.6112 \mathrm{E}+09$

AM-241 (165.92 keV) to U $-235(163.36 \mathrm{keV})$ : (RATIO NOT DETERMINABLE)

$x, t$ corrected numerator gps $=0.4078 \mathrm{E}+11$, error $=0.7812 \mathrm{E}+11$

$\exp \left(m u^{*} \mathrm{x}\right)=0.2899 \mathrm{E}+01, \exp \left(\mathrm{smu}^{*} \mathrm{t}\right)=0.1388 \mathrm{E}+01, \quad$ INTCOR subtraction $=0.0000 \mathrm{E}+00$

uncorrected numerator gps $=0.1014 \mathrm{E}+11$, error $=0.1940 \mathrm{E}+11$

$\exp \left(m u^{*} x\right)=0.2915 \mathrm{E}+01, \exp \left(\mathrm{smu}^{*} \mathrm{t}\right)=0.1409 \mathrm{E}+01$, INTCOR subtraction $=0.0000 \mathrm{E}+00$

uncorrected denominator gps $=-.6391 \mathrm{E}+05$, error $=-.9065 \mathrm{E}+05$

AM-241 (169.56 keV) to U $-235(163.36 \mathrm{keV})$ : (RATIO NOT DETERMINABLE)

$x, t$ corrected numerator gps $=0.4621 \mathrm{E}+11$, error $=0.1044 \mathrm{E}+11$

$\exp \left(\mathrm{mu}^{*} \mathrm{x}\right)=0.2876 \mathrm{E}+01, \exp \left(\mathrm{smu}^{*} \mathrm{t}\right)=0.1361 \mathrm{E}+01$, INTCOR subtraction=0.0000E+00

uncorrected numerator gps $=0.1181 \mathrm{E}+11$, error $=0.2478 \mathrm{E}+10$
$\mathrm{x}, \mathrm{t}$ corrected denominator $\mathrm{gps}=-.2626 \mathrm{E}+06$, error $=0.3730 \mathrm{E}+06$

$\exp \left(\mathrm{mu}^{*} \mathrm{x}\right)=0.2915 \mathrm{E}+01, \exp \left(\mathrm{smu}^{*} t\right)=0.1409 \mathrm{E}+01$, INTCOR subtraction $=0.0000 \mathrm{E}+00$

uncorrected denominator gps $=-.6391 \mathrm{E}+05$, error $=-.9065 \mathrm{E}+05$

AM-241 (169.56 keV) to U $-235(185.72 \mathrm{keV}):(1.2+1-1.4) \mathrm{E}+02$

$x, t$ correçted numerator gps $=0.4621 \mathrm{E}+11$, error $=0.1044 \mathrm{E}+11$

$\exp \left(\mathrm{mu}^{*} x\right)=0.2876 \mathrm{E}+01, \exp (\mathrm{smu} * t)=0.1361 \mathrm{E}+01$, INTCOR subtraction $=0.0000 \mathrm{E}+00$ 
$\begin{aligned} & \text { uncorrected numerator gps }=0.1181 \mathrm{E}+11, \text { error }=0.2478 \mathrm{E}+10 \\ & x, t \text { corrected denominator } \mathrm{gps}=0.2461 \mathrm{E}+05, \text { error }=0.2973 \mathrm{E}+05\end{aligned}$

$\exp \left(\mathrm{mu}^{*} \mathrm{x}\right)=0.2785 \mathrm{E}+01, \exp \left(\mathrm{smu} \mathrm{s}^{*} \mathrm{t}\right)=0.1307 \mathrm{E}+01$, INTCOR subtract $i$ on $=0.0000 \mathrm{E}+00$

uncorrected denominator gps $=0.6760 \mathrm{E}+04$, error $=0.8147 \mathrm{E}+04$

AM-241 (125.29 keV) to U $-235(185.72 \mathrm{keV})$ : ( $8 .+1-\quad 10$.$) E+$

$x, t$ corrected numerator gps $=0.3600 \mathrm{E}+11$, error $=0.2702 \mathrm{E}+10$

WERE FIT BY LINEAR METHODS - THE RATIO MAY BE IN ERROR $\exp \left(\mathrm{mu}^{*} \mathrm{x}\right)=0.3255 \mathrm{E}+01, \exp \left(\mathrm{smu}^{*} \mathrm{t}\right)=0.1877 \mathrm{E}+01$, INTCOR subt ract ion=0.5185E+09 uncorrected numerator gps $=0.5892 \mathrm{E}+10$, error $=0.2249 \mathrm{E}+09$

$x, t$ corrected denominator gps $=0.2461 E+05$,

$\exp \left(m u^{*} \mathrm{X}\right)=0.2785 \mathrm{E}+01, \exp (\mathrm{smu} * \mathrm{t})=0.1307 \mathrm{E}+01, \quad$ INTCOR subtraction $=0.0000 \mathrm{E}+00$ uncorrected denominator gps $=0.6760 \mathrm{E}+04$, error $=0.8147 \mathrm{E}+04$ 


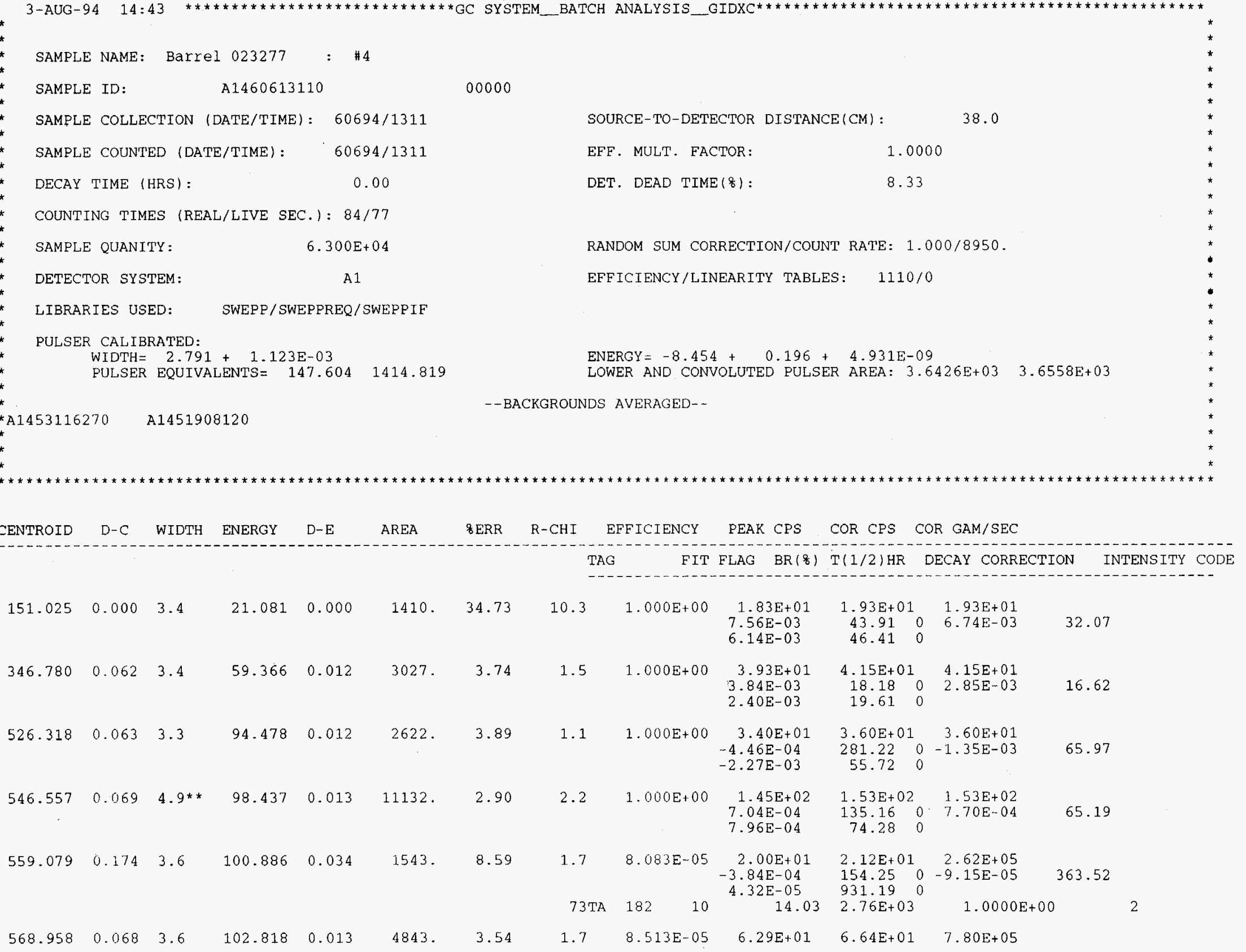




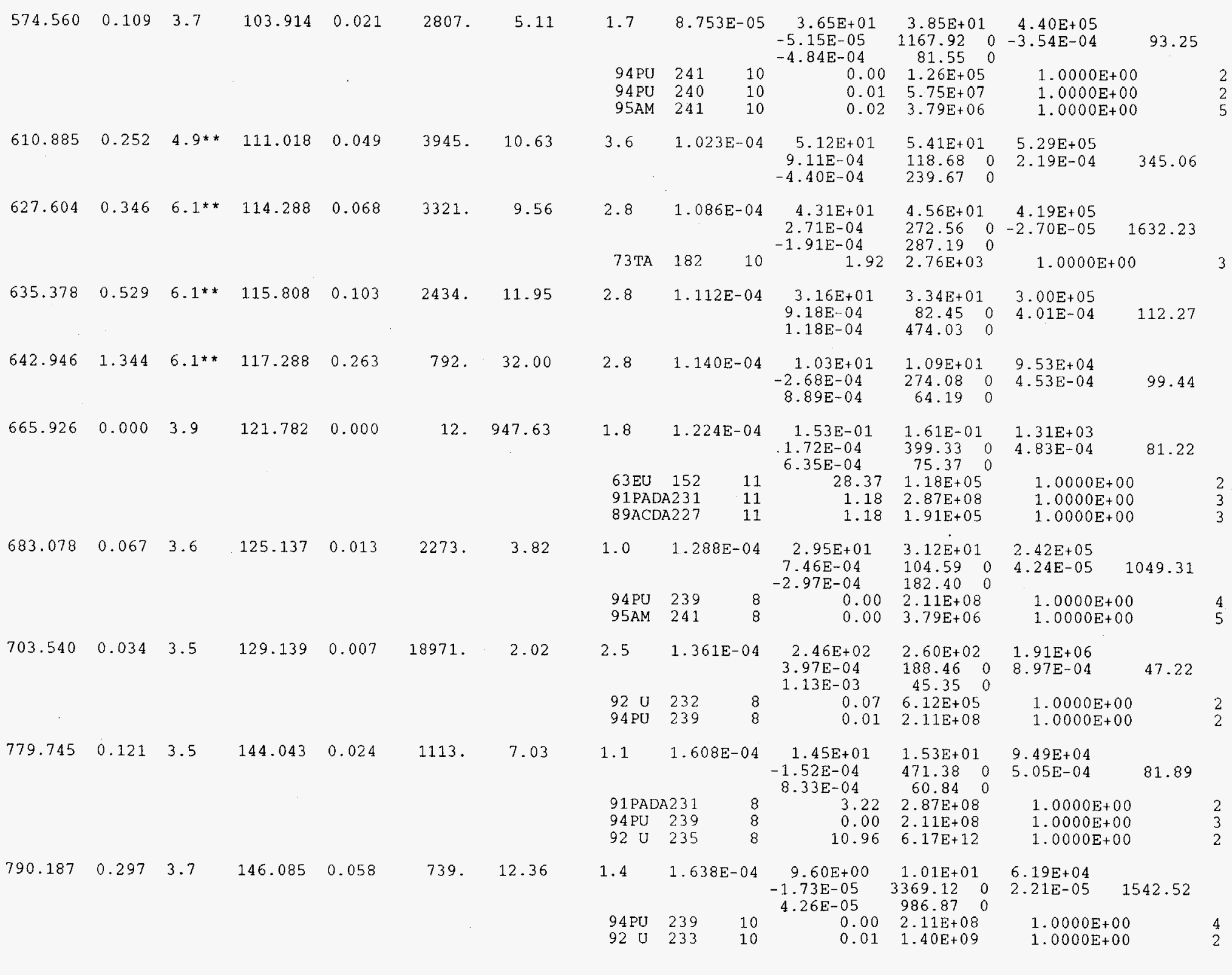




\begin{tabular}{|c|c|c|c|c|c|c|c|c|c|c|c|c|c|c|}
\hline & & & & & & & $95 \mathrm{AM}$ & 241 & 10 & 0.00 & $3.79 \mathrm{E}+06$ & $1.0000 \mathrm{E}+00$ & & 1 \\
\hline \multirow[t]{2}{*}{802.088} & 0.087 & 3.7 & 148.412 & 0.017 & 2398. & 4.71 & 1.4 & $1.668 \mathrm{E}$ & -04 & \multirow{2}{*}{$\begin{array}{r}3.11 E+01 \\
-7.47 \mathrm{E}-04 \\
8.65 \mathrm{E}-04 \\
0.00\end{array}$} & \multirow{2}{*}{$\begin{array}{c}3.29 E+01 \\
74.160 \\
49.520 \\
1.26 \mathrm{E}+05\end{array}$} & $\begin{array}{l}1.97 \mathrm{E}+05 \\
2.62 \mathrm{E}-04\end{array}$ & \multirow[t]{2}{*}{210.69} & \\
\hline & & & & & & & $94 \mathrm{PU}$ & 241 & 10 & & & $1.0000 \mathrm{E}+00$ & & 1 \\
\hline \multirow[t]{3}{*}{824.113} & 0.000 & 4.1 & 152.720 & 0.000 & 103. & 66.31 & 1.0 & $1.717 \mathrm{E}-$ & -04 & $\begin{array}{r}1.33 \mathrm{E}+00 \\
-3.62 \mathrm{E}-04\end{array}$ & $\begin{array}{l}1.41 E+00 \\
229.360\end{array}$ & $\begin{array}{r}8.21 \mathrm{E}+03 \\
-1.16 \mathrm{E}-04\end{array}$ & \multirow[t]{3}{*}{440.90} & \\
\hline & & & & & & & & & & $3.47 \mathrm{E}-05$ & 1872.490 & & & \\
\hline & & & & & & & $\begin{array}{l}94 \mathrm{PU} \\
73 \mathrm{TA}\end{array}$ & $\begin{array}{l}238 \\
182\end{array}$ & $\begin{array}{l}9 \\
9\end{array}$ & $\begin{array}{r}0.00 \\
7.18\end{array}$ & $\begin{array}{l}7.69 E+05 \\
2.76 E+03\end{array}$ & $\begin{array}{l}1.0000 \mathrm{E}+00 \\
1.0000 \mathrm{E}+00\end{array}$ & & $\begin{array}{l}1 \\
2\end{array}$ \\
\hline \multirow[t]{2}{*}{862.035} & 0.223 & 3.4 & 160.137 & 0.044 & 565. & 11.19 & 1.1 & $1.784 \mathrm{E}-$ & -04 & $\begin{array}{l}7.34 \mathrm{E}+00 \\
2.56 \mathrm{E}-05\end{array}$ & $\begin{array}{c}7.75 \mathrm{E}+00 \\
2815.370\end{array}$ & $\begin{array}{r}4.35 E+04 \\
-6.26 E-04\end{array}$ & \multirow[t]{2}{*}{71.43} & \\
\hline & & & & & & & $\begin{array}{l}94 \mathrm{PU} \\
94 \mathrm{PU} \\
94 \mathrm{PU}\end{array}$ & $\begin{array}{l}239 \\
240 \\
241\end{array}$ & $\begin{array}{l}10 \\
10 \\
10\end{array}$ & $\begin{array}{l}0.00 \\
0.00 \\
0.00\end{array}$ & $\begin{array}{l}2.11 E+08 \\
5.75 E+07 \\
1.26 E+05\end{array}$ & $\begin{array}{l}1.0000 \mathrm{E}+00 \\
1.0000 \mathrm{E}+00 \\
1.0000 \mathrm{E}+00\end{array}$ & & $\begin{array}{l}5 \\
1 \\
3\end{array}$ \\
\hline \multirow[t]{3}{*}{867.874} & 0.182 & 3.4 & 161.279 & 0.036 & 665. & 9.78 & 1.1 & $1.792 \mathrm{E}-$ & -04 & $\begin{aligned} & 8.64 \mathrm{E}+00 \\
-1.53 \mathrm{E}-03 & -1.27 \mathrm{E}-03\end{aligned}$ & $\begin{array}{cc}9.13 \mathrm{E}+00 \\
43.56 & 0 \\
44.15 & 0\end{array}$ & $\begin{array}{r}5.09 \mathrm{E}+04 \\
-1.38 \mathrm{E}-03\end{array}$ & \multirow[t]{3}{*}{31.15} & \\
\hline & & & & & & & $\begin{array}{l}94 \mathrm{PU} \\
95 \mathrm{AM}\end{array}$ & $\begin{array}{l}239 \\
241\end{array}$ & $\begin{array}{l}10 \\
10\end{array}$ & $\begin{array}{l}0.00 \\
0.00\end{array}$ & $\begin{array}{l}2.11 E+08 \\
3.79 E+06\end{array}$ & $\begin{array}{l}1.0000 \mathrm{E}+00 \\
1.0000 \mathrm{E}+00\end{array}$ & & $\begin{array}{l}4 \\
6\end{array}$ \\
\hline & & & & & & & $94 \mathrm{PU}$ & 240 & 10 & 0.00 & $5.75 \mathrm{E}+07$ & $1.0000 E+00$ & & \\
\hline \multirow[t]{2}{*}{878.500} & 0.000 & 4.1 & 163.357 & 0.000 & -43 & 141.82 & 1.1 & $1.805 \mathrm{E}-$ & -04 & \multirow{2}{*}{$\begin{array}{r}-5.55 \mathrm{E}-01 \\
-6.02 \mathrm{E}-04 \\
2.55 \mathrm{E}-04 \\
5.08\end{array}$} & $\begin{array}{c}-5.86 \mathrm{E}-01 \\
92.610\end{array}$ & $\begin{array}{l}-3.25 \mathrm{E}+03 \\
-5.71 \mathrm{E}-05\end{array}$ & \multirow{2}{*}{588.78} & \\
\hline & & & & & & & $92 \mathrm{U}$ & 235 & 11 & & $6.17 \mathrm{E}+12$ & $1.0000 \mathrm{E}+00$ & & 3 \\
\hline \multirow[t]{2}{*}{883.893} & 0.205 & 4.4 & 164.412 & 0.040 & 866. & 9.72 & 1.1 & $1.811 \mathrm{E}$ & -04 & $\begin{array}{c}1.13 \mathrm{E}+01 \\
5.31 \mathrm{E}-04 \\
-3.67 \mathrm{E}-05\end{array}$ & $\begin{array}{l}1.19 \mathrm{E}+01 \\
139.650\end{array}$ & $\begin{array}{l}6.56 \mathrm{E}+04 \\
1.62 \mathrm{E}-04\end{array}$ & \multirow[t]{2}{*}{271.15} & \\
\hline & & & & & & & $\begin{array}{l}92 \mathrm{U} \\
94 \mathrm{PUDt}\end{array}$ & $\begin{array}{r}233 \\
4241\end{array}$ & $\begin{array}{l}8 \\
8\end{array}$ & $\begin{array}{l}0.01 \\
1.87\end{array}$ & $\begin{array}{l}1.40 E+09 \\
1.26 E+05\end{array}$ & $\begin{array}{l}1.0000 \mathrm{E}+00 \\
1.0000 \mathrm{E}+00\end{array}$ & & $\begin{array}{l}2 \\
3\end{array}$ \\
\hline \multirow[t]{2}{*}{891.613} & 0.000 & 4.1 & 165.922 & 0.000 & 32 . & 191.38 & 1.1 & $1.816 \mathrm{E}$ & -04 & \multirow{2}{*}{$\begin{array}{r}4.19 \mathrm{E}-01 \\
6.40 \mathrm{E}-04 \\
5.36 \mathrm{E}-04 \\
0.00\end{array}$} & $\begin{array}{l}4.42 \mathrm{E}-01 \\
100.440\end{array}$ & $\begin{array}{l}2.43 \mathrm{E}+03 \\
5.67 \mathrm{E}-04\end{array}$ & \multirow{2}{*}{62.18} & \\
\hline & & & & & & & $95 \mathrm{AM}$ & 241 & 11 & & $3.79 E+06$ & $1.0000 E+00$ & & 6 \\
\hline \multirow[t]{2}{*}{910.213} & 0.000 & 4.2 & 169.559 & 0.000 & 271. & 20.99 & 1.0 & $1.832 \mathrm{E}-$ & -04 & \multirow{2}{*}{$\begin{array}{r}3.52 \mathrm{E}+00 \\
-4.53 \mathrm{E}-04 \\
-5.75 \mathrm{E}-04 \\
0.00\end{array}$} & $\begin{array}{l}3.72 E+00 \\
123.1000\end{array}$ & $\begin{array}{r}2.03 E+04 \\
-5.33 E-04\end{array}$ & \multirow[t]{2}{*}{61.62} & \\
\hline & & & & & & & $95 \mathrm{AM}$ & 241 & 11 & & $3.79 E+06$ & $1.0000 \mathrm{E}+00$ & & 6 \\
\hline 918.737 & 0.185 & 4.4 & 171.226 & 0.036 & 863. & 8.74 & 1.0 & $1: 838 \mathrm{E}$ & -04 & $\begin{array}{c}1.12 \mathrm{E}+01 \\
-4.83 \mathrm{E}-04 \\
2.34 \mathrm{E}-04\end{array}$ & $\begin{array}{l}1.18 \mathrm{E}+01 \\
141.250 \\
21.030\end{array}$ & $\begin{array}{r}6.44 \mathrm{E}+04 \\
-1.39 \mathrm{E}-05\end{array}$ & 2883.60 & \\
\hline \multirow[t]{2}{*}{958.849} & 0.283 & 3.4 & 179.071 & 0.055 & 399. & 16.97 & & $1.854 \mathrm{E}-$ & -04 & \multirow{2}{*}{$\begin{array}{r}5.18 \mathrm{E}+00 \\
-7.89 \mathrm{E}-04 \\
-8.26 \mathrm{E}-04 \\
3.14\end{array}$} & $\begin{array}{c}5.47 \mathrm{E}+00 \\
79.59 \quad 0 \\
48.37 \quad 0\end{array}$ & $\begin{array}{r}2.95 \mathrm{E}+04 \\
-8.16 \mathrm{E}-04\end{array}$ & \multirow[t]{2}{*}{41.34} & \\
\hline & & & & & & & 73TA & 182 & 8 & & $2.76 \mathrm{E}+03$ & $1.0000 \mathrm{E}+00$ & & 3 \\
\hline 992.853 & 0.000 & 4.2 & 185.722 & 0.000 & 53. & 120.52 & 1.0 & $1.857 \mathrm{E}-$ & -04 & $\begin{array}{l}6.85 \mathrm{E}-01 \\
5.59 \mathrm{E}-03 \\
4.13 \mathrm{E}-03\end{array}$ & $\begin{array}{c}7.18 \mathrm{E}-01 \\
13.580 \\
15.440\end{array}$ & $\begin{array}{l}3.87 \mathrm{E}+03 \\
4.73 \mathrm{E}-03\end{array}$ & 10.74 & \\
\hline
\end{tabular}




\begin{tabular}{|c|c|c|c|c|c|c|c|c|c|c|c|c|}
\hline 1043.140 & 0.154 & 4.1 & 195.557 & 0.030 & 856. & 7.68 & 1.0 & $1.853 \mathrm{E}-04$ & $\begin{array}{c}1.11 \mathrm{E}+01 \\
2.83 \mathrm{E}-04 \\
-7.93 \mathrm{E}-04\end{array}$ & $\begin{array}{c}1.17 \mathrm{E}+01 \\
314.67 \quad 0 \\
62.20 \quad 0\end{array}$ & $\begin{array}{r}6.34 E+04 \\
-5.40 E-04\end{array}$ & 79.86 \\
\hline 1083.101 & 0.041 & 4.1 & 203.373 & 0.008 & 4157. & 2.09 & $\begin{array}{l}1.0 \\
94 \mathrm{PU} \\
95 \mathrm{AM}\end{array}$ & $\begin{array}{ll}239 & 8 \\
241 & 8\end{array}$ & $\begin{array}{r}5.40 \mathrm{E}+01 \\
3.44 \mathrm{E}-04 \\
-8.69 \mathrm{E}-06 \\
0.00 \\
0.00\end{array}$ & $\begin{array}{c}5.70 \mathrm{E}+01 \\
174.750 \\
5231.610 \\
2.11 \mathrm{E}+08 \\
3.79 \mathrm{E}+06\end{array}$ & $\begin{array}{l}3.10 \mathrm{E}+05 \\
1.20 \mathrm{E}-04 \\
\\
1.0000 \mathrm{E}+ \\
1.0000 \mathrm{E}+\end{array}$ & $\begin{aligned} & 302.90 \\
&+00 \\
& 00\end{aligned}$ \\
\hline 1093.048 & 0.000 & 4.3 & 205.318 & 0.000 & 92. & 50.12 & $\begin{array}{l}1.0 \\
92 \mathrm{U}\end{array}$ & $\begin{array}{l}1.836 \mathrm{E}-04 \\
235 \quad 11\end{array}$ & $\begin{array}{r}1.19 \mathrm{E}+00 \\
5.04 \mathrm{E}-04 \\
3.25 \mathrm{E}-05 \\
5.01\end{array}$ & $\begin{array}{c}1.25 \mathrm{E}+00 \\
105.820 \\
1266.140 \\
6.17 \mathrm{E}+12\end{array}$ & $\begin{array}{l}6.83 E+03 \\
2.08 E-04 \\
1.0000 E+\end{array}$ & $00^{156.35}$ \\
\hline 1105.860 & 0.024 & 4.1 & 207.824 & 0.005 & 11843 & 1.23 & $\begin{array}{l}1.2 \\
95 \text { AM } \\
94 \text { PUDA } \\
92 \mathrm{U}\end{array}$ & $\begin{array}{rr}241 & 8 \\
A 241 & 8 \\
233 & 8\end{array}$ & $\begin{array}{r}1.54 \mathrm{E}+02 \\
4.39 \mathrm{E}-04 \\
4.00 \mathrm{E}-04 \\
0.00 \\
21.63 \\
0.00\end{array}$ & $\begin{array}{l}1.62 \mathrm{E}+02 \\
138.54 \quad 0 \\
109.420 \\
3.79 \mathrm{E}+06 \\
1.26 \mathrm{E}+05 \\
1.40 \mathrm{E}+09\end{array}$ & $\begin{array}{l}8.87 \mathrm{E}+05 \\
4.13 \mathrm{E}-04 \\
1.0000 \mathrm{E}+ \\
1.0000 \mathrm{E}+ \\
1.0000 \mathrm{E}+\end{array}$ & $\begin{array}{l}.00 \\
.00 \\
00\end{array}$ \\
\hline 1195.977 & 0.000 & 4.5 & 225.449 & 0.000 & 155. & 32.06 & 1.0 & $1.767 \mathrm{E}-04$ & $\begin{array}{c}2.01 E+00 \\
5.19 E-04 \\
-1.27 E-04\end{array}$ & $\begin{array}{l}2.13 E+00 \\
115.25 \quad 0 \\
391.51 \quad 0\end{array}$ & $\begin{array}{l}1.20 \mathrm{E}+04 \\
1.36 \mathrm{E}-04\end{array}$ & 279.90 \\
\hline 1258.074 & 0.555 & 4.1 & 237.594 & 0.109 & 160 & 27.64 & 1.0 & $1.706 \mathrm{E}-04$ & $\begin{array}{l}2.08 E+00 \\
-4.33 E-04 \\
-1.41 E-03\end{array}$ & $\begin{array}{l}2.19 \mathrm{E}+00 \\
184.910 \\
64.190\end{array}$ & $\begin{array}{r}1.28 E+04 \\
-8.62 E-04\end{array}$ & 69.56 \\
\hline 1348.384 & 0.267 & 4.9 & 255.257 & 0.052 & 603. & 11.20 & $\begin{array}{l}1.3 \\
\text { 91 PADA } \\
\text { 89ACDA }\end{array}$ & $\begin{array}{ll}A 231 & 8 \\
2227 & 8\end{array}$ & $\begin{array}{r}7.83 E+00 \\
3.61 E-04 \\
-3.05 E-04 \\
6.66 \\
6.67\end{array}$ & $\begin{array}{l}8.26 \mathrm{E}+00 \\
166.47 \quad 0 \\
126.310 \\
2.87 \mathrm{E}+08 \\
1.91 \mathrm{E}+05\end{array}$ & $\begin{array}{r}5.15 \mathrm{E}+04 \\
-1.11 \mathrm{E}-04 \\
\\
1.0000 \mathrm{E}+\mathrm{C} \\
1.0000 \mathrm{E}+\mathrm{C}\end{array}$ & $\begin{array}{l}292.40 \\
00 \\
00\end{array}$ \\
\hline 1392.141 & 0.381 & $3.6 * \star$ & 263.815 & 0.075 & 173 & 21.35 & $\begin{array}{l}1.0 \\
73 \mathrm{TA}\end{array}$ & $182 \quad 8$ & $\begin{array}{r}2.25 \mathrm{E}+00 \\
1.04 \mathrm{E}-04 \\
-5.67 \mathrm{E}-05 \\
3.63\end{array}$ & $\begin{array}{l}2.38 \mathrm{E}+00 \\
435.80 \quad 0 \\
579.660 \\
2.76 \mathrm{E}+03\end{array}$ & $\begin{array}{r}1.53 E+04 \\
-1.35 E-06 \\
1.0000 E+0\end{array}$ & $\begin{array}{l}19692.55 \\
00\end{array}$ \\
\hline 1410.310 & 0.213 & 4.5 & 267.369 & 0.042 & 438 & 9.74 & $\begin{array}{l}1.0 \\
94 \text { PUDA }\end{array}$ & $\begin{array}{l}1.539 E-04 \\
2241 \quad 8\end{array}$ & $\begin{array}{r}5.69 \mathrm{E}+00 \\
-8.06 \mathrm{E}-05 \\
1.47 \mathrm{E}-04 \\
0.73\end{array}$ & $\begin{array}{l}6.00 \mathrm{E}+00 \\
832.93 \quad 0 \\
256.930 \\
1.26 \mathrm{E}+05\end{array}$ & $\begin{array}{l}3.90 \mathrm{E}+04 \\
9.22 \mathrm{E}-05 \\
1.0000 \mathrm{E}+0\end{array}$ & $\begin{array}{l}356.35 \\
00\end{array}$ \\
\hline 1521.017 & 0.000 & 4.8 & 289.021 & 0.000 & 92. & 39.33 & 1.0 & $1.437 \mathrm{E}-04$ & $\begin{array}{c}1.20 \mathrm{E}+00 \\
-4.28 \mathrm{E}-04 \\
3.56 \mathrm{E}-04\end{array}$ & $\begin{array}{l}1.26 \mathrm{E}+00 \\
119.530 \\
104.890\end{array}$ & $\begin{array}{l}8.78 E+03 \\
8.35 E-05\end{array}$ & 360.88 \\
\hline 1562.604 & 0.228 & 4.5 & 297.155 & 0.045 & 361. & 10.33 & 1.0 & $1.403 \mathrm{E}-04$ & $\begin{array}{c}4.69 \mathrm{E}+00 \\
-3.57 \mathrm{E}-04 \\
2.88 \mathrm{E}-05\end{array}$ & $\begin{array}{cc}4.95 E+00 \\
185.36 & 0 \\
1288.25 & 0\end{array}$ & $\begin{array}{r}3.53 E+04 \\
-6.33 E-05\end{array}$ & 510.33 \\
\hline 1577.958 & 0.000 & 4.9 & 300.158 & 0.000 & 140 & 31.06 & 1.0 & $1.391 \mathrm{E}-04$ & $\begin{array}{c}1.82 \mathrm{E}+00 \\
3.55 \mathrm{E}-04 \\
-9.97 \mathrm{E}-05\end{array}$ & $\begin{array}{l}1.92 \mathrm{E}+00 \\
161.01 \quad 0 \\
540.23 \quad 0\end{array}$ & $\begin{array}{l}1.38 \mathrm{E}+04 \\
1.14 \mathrm{E}-04\end{array}$ & 343.17 \\
\hline
\end{tabular}




\begin{tabular}{|c|c|c|c|c|c|c|c|c|c|c|c|c|c|}
\hline \multirow{3}{*}{1636.772} & \multirow{3}{*}{0.145} & \multirow{3}{*}{4.9} & \multirow{3}{*}{311.661} & \multirow{3}{*}{0.028} & \multirow{3}{*}{717 . } & \multirow{3}{*}{6.00} & \multicolumn{2}{|c|}{$\begin{array}{l}\text { 93NPPA237 } \\
90 \text { THDA228 } \\
91 \text { PADA231 }\end{array}$} & \multirow{3}{*}{$\begin{array}{r}6.63 \\
3.25 \\
4.48 \\
\\
9.32 \mathrm{E}+00 \\
-4.37 \mathrm{E}-04 \\
4.98 \mathrm{E}-04 \\
38.63\end{array}$} & \multirow{3}{*}{$\begin{array}{l}1.88 \mathrm{E}+10 \\
1.68 \mathrm{E}+04 \\
2.87 \mathrm{E}+08 \\
9.83 \mathrm{E}+00 \\
108.58 \quad 0 \\
71.970 \\
1.88 \mathrm{E}+10\end{array}$} & \multicolumn{2}{|l|}{$\begin{array}{l}1.0000 \mathrm{E}+00 \\
1.0000 \mathrm{E}+00 \\
1.0000 \mathrm{E}+00\end{array}$} & $\begin{array}{l}2 \\
3 \\
2\end{array}$ \\
\hline & & & & & & & 1.0 & $1.344 \mathrm{E}-04$ & & & $\begin{array}{l}\text { 7. } 31 \mathrm{E}+04 \\
1.58 \mathrm{E}-04\end{array}$ & 200.72 & \\
\hline & & & & & & & 93NPPA & 2237 & & & $1.0000 \mathrm{E}+00$ & & 1 \\
\hline \multirow[t]{2}{*}{1660.085} & \multirow[t]{2}{*}{0.353} & \multirow[t]{2}{*}{$2.0 * *$} & \multirow[t]{2}{*}{316.221} & \multirow[t]{2}{*}{0.069} & \multirow[t]{2}{*}{61.} & \multirow[t]{2}{*}{35.01} & 1.0 & $1.326 \mathrm{E}-04$ & \multirow{2}{*}{$\begin{array}{r}7.96 \mathrm{E}-01 \\
3.45 \mathrm{E}-04 \\
3.52 \mathrm{E}-04 \\
0.01\end{array}$} & \multirow{2}{*}{$\begin{array}{l}8.40 \mathrm{E}-01 \\
88.260 \\
56.400 \\
1.40 \mathrm{E}+09\end{array}$} & $\begin{array}{l}6.33 E+03 \\
3.50 E-04\end{array}$ & \multirow[t]{2}{*}{47.52} & \\
\hline & & & & & & & $92 \mathrm{U}$ & 233 & & & $1.0000 \mathrm{E}+00$ & & 1 \\
\hline \multirow[t]{2}{*}{1682.066} & \multirow[t]{2}{*}{0.000} & \multirow[t]{2}{*}{5.0} & \multirow[t]{2}{*}{320.520} & \multirow[t]{2}{*}{0.000} & \multirow[t]{2}{*}{343} & \multirow[t]{2}{*}{19.79} & 1.4 & $1.310 \mathrm{E}-04$ & $\begin{array}{l}4.45 \mathrm{E}+00 \\
-6.60 \mathrm{E}-04 \\
-4.44 \mathrm{E}-04\end{array}$ & \multirow{2}{*}{$\begin{array}{l}4.70 \mathrm{E}+00 \\
92.44 \quad 0 \\
109.78 \quad 0 \\
1.40 \mathrm{E}+09\end{array}$} & $\begin{array}{r}3.59 E+04 \\
-5.28 E-04\end{array}$ & \multirow[t]{2}{*}{72.10} & \\
\hline & & & & & & & $92 \mathrm{u}$ & 233 & 0.00 & & $1.0000 \mathrm{E}+00$ & & 3 \\
\hline \multirow[t]{2}{*}{1698.025} & 0.244 & 4.2 & 323.641 & 0.048 & 303. & 11.68 & 1.0 & $1.298 \mathrm{E}-04$ & $\begin{array}{l}3.94 \mathrm{E}+00 \\
4.71 \mathrm{E}-04 \\
1.21 \mathrm{E}-04\end{array}$ & $\begin{array}{c}4.15 E+00 \\
95.40 \quad 0 \\
281.04 \quad 0\end{array}$ & $\begin{array}{l}3.20 \mathrm{E}+04 \\
2.49 \mathrm{E}-04\end{array}$ & 108.99 & \\
\hline & & & & & & & $\begin{array}{l}\text { 91PADF } \\
\text { 89ACDF }\end{array}$ & $\begin{array}{l}A 231 \\
4227\end{array}$ & $\begin{array}{l}3.85 \\
3.86\end{array}$ & $\begin{array}{l}2.87 \mathrm{E}+08 \\
1.91 \mathrm{E}+05\end{array}$ & $\begin{array}{l}1.0000 E+00 \\
1.0000 E+00\end{array}$ & & $\begin{array}{l}2 \\
2\end{array}$ \\
\hline 1743.838 & 0.093 & 5.2 & 332.602 & 0.018 & 3951 . & 3.67 & 2.0 & $1.265 \mathrm{E}-04$ & $\begin{array}{c}5.13 \mathrm{E}+01 \\
-9.64 \mathrm{E}-05 \\
7.47 \mathrm{E}-04\end{array}$ & $\begin{array}{l}5.41 E+01 \\
530.990 \\
55.210\end{array}$ & $\begin{array}{l}4.28 \mathrm{E}+05 \\
4.15 \mathrm{E}-04\end{array}$ & 77.38 & \\
\hline & & & & & & & $\begin{array}{l}94 \mathrm{PUDF} \\
95 \mathrm{AM} \\
94 \mathrm{PU}\end{array}$ & $\begin{array}{r}4241 \\
241 \\
239\end{array}$ & $\begin{array}{l}1.21 \\
0.00 \\
0.00\end{array}$ & $\begin{array}{l}1.26 \mathrm{E}+05 \\
3.79 \mathrm{E}+06 \\
2.11 \mathrm{E}+08\end{array}$ & $\begin{array}{l}1.0000 \mathrm{E}+00 \\
1.0000 \mathrm{E}+00 \\
1.0000 \mathrm{E}+00\end{array}$ & & $\begin{array}{l}3 \\
6 \\
3\end{array}$ \\
\hline 1759.381 & 0.130 & $6.6 * *$ & 335.642 & 0.025 & 1372 & 4.16 & 1.0 & 1. $254 \mathrm{E}-04$ & $\begin{array}{c}1.78 E+01 \\
-1.11 E-04 \\
1.77 E-04\end{array}$ & $\begin{array}{l}1.88 \mathrm{E}+01 \\
561.540 \\
257.070\end{array}$ & $\begin{array}{l}1.50 \mathrm{E}+05 \\
7.69 \mathrm{E}-05\end{array}$ & 478.30 & \\
\hline & & & & & & & $95 \mathrm{AM}$ & 241 & 0.00 & $3.79 E+06$ & $1.0000 \mathrm{E}+00$ & & 6 \\
\hline 1788.123 & 0.207 & 4.8 & 341.263 & 0.040 & 400 & 8.79 & 1.0 & 1. $234 \mathrm{E}-04$ & $\begin{array}{c}5.19 E+00 \\
-6.73 E-04 \\
1.76 E-04\end{array}$ & $\begin{array}{l}5.47 \mathrm{E}+00 \\
71.52 \quad 0 \\
176.770\end{array}$ & $\begin{array}{r}4.44 \mathrm{E}+04 \\
-7.47 \mathrm{E}-05\end{array}$ & 366.99 & \\
\hline & & & & & & & $93 \mathrm{NPPF}$ & 4237 & 4.50 & $1.88 \mathrm{E}+10$ & $1.0000 E+00$ & & 2 \\
\hline 1806.330 & 0.049 & 5.0 & 344.824 & 0.010 & 3813. & 2.09 & 1.2 & $1.222 \mathrm{E}-04$ & $\begin{array}{c}4.95 E+01 \\
8.55 E-05 \\
3.82 E-04\end{array}$ & $\begin{array}{c}5.22 \mathrm{E}+01 \\
520.680 \\
86.180\end{array}$ & $\begin{array}{l}4.28 E+05 \\
2.77 E-04\end{array}$ & 95.49 & \\
\hline . & & & & & & & $\begin{array}{l}94 \mathrm{PU} \\
63 \mathrm{EU}\end{array}$ & $\begin{array}{l}239 \\
152\end{array}$ & $\begin{array}{r}0.00 \\
26.57\end{array}$ & $\begin{array}{l}2.11 \mathrm{E}+08 \\
1.18 \mathrm{E}+05\end{array}$ & $\begin{array}{l}1.0000 \mathrm{E}+00 \\
1.0000 \mathrm{E}+00\end{array}$ & & $\begin{array}{l}3 \\
2\end{array}$ \\
\hline 1919.199 & 0.161 & 4.9 & 366.900 & 0.032 & 553 & 5.87 & 1.0 & $1.150 \mathrm{E}-04$ & $\begin{array}{c}7.18 E+00 \\
-6.49 E-04 \\
8.83 E-05\end{array}$ & $\begin{array}{c}7.57 \mathrm{E}+00 \\
48.740 \\
282.46 \quad 0\end{array}$ & $\begin{array}{r}6.58 E+04 \\
-1.94 E-04\end{array}$ & 130.45 & \\
\hline 1926.900 & 0.113 & 4.9 & 368.406 & 0.022 & 889 & 4.35 & 1.0 & $1.145 \mathrm{E}-04$ & $\begin{array}{c}1.15 E+01 \\
6.71 E-04 \\
-3.15 E-04\end{array}$ & $\begin{array}{c}1.22 \mathrm{E}+01 \\
54.280 \\
75.880\end{array}$ & $\begin{array}{r}1.06 \mathrm{E}+05 \\
-1.79 \mathrm{E}-05\end{array}$ & 1790.50 & \\
\hline & & & & & & & $\begin{array}{l}94 \mathrm{PU} \\
95 \mathrm{AM}\end{array}$ & $\begin{array}{l}239 \\
241\end{array}$ & $\begin{array}{l}0.00 \\
0.00\end{array}$ & $\begin{array}{l}2.11 \mathrm{E}+08 \\
3.79 \mathrm{E}+06\end{array}$ & $\begin{array}{l}1.0000 \mathrm{E}+00 \\
1.0000 \mathrm{E}+00\end{array}$ & & $\begin{array}{l}4 \\
6\end{array}$ \\
\hline 1960.014 & 0.026 & 5.1 & 374.883 & 0.005 & 9688. & 1.07 & 1.0 & $1.125 \mathrm{E}-04$ & $\begin{array}{l}1.26 \mathrm{E}+02 \\
4.87 \mathrm{E}-04\end{array}$ & $\begin{array}{c}1.33 E+02 \\
87.5400\end{array}$ & $\begin{array}{l}1.18 \mathrm{E}+06 \\
9.17 \mathrm{E}-04\end{array}$ & 27.59 & \\
\hline
\end{tabular}




\begin{tabular}{|c|c|c|c|c|c|c|c|c|c|c|c|c|}
\hline 1986.195 & 0.070 & 5.2 & 380.004 & 0.014 & 1890. & 2.82 & $\begin{array}{l}94 \mathrm{PU} \\
51 \mathrm{SB}\end{array}$ & $1.110 \mathrm{E}-04$ & $\begin{array}{r}2.45 \mathrm{E}+01 \\
4.04 \mathrm{E}-04 \\
4.06 \mathrm{E}-04 \\
0.00 \\
. \quad 1.51\end{array}$ & $\begin{array}{l}2.59 \mathrm{E}+01 \\
105.08 \quad 0 \\
61.990 \\
2.11 \mathrm{E}+08 \\
2.42 \mathrm{E}+04\end{array}$ & $\begin{array}{l}2.33 \mathrm{E}+05 \\
4.05 \mathrm{E}-04 \\
1.0000 \mathrm{E}+00 \\
1.0000 \mathrm{E}+00\end{array}$ & 53.39 \\
\hline 1999.433 & 0.078 & 5.2 & 382.593 & 0.015 & 1570 . & 3.11 & $\begin{array}{l}1.1 \\
94 \mathrm{PU}\end{array}$ & $239 \quad 10$ & $\begin{array}{r}2.04 \mathrm{E}+01 \\
2.33 \mathrm{E}-04 \\
-3.22 \mathrm{E}-04 \\
0.00\end{array}$ & $\begin{array}{l}2.15 \mathrm{E}+01 \\
171.870 \\
70.970 \\
2.11 \mathrm{E}+08\end{array}$ & $\begin{array}{r}1.95 \mathrm{E}+05 \\
-1.86 \mathrm{E}-04 \\
1.0000 \mathrm{E}+00\end{array}$ & 106.85 \\
\hline 2051.385 & 0.062 & 6.4 & 392.754 & 0.012 & 3393. & 2.01 & $\begin{array}{l}1.0 \\
94 \mathrm{PU}\end{array}$ & $\begin{array}{l}1.074 \mathrm{E}-04 \\
239 \quad 8\end{array}$ & $\begin{array}{l}4.41 E+01 \\
5.01 E-04 \\
5.49 E-04 \\
0.00\end{array}$ & $\begin{array}{l}4.65 E+01 \\
86.730 \\
56.800 \\
2.11 E+08\end{array}$ & 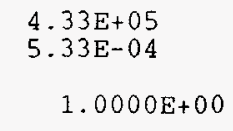 & 47.56 \\
\hline 2157.704 & 0.043 & 5.5 & 413.549 & 0.008 & 8723. & 1.71 & $\begin{array}{l}1.5 \\
94 \mathrm{PU}\end{array}$ & $1.020 \mathrm{E}-04$ & $\begin{array}{r}1.13 E+02 \\
2.31 E-03 \\
1.22 E-03 \\
0.00\end{array}$ & $\begin{array}{c}1.19 E+02 \\
19.540 \\
23.060 \\
2.11 E+08\end{array}$ & $\begin{array}{l}1.17 \mathrm{E}+06 \\
1.53 \mathrm{E}-03 \\
1.0000 \mathrm{E}+00\end{array}$ & 22.53 \\
\hline 2203.274 & 0.110 & 5.3 & 422.462 & 0.022 & 691. & 4.41 & $\begin{array}{l}1.0 \\
.94 \mathrm{PU}\end{array}$ & $9.982 \mathrm{E}-05$ & $\begin{array}{r}8.97 E+00 \\
1.99 E-04 \\
4.51 E-06 \\
0.00\end{array}$ & $\begin{array}{c}9.46 \mathrm{E}+00 \\
189.490 \\
5871.970 \\
2.11 E+08\end{array}$ & $\begin{array}{l}9.47 \mathrm{E}+04 \\
6.88 \mathrm{E}-05 \\
1.0000 \mathrm{E}+00\end{array}$ & 315.18 \\
\hline 2223.687 & 0.327 & 5.2 & 426.455 & 0.064 & 145. & 12.92 & 1.0 & $9.887 \mathrm{E}-05$ & $\begin{array}{l}1.88 E+00 \\
2.22 E-04 \\
1.83 E-04\end{array}$ & $\begin{array}{l}1.98 \mathrm{E}+00 \\
172.300 \\
154.10 \quad 0\end{array}$ & $\begin{array}{l}2.00 \mathrm{E}+04 \\
1.97 \mathrm{E}-04\end{array}$ & 115.38 \\
\hline 2350.674 & 0.099 & 5.8 & 451.292 & 0.019 & 1077 . & 3.57 & $\begin{array}{l}1.0 \\
94 \mathrm{PU}\end{array}$ & $\begin{array}{l}9.334 \mathrm{E}-05 \\
239 \quad 8\end{array}$ & $\begin{array}{c}1.40 E+01 \\
9.38 E-04 \\
9.73 E-05 \\
0.00\end{array}$ & $\begin{array}{l}1.47 E+01 \\
45.100 \\
263.690 \\
2.11 E+08\end{array}$ & $\begin{array}{l}1.58 \mathrm{E}+05 \\
3.23 \mathrm{E}-04 \\
1.0000 \mathrm{E}+00\end{array}$ & 81.50 \\
\hline 2706.160 & 0.000 & 6.1 & 520.823 & 0.000 & 8. & 116.66 & 1.0 & $8.064 \mathrm{E}-05$ & $\begin{array}{l}1.08 \mathrm{E}-01 \\
4.51 \mathrm{E}-04 \\
8.11 \mathrm{E}-05\end{array}$ & $\begin{array}{c}1.14 \mathrm{E}-01 \\
81.160 \\
279.17 \quad 0\end{array}$ & $\begin{array}{l}1.41 \mathrm{E}+03 \\
1.84 \mathrm{E}-04\end{array}$ & 104.95 \\
\hline 2799.121 & 0.000 & 6.2 & 539.006 & 0.000 & 25. & 40.41 & 1.0 & $7.790 \mathrm{E}-05$ & $\begin{array}{l}3.20 \mathrm{E}-01 \\
1.71 \mathrm{E}-04 \\
9.66 \mathrm{E}-05\end{array}$ & $\begin{array}{l}3.37 \mathrm{E}-01 \\
203.960 \\
279.830\end{array}$ & $\begin{array}{l}4.33 \mathrm{E}+03 \\
1.25 \mathrm{E}-04\end{array}$ & 171.56 \\
\hline 3024.740 & 0.608 & $4.8 * *$ & 583.137 & 0.119 & 39. & 26.40 & $\begin{array}{l}1.1 \\
90 \mathrm{THD}\end{array}$ & $7.197 \mathrm{E}-05$ & $\begin{array}{r}5.08 \mathrm{E}-01 \\
9.89 \mathrm{E}-04 \\
1.04 \mathrm{E}-03 \\
30.58\end{array}$ & $\begin{array}{c}5.34 \mathrm{E}-01 \\
27.610 \\
22.050 \\
1.68 \mathrm{E}+04\end{array}$ & $\begin{array}{l}7.42 \mathrm{E}+03 \\
1.02 \mathrm{E}-03 \\
1.0000 \mathrm{E}+00\end{array}$ & 17.24 \\
\hline 3100.112 & 1.020 & $7.9 * *$ & 597.879 & 0.199 & 45. & 26.51 & 1.2 & $7.018 \mathrm{E}-05$ & $\begin{array}{c}5.79 E-01 \\
2.43 E-04 \\
-4.02 E-04\end{array}$ & $\begin{array}{c}6.11 \mathrm{E}-01 \\
183.910 \\
92.300\end{array}$ & $\begin{array}{r}8.70 \mathrm{E}+03 \\
-1.39 \mathrm{E}-04\end{array}$ & 205.67 \\
\hline 3139.000 & 0.000 & 6.5 & 605.486 & 0.000 & 23 . & 36.55 & $\begin{array}{l}1.0 \\
55 \mathrm{cs}\end{array}$ & $\begin{array}{l}6.930 \mathrm{E}-05 \\
134 \quad 9\end{array}$ & $\begin{array}{r}3.03 \mathrm{E}-01 \\
-6.05 \mathrm{E}-04 \\
-2.80 \mathrm{E}-04 \\
97.63\end{array}$ & $\begin{array}{c}3.20 \mathrm{E}-01 \\
65.540 \\
96.570 \\
1.81 \mathrm{E}+04\end{array}$ & $\begin{array}{r}4.61 \mathrm{E}+03 \\
-3.83 \mathrm{E}-04 \\
1.0000 \mathrm{E}+00\end{array}$ & 58.31 \\
\hline
\end{tabular}




\begin{tabular}{|c|c|c|c|c|c|c|c|c|c|c|c|c|}
\hline 3205.740 & 0.696 & $8.3 * *$ & 618.540 & 0.136 & 62. & 17.83 & 1.0 & $6.784 \mathrm{E}-05$ & $\begin{array}{l}8.01 \mathrm{E}-01 \\
1.39 \mathrm{E}-05 \\
4.33 \mathrm{E}-04\end{array}$ & $\begin{array}{cc}8.43 \mathrm{E}-01 \\
2152.64 & 0 \\
53.80 & 0\end{array}$ & $\begin{array}{l}1.24 E+04 \\
2.74 E-04\end{array}$ & 66.95 \\
\hline 3344.770 & 0.403 & $5.4 * *$ & 645.735 & 0.079 & 62. & 15.62 & 1.0 & $6.505 \mathrm{E}-05$ & $\begin{array}{l}8.06 \mathrm{E}-01 \\
-1.54 \mathrm{E}-04 \\
-1.84 \mathrm{E}-04\end{array}$ & $\begin{array}{l}8.49 \mathrm{E}-01 \\
151.73 \quad 0 \\
126.37 \quad 0\end{array}$ & $\begin{array}{r}1.31 \mathrm{E}+04 \\
-1.69 \mathrm{E}-04\end{array}$ & 97.48 \\
\hline 3377.293 & 0.697 & 7.1 & 652.096 & 0.136 & 56. & 19.89 & 1.0 & $6.443 \mathrm{E}-05$ & $\begin{array}{l}7.33 \mathrm{E}-01 \\
1.30 \mathrm{E}-04 \\
4.07 \mathrm{E}-04\end{array}$ & $\begin{array}{c}7.72 \mathrm{E}-01 \\
215.90 \quad 0 \\
53.83\end{array}$ & $\begin{array}{l}1.20 \mathrm{E}+04 \\
3.02 \mathrm{E}-04\end{array}$ & 57.14 \\
\hline \multirow[t]{2}{*}{3428.885} & \multirow[t]{2}{*}{0.199} & \multirow[t]{2}{*}{5.6} & \multirow[t]{2}{*}{662.188} & \multirow[t]{2}{*}{0.039} & \multirow[t]{2}{*}{289.} & \multirow[t]{2}{*}{7.46} & 1.2 & $6.347 \mathrm{E}-05$ & $\begin{array}{l}3.75 E+00 \\
8.99 E-03 \\
9.96 E-03\end{array}$ & \multirow{2}{*}{$\begin{array}{l}3.94 \mathrm{E}+00 \\
15.13 \quad 0 \\
13.550 \\
3.79 \mathrm{E}+06 \\
2.65 \mathrm{E}+05\end{array}$} & $\begin{array}{l}6.21 \mathrm{E}+04 \\
9.48 \mathrm{E}-03\end{array}$ & \multirow[t]{2}{*}{10.11} \\
\hline & & & & & & & $\begin{array}{l}95 \mathrm{AM} \\
55 \mathrm{CS}\end{array}$ & $\begin{array}{ll}241 & 8 \\
137 & 8\end{array}$ & $\begin{array}{r}0.00 \\
85.20\end{array}$ & & $\begin{array}{l}1.0000 \mathrm{E}+00 \\
1.0000 \mathrm{E}+00\end{array}$ & \\
\hline 3563.950 & 0.000 & 7.0 & 688.607 & 0.000 & 22 . & 42.80 & 1.0 & $6.114 \mathrm{E}-05$ & $\begin{array}{c}2.80 \mathrm{E}-01 \\
-3.45 \mathrm{E}-04 \\
3.52 \mathrm{E}-04\end{array}$ & 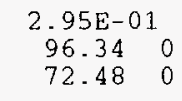 & $\begin{array}{l}4.83 \mathrm{E}+03 \\
9.36 \mathrm{E}-05\end{array}$ & 254.53 \\
\hline 3599.011 & 0.000 & 7.0 & 695.465 & 0.000 & 9. & 61.32 & 1.0 & $6.055 \mathrm{E}-05$ & $\begin{aligned} & 1.22 \mathrm{E}-01 \\
-1.45 \mathrm{E}-04 & -9.84 \mathrm{E}-05\end{aligned}$ & $\begin{array}{l}1.29 \mathrm{E}-01 \\
184.40 \quad 0 \\
240.46 \quad 0\end{array}$ & $\begin{array}{r}2.12 \mathrm{E}+03 \\
-1.19 \mathrm{E}-04\end{array}$ & 149.11 \\
\hline 3641.000 & 0.000 & 7.1 & 703.678 & 0.000 & 16. & 37.45 & 1.0 & $5.987 \mathrm{E}-05$ & $\begin{array}{l}2.08 \mathrm{E}-01 \\
-6.52 \mathrm{E}-06 \\
-1.03 \mathrm{E}-04\end{array}$ & $\begin{array}{cc}2.19 \mathrm{E}-01 \\
3752.71 & 0 \\
166.19 & 0\end{array}$ & $\begin{array}{r}3.66 \mathrm{E}+03 \\
-7.14 \mathrm{E}-05\end{array}$ & 197.02 \\
\hline 3709.750 & 0.000 & 7.1 & 717.126 & 0.000 & 13. & 54.46 & 1.0 & $5.880 \mathrm{E}-05$ & $\begin{array}{c}1.75 E-01 \\
1.01 E-04 \\
-3.79 E-04\end{array}$ & $\begin{array}{c}1.84 \mathrm{E}-01 \\
303.92 \quad 0 \\
62.920\end{array}$ & $\begin{array}{r}3.13 \mathrm{E}+03 \\
-1.98 \mathrm{E}-04\end{array}$ & 95.21 \\
\hline 3733.370 & 0.273 & 6.5 & 721.746 & 0.053 & 158. & 8.94 & 1.0 & $5.844 \mathrm{E}-05$ & $\begin{array}{c}2.05 \mathrm{E}+00 \\
-1.22 \mathrm{E}-04 \\
1.23 \mathrm{E}-04\end{array}$ & \multirow{2}{*}{$\begin{array}{l}2.16 \mathrm{E}+00 \\
167.280 \\
129.170 \\
3.79 \mathrm{E}+06\end{array}$} & $\begin{array}{l}3.69 E+04 \\
3.04 E-05\end{array}$ & \multirow[t]{2}{*}{412.96} \\
\hline & & & & & & & $95 \mathrm{AM}$ & 241 & 0.00 & & $1.0000 \mathrm{E}+0$ & \\
\hline 3797.750 & 0.000 & 7.2 & 734.340 & 0.000 & 4. & 112.57 & 1.0 & $5.750 E-05$ & $\begin{array}{l}5.32 E-02 \\
-3.90 E-04 \\
-3.15 E-06\end{array}$ & $\begin{array}{cc}5.62 \mathrm{E}-02 & \\
55.47 & 0 \\
5158.99 & 0\end{array}$ & $\begin{array}{r}9.77 \mathrm{E}+02 \\
-1.43 \mathrm{E}-04\end{array}$ & 91.81 \\
\hline 3909.800 & 0.000 & 7.4 & 756.257 & 0.000 & 7. & 85.12 & 1.0 & $5.592 \mathrm{E}-05$ & $\begin{array}{c}9.31 E-02 \\
-1.45 E-04 \\
4.35 E-04\end{array}$ & \multirow{2}{*}{$\begin{array}{c}9.78 \mathrm{E}-02 \\
191.430 \\
49.900 \\
1.54 \mathrm{E}+03 \\
1.54 \mathrm{E}+03 \\
7.53 \mathrm{E}+04\end{array}$} & $\begin{array}{l}1.75 E+03 \\
2.15 E-04\end{array}$ & \multirow[t]{2}{*}{92.44} \\
\hline & & & & & & & $\begin{array}{l}40 \mathrm{ZR} \\
40 \mathrm{RNNB} \\
63 \mathrm{EU}\end{array}$ & $\begin{array}{r}95 \\
895 \\
154\end{array}$ & $\begin{array}{r}54.50 \\
54.50 \\
4.34\end{array}$ & & $\begin{array}{l}1.0000 \mathrm{E}+0 \\
1.0000 \mathrm{E}+0 \\
1.0000 \mathrm{E}+0\end{array}$ & \\
\hline 3940.400 & 0.000 & 7.4 & 762.243 & 0.000 & 5. & 103.31 & 1.0 & $5.551 \mathrm{E}-05$ & $\begin{array}{c}6.97 \mathrm{E}-02 \\
1.01 \mathrm{E}-04 \\
-1.02 \mathrm{E}-04\end{array}$ & $\begin{array}{l}7.34 \mathrm{E}-02 \\
289.34: 0 \\
184.17: 0\end{array}$ & $\begin{array}{r}1.32 E+03 \\
-4.29 E-05\end{array}$ & 369.60 \\
\hline \multirow[t]{2}{*}{3975.736} & 0.588 & 6.4 & 769.155 & 0.115 & 40. & 18.84 & 1.0 & $5.504 \mathrm{E}-05$ & $\begin{array}{c}5.24 \mathrm{E}-01 \\
-1.18 \mathrm{E}-04 \\
7.98 \mathrm{E}-05\end{array}$ & \multirow{2}{*}{$\begin{array}{l}5.52 \mathrm{E}-01 \\
169.00 \quad 0 \\
184.43 \quad 0 \\
6.61 \mathrm{E}+08 \\
2.16 \mathrm{E}+09 \\
1.40 \mathrm{E}+07\end{array}$} & $\begin{array}{l}1.00 E+04 \\
9.90 E-06\end{array}$ & \multirow[t]{2}{*}{1194.75} \\
\hline & & & & & & & $\begin{array}{l}\text { 90THDA } \\
\text { 92UDA } \\
\text { 88RADA }\end{array}$ & $\begin{array}{r}\quad 230 \\
234 \\
9226\end{array}$ & $\begin{array}{r}4.89 \\
4.89 \\
4.89\end{array}$ & & $\begin{array}{l}1.0000 \mathrm{E}+0 \\
1.0000 \mathrm{E}+0 \\
1.0000 \mathrm{E}+0\end{array}$ & \\
\hline
\end{tabular}




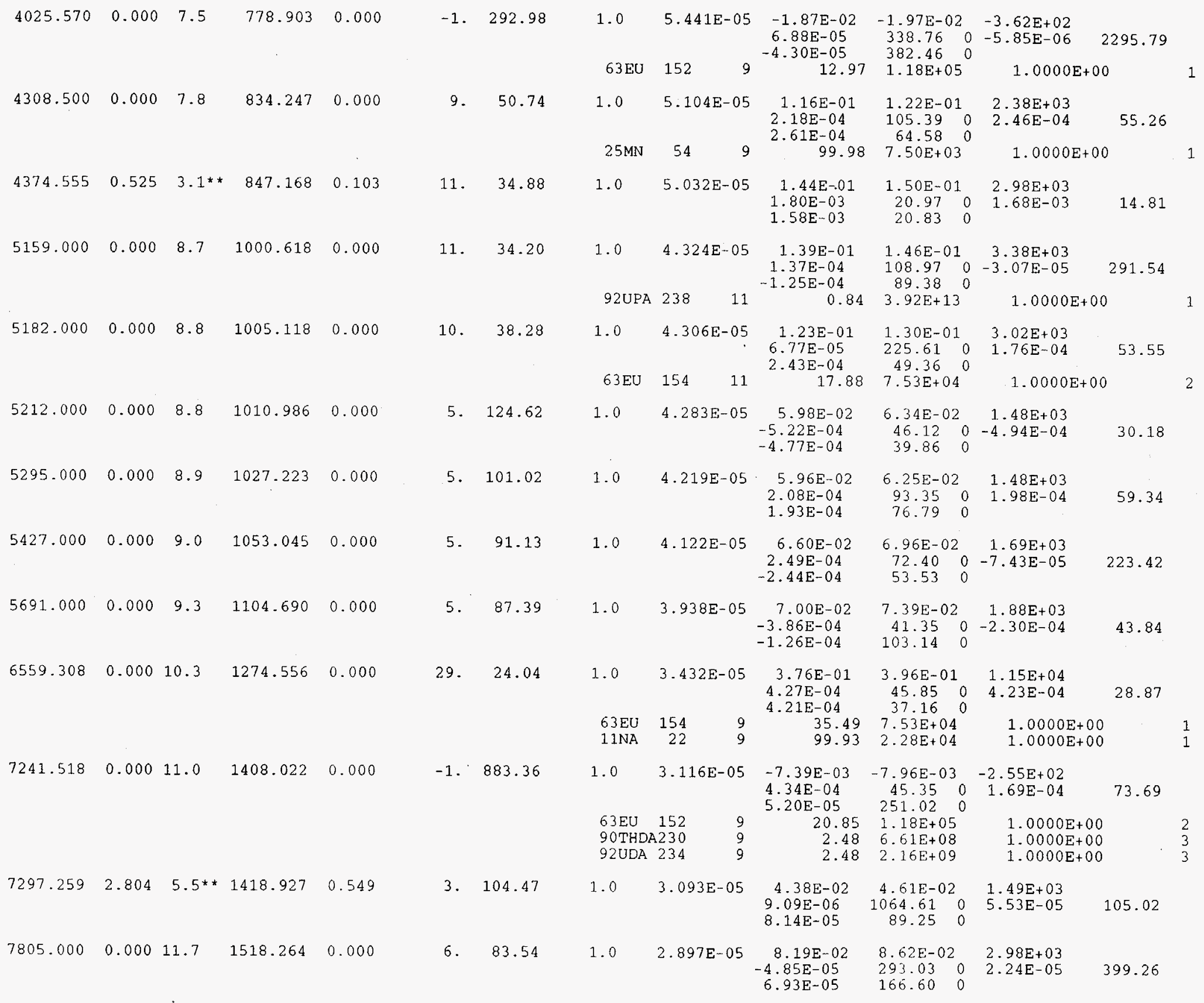




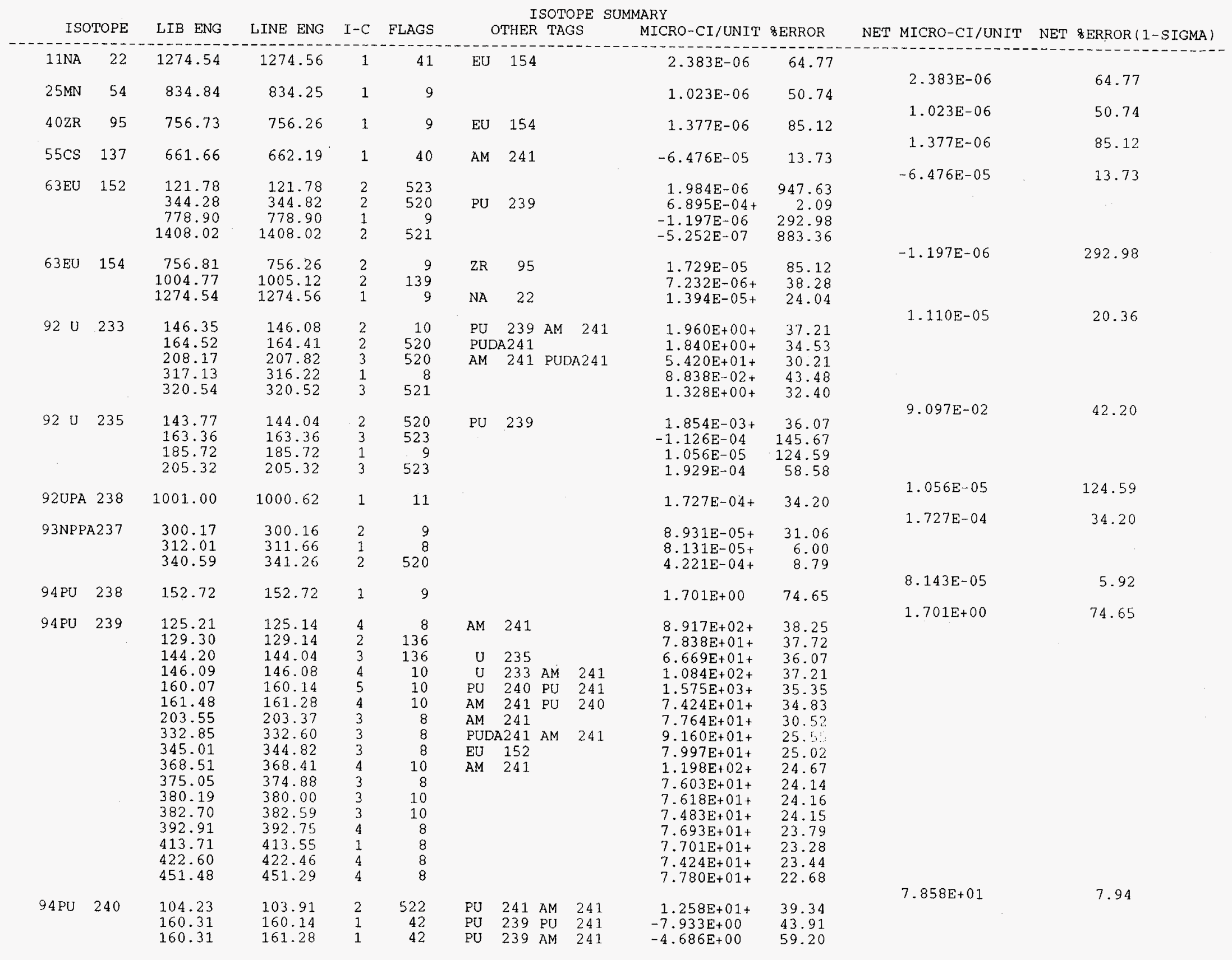




\begin{tabular}{|c|c|c|c|c|c|c|c|c|c|}
\hline $94 \mathrm{PU}$ & 241 & $\begin{array}{l}103.65 \\
103.65 \\
148.54 \\
159.93\end{array}$ & $\begin{array}{l}102.82 \\
103.91 \\
148.41 \\
160.14\end{array}$ & $\begin{array}{l}2 \\
2 \\
1 \\
3\end{array}$ & $\begin{array}{r}10 \\
10 \\
138 \\
522\end{array}$ & $\begin{array}{l}\mathrm{AM} \\
\mathrm{PU}\end{array}$ & $\begin{array}{l}241 \\
240\end{array}$ & PU & 240 \\
\hline 94 PUDA & A2 41 & $\begin{array}{l}164.59 \\
208.01 \\
267.54 \\
332.36\end{array}$ & $\begin{array}{l}164.41 \\
207.82 \\
267.37 \\
332.60\end{array}$ & $\begin{array}{l}3 \\
2 \\
1 \\
3\end{array}$ & $\begin{array}{r}8 \\
8 \\
8 \\
520\end{array}$ & $\begin{array}{l}\mathrm{U} \\
\mathrm{AM} \\
\mathrm{AM}\end{array}$ & $\begin{array}{l}233 \\
241 \\
241\end{array}$ & $\begin{array}{r}\mathrm{U} \\
\mathrm{PU}\end{array}$ & $\begin{array}{l}233 \\
239\end{array}$ \\
\hline $95 \mathrm{AM}$ & 241 & $\begin{array}{l}102.95 \\
102.95 \\
125.29 \\
146.55 \\
161.70 \\
165.92 \\
169.56 \\
203.87 \\
208.01 \\
332.36 \\
335.40 \\
368.59 \\
662.43 \\
722.70\end{array}$ & $\begin{array}{l}102.82 \\
103.91 \\
125.14 \\
146.08 \\
161.28 \\
165.92 \\
169.56 \\
203.37 \\
207.82 \\
332.60 \\
335.64 \\
368.41 \\
662.19 \\
721.75\end{array}$ & $\begin{array}{l}5 \\
5 \\
5 \\
1 \\
6 \\
6 \\
6 \\
6 \\
6 \\
6 \\
6 \\
6 \\
6 \\
6\end{array}$ & $\begin{array}{r}10 \\
10 \\
40 \\
42 \\
522 \\
11 \\
11 \\
520 \\
520 \\
520 \\
8 \\
522 \\
8 \\
136\end{array}$ & $\begin{array}{l}\text { PU } \\
\text { PU } \\
\text { PU } \\
\text { PU } \\
\text { PU } \\
\\
\text { PU } \\
\text { PUDA } \\
\text { PUDA. }\end{array}$ & $\begin{array}{l}241 \\
241 \\
239 \\
239 \\
239\end{array}$ & $\begin{array}{r}\mathrm{PU} \\
\mathrm{U} \\
\mathrm{PU}\end{array}$ & $\begin{array}{l}240 \\
233 \\
240\end{array}$ \\
\hline
\end{tabular}

$\begin{array}{lr}1.551 \mathrm{E}+03+ & 39.32 \\ 8.935 \mathrm{E}+02+ & 39.34 \\ 2.154 \mathrm{E}+02+ & 35.12 \\ 1.198 \mathrm{E}+03+ & 35.35 \\ & \\ 1.503 \mathrm{E}-03+ & 9.72 \\ 1.760 \mathrm{E}-03+ & 1.23 \\ 2.290 \mathrm{E}-03+ & 9.74 \\ 1.514 \mathrm{E}-02+ & 3.67 \\ & \\ 8.215 \mathrm{E}+00+ & 39.32 \\ 4.733 \mathrm{E}+00+ & 39.34 \\ 1.409 \mathrm{E}+01+ & 38.29 \\ 1.070 \mathrm{E}+01+ & 49.02 \\ 1.014 \mathrm{E}+03+ & 34.83 \\ 1.749 \mathrm{E}+01+ & 194.20 \\ 1.982 \mathrm{E}+01+ & 38.84 \\ 1.525 \mathrm{E}+04+ & 30.52 \\ 1.571 \mathrm{E}+02+ & 30.21 \\ 3.012 \mathrm{E}+02+ & 25.55 \\ 3.185 \mathrm{E}+01+ & 25.54 \\ 4.880 \mathrm{E}+01+ & 24.67 \\ 1.414 \mathrm{E}+01+ & 20.43 \\ 2.272 \mathrm{E}+01+ & 20.35\end{array}$


SAMPLE NAME: Barrel 023277 : \#4

SAMPLE ID: $\quad$ A1460613110

SAMPLE COLLECTION (DATE/TIME): $60694 / 1311$

SAMPLE COUNTED (DATE/TIME):

$60694 / 1311$

SAMPLE QUANTITY: $6.30000 \mathrm{E}+04$ QUANTITY UNITS:

ATTENUATION TABLE USED: 02

$\begin{array}{ccc}\text { RADIONUCLIDE } & \text { SAMPLE ACTIVITY }(\mathrm{UCI} / \mathrm{G}) \\ \text { 11NA } 22 & 2.383 \mathrm{~N}-06 \\ 25 \mathrm{MN} & 54 & 1.023 \mathrm{E}-06 \\ 40 \mathrm{ZR} & 95 & 1.377 \mathrm{E}-06 \\ 55 \mathrm{CS} & 137 & -6.476 \mathrm{E}-05 \\ 63 \mathrm{EU} & 152 & -1.197 \mathrm{E}-06 \\ 63 \mathrm{EU} & 154 & 1.110 \mathrm{E}-05 \\ 92 \mathrm{U} & 235 & 1.056 \mathrm{E}-05 \\ 92 \mathrm{U} & 233 & 9.097 \mathrm{E}-02 \\ 92 \mathrm{UPA} & 238 & 1.727 \mathrm{E}-04 \\ 93 \mathrm{NPPA} 237 & 8.143 \mathrm{E}-05 \\ 94 \mathrm{PU} & 241 & 2.406 \mathrm{E}+02 \\ 94 \mathrm{PU} & 240 & -4.686 \mathrm{E}+00 \\ 94 \mathrm{PU} & 239 & 7.858 \mathrm{E}+01 \\ 94 \mathrm{PU} & 238 & 1.701 \mathrm{E}+00 \\ 94 \mathrm{PUDA} 241 & 1.766 \mathrm{E}-03 \\ \text { 95AM 241 } 241 & 9.869 \mathrm{E}+00\end{array}$

PU-239 MASS ASSUMING "POINT SOURCE": 1
00000

G

ANALYST:

APPROVED BY:

COMMENTS :

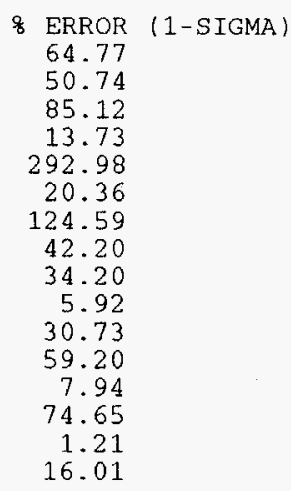

$8.0+/-\quad 0.6) E+01$ Grams

\section{B.6 XTP Plot from the above Single Spectrum Analysis}

(The plot appears on the next page.) 


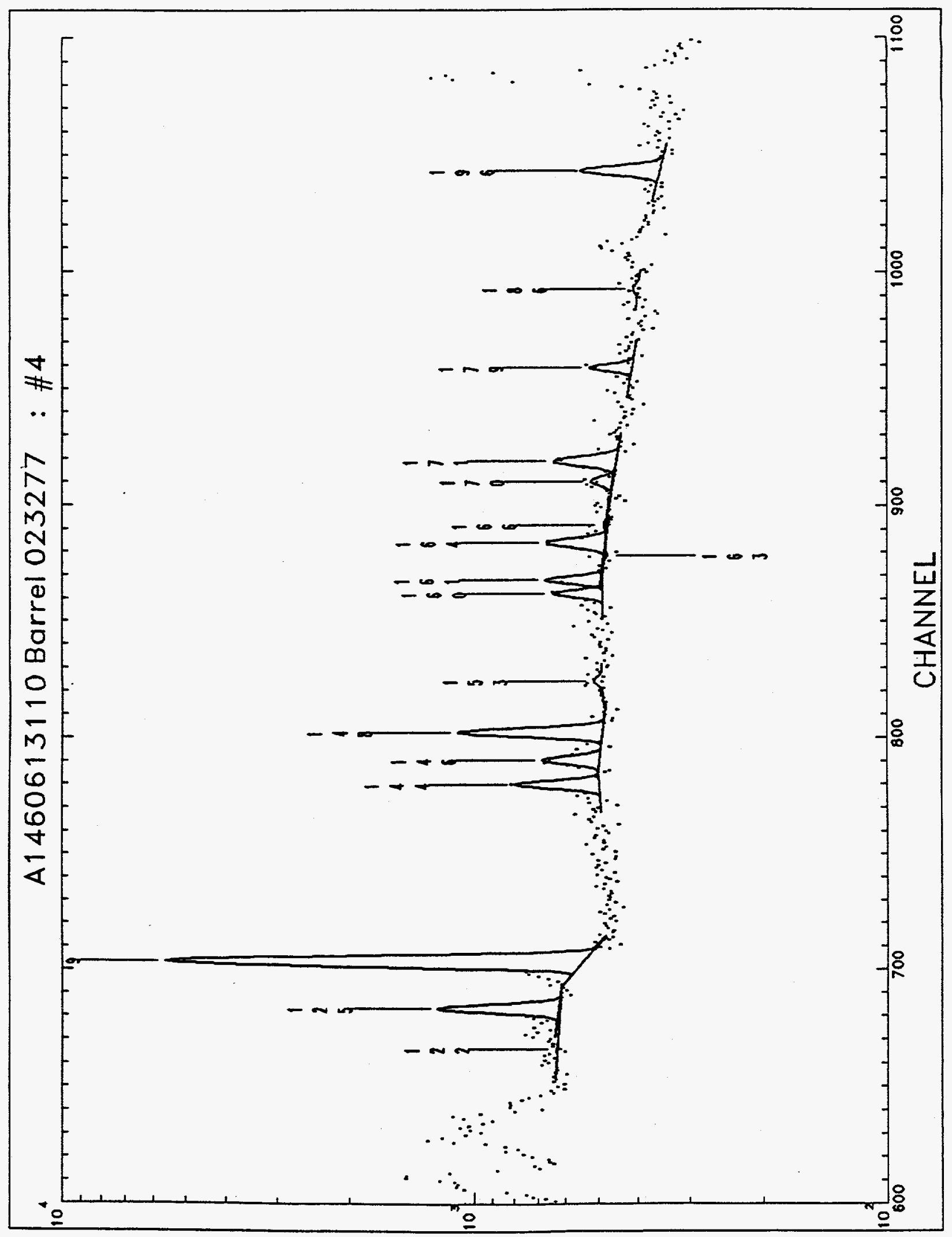

